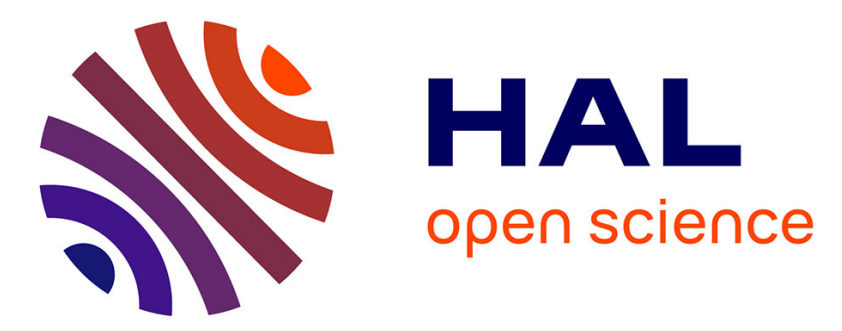

\title{
Spatial and temporal variability of sediment infilling and episodic rifting in the North Pearl River Mouth Basin, South China Sea
}

\author{
Chao Fu, Shengli Li, Shunli Li, Jianyong Xu
}

\section{- To cite this version:}

Chao Fu, Shengli Li, Shunli Li, Jianyong Xu. Spatial and temporal variability of sediment infilling and episodic rifting in the North Pearl River Mouth Basin, South China Sea. Journal of Asian Earth Sciences, In press, pp.104702. 10.1016/j.jseaes.2021.104702 . insu-03150749

HAL Id: insu-03150749

https://hal-insu.archives-ouvertes.fr/insu-03150749

Submitted on 24 Feb 2021

HAL is a multi-disciplinary open access archive for the deposit and dissemination of scientific research documents, whether they are published or not. The documents may come from teaching and research institutions in France or abroad, or from public or private research centers.
L'archive ouverte pluridisciplinaire HAL, est destinée au dépôt et à la diffusion de documents scientifiques de niveau recherche, publiés ou non, émanant des établissements d'enseignement et de recherche français ou étrangers, des laboratoires publics ou privés. 


\section{Journal Pre-proofs}

Spatial and temporal variability of sediment infilling and episodic rifting in the North Pearl River Mouth Basin, South China Sea

Chao Fu, Shengli Li, Shunli Li, Jianyong Xu

PII:

S1367-9120(21)00040-7

DOI: https://doi.org/10.1016/j.jseaes.2021.104702

Reference: JAES 104702

To appear in:

Journal of Asian Earth Sciences

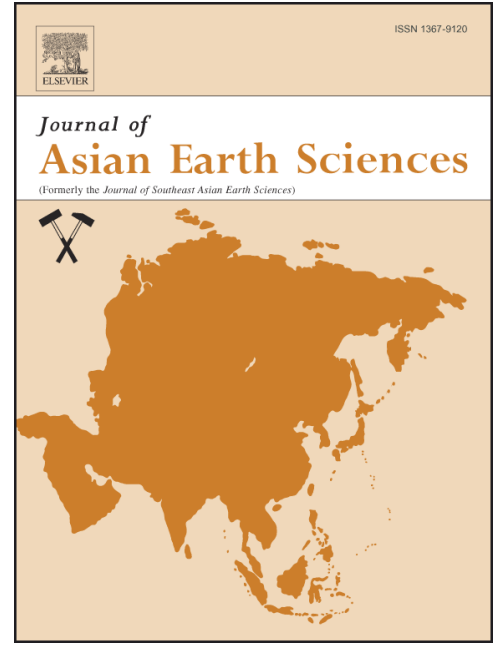

Received Date: $\quad 16$ September 2020

Revised Date: $\quad 25$ January 2021

Accepted Date: $\quad$ 29 January 2021

Please cite this article as: Fu, C., Li, S., Li, S., Xu, J., Spatial and temporal variability of sediment infilling and episodic rifting in the North Pearl River Mouth Basin, South China Sea, Journal of Asian Earth Sciences (2021), doi: https://doi.org/10.1016/j.jseaes.2021.104702

This is a PDF file of an article that has undergone enhancements after acceptance, such as the addition of a cover page and metadata, and formatting for readability, but it is not yet the definitive version of record. This version will undergo additional copyediting, typesetting and review before it is published in its final form, but we are providing this version to give early visibility of the article. Please note that, during the production process, errors may be discovered which could affect the content, and all legal disclaimers that apply to the journal pertain.

(c) 2021 Elsevier Ltd. All rights reserved. 
MoutI DasIII, suulII CIIIII sea

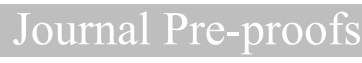

Chao $\mathrm{Fu}^{\mathrm{a}, \mathrm{b}}$, Shengli $\mathrm{Li}^{\mathrm{a}, *}$, Shunli $\mathrm{Li}^{\mathrm{a}}$, Jianyong $\mathrm{Xu}{ }^{\mathrm{c}}$

a School of Energy, China University of Geosciences, Beijing 100083, China;

b Rennes Geosciences, Université de Rennes 1, Rennes 35000, France

c CNOOC Research Institute, Beijing 100028, China

corresponding author: slli@cugb.edu.cn

Abstract: Pearl River Mouth Basin (PRMB) is a typical episodically rifting basin, and its sediment records exhibit a multistage infilling process. To build the coupling relationship between the spatial variability of tectonic movement and sediment dispersal pattern, we character the source-to-sink system distribution within continental margin and analysis their dominated factors with quantitative statistical methods. First, we identify the faults and calculate the rifting rate by interpreting the twodimensional (2D) seismic data and zircon or apatite fission-track data (ZFT/AFT). Accordingly, based on the various trending of the rifting rate evolution, we classified rifting process episodically into three patterns: accelerated rifting decelerated rifting, and uniform rifting. Then, we integrated the data available on detrital zircon $\mathrm{U}-\mathrm{Pb}$, rare earth element, and heavy mineral assemblage to identify the responding S2S components associated with the above various rifting processes. Results show that in the first tectonic stage during the early Eocene, the sediments were mainly sourced from an intrabasin provenance area, whereas in the late Eocene to the Oligocene, the paleo-Pearl River provided the sediments to the sink area. We restore the facies association of the sink area by studying the core samples, electric well logs, and three-dimensional (3D) seismic data. During the accelerated and uniform rifting processes, coarse-grained deposited along the boundary faults, which includes the fan delta and subaqueous fans. During decelerated rifting, the depositional environment was dominated by braided channels, meandering channels, and tide-influenced channel accretion. Based on the quantitative analysis the relationship between the grain size of the sediment in each S2S segment and the rifting rate, more fine-grained components were preserved in the decelerated rifting system, while coarse-grained sediments fill the accelerated rifting depression and uniform rifting components. Furthermore, the sediment supply and relative height can influence the volume of the S2S system in 
the uniform rifting system. In the decelerated rifting basin, the sediment supply is the major factor

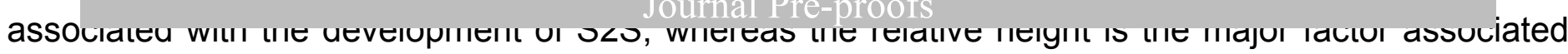
with the accelerated rifting basin.

Keywords: North Pearl River Mouth Basin, Source-to-sink system, Detrital zircon U-Pb data, Rifting

\section{Process}

\section{Introduction}

The Pearl River Mouth Basin (PRMB) (Fig. 1) is a typical episodically rifting basin (Li and Rao., 1994) that can be attributed to the impact of the convergence of the Pacific, Eurasian, and IndoAustralian plates. During the Paleogene epoch, the PRMB framework was determined by two stages of rifting: the Zhuqiong I and Zhuqiong II phases (Li and Rao, 1994; Wu et al., 2016; Ge et al., 2017; Shao et al., 2017; Wang et al., 2019). PRMB is an ideal case that can be studied to explore the infilling process associated with a continental margin in case of an episodically rifting basin, including sediment transport and the sediment dispersal pattern in the sink area (Wang et al., 2019). In this study, we aim to establish the infilling process of the episodic rift basin based on the insights obtained from the case study of source-to-sink (S2S) in the Pearl River Mouth Basin.

Previous studies have indicated that the basin structure and the geomorphology change caused by rifting tectonic movement would lead to the spatial and temporal variability during the filling process (Keen and Dehler., 1993; Ziegler and Cloetingh., 2004; Li et al., 2020; Tang et al., 2020). Martin et al., (2009) and Paola and Martin., (2012) have reworked a credible filling process in a simple rifting basin, which characters by a single simple rifting process defined as Merle (2011). However, as to the more complex infilling process in the episodic rift basin, the relation between sediment infilling and the tectonic processes remains unclear, especially with regard to the relation between multiple stages, during which the rifting rate is observed to change. Some studies indicate that the infilling process in various stages is independent of the rifting rate, whereas others indicate that the former process is affected by the latter (Li and Rao., 1994; Xie. et al., 1996; Mugisha et al., 1997; Shao et al., 2018; Xie et al., 2019).

Further, we focus on the cause to spatial and temporal variability during the filling process. Saneyoshi et al., (2006), Cao et al., (2018) and Wu et al., (2019) have stated that internal factors, such 
as the fault stack patterns or rifting rate, would influence the sedimentary process, whereas Gawthorpe

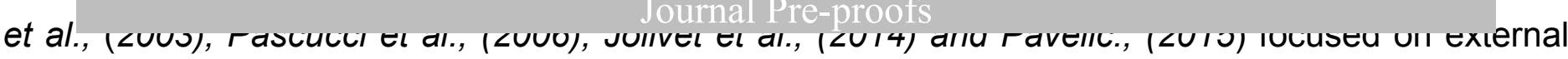
factors such as sediment supply or the rework process. In the case of the PMRB, all the aforementioned factors continuously changed during the Eocene to Oligocene epochs (Wang., 2015; Xie et al., 2019). Lots of publishes have also investigated the infilling process with respect to the change in the sourceto-sink system (Li and Rao., 1994; Ren et al., 1996; Jiao et al., 1997; Liu et al., 2013; Wang., 2015; Lin. et al., 2018). They rebuild the provenance area(Wang et al., 2019), volcanic activity (Li and Rao 1994) and deposition process in the sink area (Wang., 2015; Xie et al., 2019). However, because of data limitation, they did not evaluate the planar distribution of the sediment from the paleo-river during the Eocene to Oligocene epoch.

In this study, we initially clarify the rifting process. Based on previous studies related to study methods ( $\mathrm{Li}$ and Rao, 1994; Yi et al., 2009; Li et al., 2018), we integrated thermochronology data analysis and seismic interpretation to calculate the rifting rate and classify their types. Subsequently, we characterized the regional uplift or subsidence in the northern depression zone (NDZ). Based on these analyses, the NDZ can be divided into three subregions according to the different insights obtained with respect to the rifting process when the rifting rate is varied over time, 1) accelerated rifting, which indicates an increasing extension rate during the rifting process, 2) decelerated rifting which represent a decelerating extension process, and 3) uniform rifting systems, which character by its uniform extension process. Then, as the S2S system is reconstructed, we integrate the heavy mineral assemblage and detrital zircon $\mathrm{U}-\mathrm{Pb}$ data to estimate the sediment transport distance. Additionally, we can obtain the quantitative parameters of the system spatially and temporally based on the interpreted three-dimensional (3D) seismic data. Subsequently, we explain the dominant factors associated with the change in grain size observed in the S2S system during the infilling process.

\section{Geological setting}

The PRMB is divided into three parts from north to south: northern depression zone (NDZ), central uplift, and southern depression zone (SDZ). As to the NDZ, Li and Rao, (1994) point out that the western part show character as several small sags developed with NEE-directional normal faults, while the east part is mostly big sags controlled by the faults boundaries. Thus, we name the east part in 
NDZ as Zhu I Depression or Western NDZ, and the west part as Zhu III depression (Pearl River name

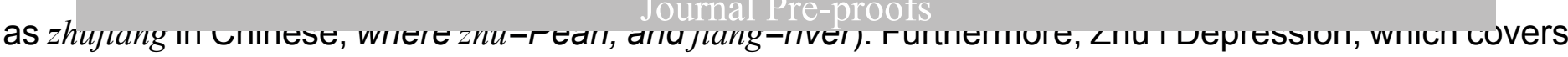
an area of $4.2 \times 10^{4}$ with hydrocarbon-rich sag like Huizhou, Enping, Xijiang, can be divided into two parts, as the eastern Zhu I Depression(Eastern NDZ), and the west Zhu I Depression(Central NDZ) according to their locations(Fig. 1).

With respect to the form obtained via impact based on the seafloor spreading of the South China Sea, the tectonic stage of PRMB can be divided into two phases (Fig. 1): a syn-rifting process during the late Cretaceous or Paleocene to the early Oligocene, and post-rifting from the late Oligocene to present (Li and Rao, 1994; Li et al,2014 and 2015; He et al., 2017; Shao et al., 2018 Wang et al, 2019; Xie et al,2019). The syn-rifting stage can be further divided into three phases: Shenhu movement, Zhuqiong I phase tectonic movement, and Zhuqiong II phase tectonic movement (Fig. 1). The Shenhu movement can be observed for a short duration and exhibits limited influence (Li and Rao, 1994). Thus, in this study, we focus on the rifting process of the Zhuqiong I and Zhuqiong II phase tectonic movements.

\subsection{Tectonic stage}

Previous studies indicate that the multiple stages of episode rifting in the north PRMB can be attributed to the extension of the paleo-South China Sea and the rotation of the Indochina and Cathaysia blocks (Shao et al., 2017; Cao et al., 2018). Since the Eocene, the corresponding dominant tectonic stress was transferred from the northwest to the southwest direction (Fig. 2) (Li and Rao, 1994; Morley., 2016). Furthermore, the relative motion of the Pacific and Asia plates caused the development of NDZ as a wide rifting pattern (Buck., 1991; Engebretson et al., 1984; Suo et al., 2019). The profiles in Fig. 2 obtained with respect to the interval of the early Eocene shows that several separate sags or half-grabens developed on the NDZ with a high rifting rate. The average rifting rate was $100 \mathrm{~m} / \mathrm{Ma}$; the its maximum became 200 m/Ma (Engebretson et al., 1984; Li and Rao, 1994; Morley., 2016; Torsvik et al., 2019).

In the Oligocene, because of the increasing velocity of the Pacific plate subduction (Morley., 2002; Torsvik et al., 2019) and the convergence of the Asian and Indian plates (Tapponnier et al., 1990; Deng et al., 2017; Shao et al., 2017), the rotation of the Cathaysia block led the second rifting process (Jiao 
et al., 1997; Morley., 2002; Lin et al., 2004; Liu et al., 2013; Wang., 2015). Thus, when the source-to

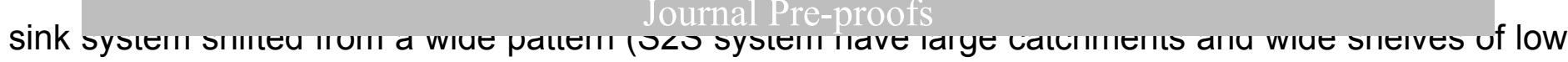
gradient bathymetry) to a narrow pattern(S2S system charactered by steep and short catchments), the spatial location variability of the aforementioned sags or half-grabens in NDZ exhibited a different rifting process (Buck., 1991; Li and Rao, 1994).

\subsection{Sedimentary setting}

According to the drilling data obtained in each depression (Fig. 3), the Paleogene (from bottom to top) comprises Shenhu Formation $\left(E_{1} s\right)$, Wenchang Formation $\left(E_{2} w\right)$, Enping Formation $\left(E_{2} e\right)$, Zhuhai Formation $\left(\mathrm{E}_{3} z\right)$. By calibrating the well-log and seismic data (Wu et al., 2016; Ge et al., 2017), the bottom $E_{2} w$ is called $\mathrm{Tg}$, the bottom $\mathrm{E}_{2} \mathrm{e}$ is $\mathrm{T} 80$, and the bottom $\mathrm{E}_{3} \mathrm{Z}$ is $\mathrm{T} 70$ (Fig. 4).

Shenhu Fm. can be observed in a limited area in PRMB, and the alluvial fan was observed to develop in this interval (Morley., 2016; Wang et al., 2019). The lithology mainly comprises coarse sandstone and fine-grained red gravel. Some volcanic rocks, including the lava, tuff, and volcanic clastic rocks, were observed to develop in the Eastern NDZ in Shenhu Fm. as Li and Rao (1994)'s study. Wenchang Fm. was generated in each separate sag during the first rifting stage. Thick mudstone with siderite also developed. Hu et al., (2012), Peng et al., (2017) and Ge et al., (2018) pointed out that the northern and southern depression zones are lacustrine setting in this interval insight from the biomass and trace element data. Enping Fm. can be divided into two members, i.e., top and bottom, according to the difference in lithology. The bottom layers are mainly interbedded sand and mudstone, whereas the upper layer includes thick mudstone or some thin coal layers. The interval of Zhuhai Fm. mostly developed in the late part of the second rifting stage. Gray sandstone with glauconite developed during this interval (Lin et al., 2018).

\section{Data and method}

\subsection{Research data}

The block in PRMB included $1892.9 \mathrm{~km}$ of 2D seismic data and 1500 sq. km. of 3D high-resolution seismic data. A total of 21 wells drilled in PRMB were selected, and the positions of the cross-well seismic sections are shown in Fig. 1c. The electric well-log curves, including gamma rays, were acquired and processed by Schlumberger. The cored intervals were observed in wells F, E, C, and B 
(Fig. 5). The rare earth element (REE) content and heavy mineral analyses in wells F, E, C, B, and M

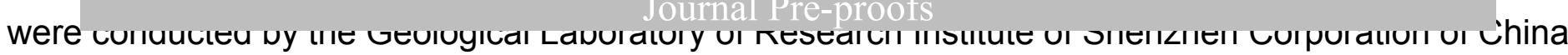
National Offshore Oil Corporation.

The fission-track (FT) analysis of wells $\mathrm{L}, \mathrm{H}, \mathrm{O}, \mathrm{P}, \mathrm{J}$ and $\mathrm{G}$ was conducted by the Institute of High Energy Physics, Chinese Academy of Sciences. The data of well K refer to the study of Li et al., (2018). The sample was covered by muscovite and the reactor irradiated with standard uranium glass UB2 and standard age sample FC3. The radiant thermal neutron flux of the apatite sample was $5.5 \times 10^{15}$ $\mathrm{cm}^{-2}$, and the neutron flux of the zircon samples was $1.5 \times 10^{15} \mathrm{~cm}^{-2}$. After irradiation, the external detectors were etched using $40 \% \mathrm{HF}$ at $20{ }^{\circ} \mathrm{C}$ for $20 \mathrm{~s}$. Then, we obtain the FT density and length, as described by Green et al., (1985), through analysis using the Auto Scan system. The sample ages were determined using the zeta calibration method and recommended age standards (Hurford and Green., 1983; Green et al., 1985) (Table 1). The ZFT central age was $366 \pm 9.6 \mathrm{Ma}$, and the ATF central age was $381.8 \pm 7.3 \mathrm{Ma}$.

U-Pb dating of the four samples (well F 3917.5, well E 4155.5, well C 2580.1, and well B 2581.1m) via LA-ICPMS analysis was conducted by the Chinese Academy of Geological Sciences (Appendix TableS 1-4). Laser ablation was performed using the NWR193UC 193-nm deep ultraviolet laser ablation sampling system (Elemental Scientific Lasers, United States). Agilent 7900 inductively coupled plasma mass spectrometry (Agilent, US) was also conducted. 120 detrital zircons from each sample were analyzed with a spot size of $30 \mu \mathrm{m}$. Every five analyses were followed by one analysis of standard zircon 91500, and GJ-Common lead correction was conducted using ComPbCorr\#3_15G. The U-Pb age calculations and concordia diagram were completed on IsoplotR software provided by University College London, United Kingdom (http://pieter-vermeesch.es.ucl.ac.uk/shiny/lsoplotR/). Only the zircon ages concordant within $90 \%-110 \%$ are discussed in the following.

\subsection{Research methods}

1) A method to reconstruct the rifting process with $2 \mathrm{D}$ seismic data and apatite and zircon FT data.

We rebuild the rifting process according to the $2 \mathrm{D}$ seismic data interpretation and calculate its rifting rate based on the Apatite fission-track/ Zircon fission-track (AFT/ZFT) data.

In this study, we refer to the thermal history modelling put out by Laslett et al., (1987), and the 
AFTslove ${ }^{\circledR}$ software to simulate the thermal history. We input the parameters, including the single

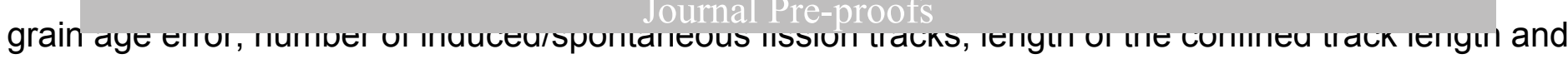
the $\mathrm{C}$-axis angle. Then, restricted by the sample's depth and their responding terrestrial heat flow as Jiang et al., (2019), we get the T-t(Temperature-time) path (104 simulation curves for each sample). Finally, we check the simulation results with k-s testing and Age GOF parameter evaluation, which show a credibility simulation with the check value over $5 \%$, and a high-quality simulation with the value over $50 \%$.

As the stable late compaction process in the PRMB (Dong et al., 2009), we can evaluate the rifting rate according to the average fault displacement and average strata thickness. Firstly, as the mudstone and sandstone show various compaction coefficient, we pre-compact the strata thickness using the compaction coefficients of $0.51 \mathrm{~km}^{-1}$ for mudstone and $0.27 \mathrm{~km}^{-1}$ for sandstone and calculated average strata thickness is H(Ma et al., 2019; Wu et al., 2019).

Then, rifting rate is represented as $\sigma(x, t)$. The basement-elevated height is $\eta(x)$, which can get from the seismic data interpretation. The time of rifting interval is $T$. The rifting rate can be calculated as

$$
\sigma(x, t)=(\eta(x)+H) / T
$$

(Equation 1)

Based on the inversion method applied in previous studies (Yi et al., 2009; Li et al., 2018), we calculated $\eta(x)$ based on the inversion of AFT/ZFT data (Table 1). $T$ is time, which can be obtained from the detrital zircon $\mathrm{U}-\mathrm{Pb}$ data and well seismic calibration.

2) A method to identify the provenance area by combining the heavy mineral assemblage and detrital zircon $\mathrm{U}-\mathrm{Pb}$ data.

By combining the results of previous studies on the provenance area of the NDZ during the Eocene (Wang et al., 2019; He et al., 2020), we established a mean U-Pb age distribution in the NDZ. By integrating the age data on the basement rocks with the tectonic background, we identified the provenance transfer from the Eocene to the Oligocene. We can infer the provenance based on the chemical activity of rare earth element (REE) by comparing the REE distribution of the fine-grained stone in NDZ and the possible source area. In this study, with regard to the REE pattern distribution around PRMB, we refer to the study conducted by Ma et al. (2016) and Shao et al. (2018). Then, we 
combined the heavy mineral assemblage (HMA) with the zircon-tourmaline-rutile (ZTR) index,

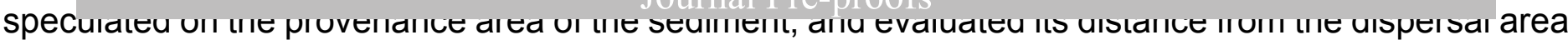
(Fu et al., 2019).

3) Quantitative evaluation of the volume of each segment in the S2S system.

We can determine the amount of quantitative geological information, including sediment composition, infilling process, and sink area distribution, through a detailed analysis of the seismic data (Anell and Midtkandal., 2015; Lin et al., 2018; Zhuo et al., 2019).

The 2D seismic data can provide insights based on which we can rebuild the paleo-morphology during the episodic rifting process. After the seismic interpretation and compaction removal, we reconstruct the geomorphology map of Wenchang Fm. and Enping Fm.

Then, we rebuild the sink area and sedimentary facies association according to the 3D seismic data interpretation. We identified three seismic facies (concave, linear, and sigmoidal) based on their seismic boundaries. They can be interpreted as a channel or sediment pathway, channel distributary or semi-deep lake-deep lake fine-grained deposit, and fan delta or subaqueous delta, respectively. Accordingly, we determine the dispersal area of the S2S system and build the accretion pattern in each sag spatially.

4) Analysis of the filling process based on the mass balance theory.

To study the S2S system and simple extension rifting setting, Paola and Martin., (2012) proposed the mass balance theory to recover the infilling process. If compaction is ignored, then the relation between the rafting rate $(\sigma(x, t))$ and the amount of sediment supply ( $\left.Q_{\text {total }}\right)$ can be shown as

$$
Q_{\text {total }}=\frac{1}{\chi(x)} \int_{0}^{x}(\sigma(x, t)+\eta(x)) d x,
$$

(Equation 2)

where $X(x)$ is the mass balance coordinate (or mass loss) and $x$ is the distance from the source to the sink.

Because the fluvial-deltaic system is dominant in the PRMB during the rifting stage (Wu et al., 2016), the relative height is determined by the thickness of the clinoform (Chen et al., 2019; Steel et al., 2019) and the rifting rate, as shown in Equation 1. Then, based on the fluvial-deltaic model (Hampson et al., 2014), the sediment migration distance is $u(x)$. Thus, Equation 2 can be rewritten as

$$
Q_{\text {total }}=\frac{a}{\chi(x)} \cdot u(t) \cdot \sigma(x, t)+b
$$


where $a$ is the rifting interval (Eocene to Oligocene) and $b$ is the thickness of the fine-grained sediment proviueu via susperısıul allu ruccuratıun.

Further, we can determine the rifting rate (plotted as $\sigma(x, t)$-x in the work of Hampson et al., (2014)), sediment migration distance $(u(x))$, and amount of sediment supply (Q). By inserting all the aforementioned variables into Equation 3, we can obtain the relation between the mass balance coordinate (mass loss) $X(x)$ and the sediment migration distance $x$ (dimensionless); this plot is also called mass extraction profile as defined by Michael et al. (2014).

Based on previous studies, the profile of mass balance coordinate (mass loss) $X(X)$ can serve as an index of grain size distribution (Martin et al., 2009; Paola. and Martin M., 2012; Michael et al., 2014; Michael et al., 2014). Thus, we build an identification chart of the aforementioned variable and infilling process based on the S2S system. This identification chart refers to the global continental margin infilling pattern proposed by Sømme et al. (2013); Gong et al. (2016); Nyberg and Howell (2016); and Nyberg et al. (2018). In the chart, the S2S system is classified as proximal and distal provenance area systems. Then, according to the mass balance coordinate (mass loss) $X(x)$, coarse-grain fan dominated $(x(x)<0.25)$, sandy pro-graded delta-dominated $(0.25<x(x)<0.75)$, and reworking sedimentdominated $(0.75<x(x)<1.0)$ data (Sheets, B. A. et al., 2002; Michael et al., 2014), we can rebuild the infilling process by responding to different rifting processes. Furthermore, we can evaluate the dominant factors in the infilling process using the volume plotting of each S2S system segment in the bubble chart (Fu et al., 2019).

\section{Lithofacies identification}

The grains of the sediments in the PRMB during the Eocene and Oligocene range from mudstone to fine conglomerate. With respect to the reworking process, we classified the deposit into ten types, namely, massive mudstone $(\boldsymbol{M})$, bioturbated sandstone $(\boldsymbol{S b})$, muddy strip composite sandstone (Scm), deformation sandstone $(\mathbf{S d})$, crossbedding composite sandstone (Scc), crossbedding sandstone (Sc), massive sandstone $(\mathbf{S m})$, planar crossbedded sandstone $(\mathbf{S p})$, massive gravel $(\mathbf{G m})$, and planar cross bedded gravel $(G p)$. The above lithofacies associations were identified and classified based on the cores from wells F, E, C, and B (Fig. 5), and the detail description were added in Table.2.

\section{Seismic data interpretation}




\subsection{Wenchang "A" Sag in Western NDZ (Section 1)}

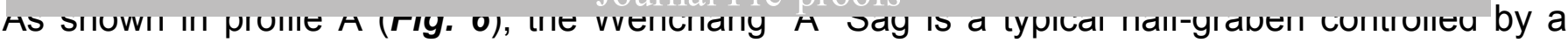
boundary fault. We divided the sag into three layers, i.e., Wenchang Fm. (Tg-T80), Enping Sag (T80T70), and Zhuhai Fm. (T70-T60) according to the aforementioned well calibration. The average strata thickness of Wenchang Fm. is 300-700 m. Enping Sag and Zhuhai Fm. exhibit similar thickness values of 300 and $280 \mathrm{~m}$, respectively.

To characterize the infilling process, we select a profile that passes through the center of the Wenchang "A" Sag (section location in Fig. 1). In the Wenchang Fm. interval, the seismic continuity event in the Wenchang "A" Sag indicates the development of a fine-grained delta, and we can distinguish four phases of the pro-graded delta from the profile (Fig. 6). Considering the volume of this delta, an average thickness of $30-50 \mathrm{~m}$ and a pro-graded distance of $100 \mathrm{~km}$ can be obtained. Furthermore, in the inner seismic package of the pro-graded delta, we can distinguish between several channels according to the convex seismic facies. These channels developed with later migration and small erosion. The cutoff of these channels indicated a pathway area of $1.3-3 \mathrm{sq} . \mathrm{km}$. In the southern Wenchang "A" Sag profile, we can distinguish between two phases of fan delta (or subaqueous fan) with an average volume of $0.5-1.0 \mathrm{sq} . \mathrm{km}$.

In the Enping Fm. and Zhuhai Fm. interval, we can distinguish between an alluvial delta or fan delta, where each phase has an average volume of $1.5 \mathrm{sq} . \mathrm{km}$. and $0.7 \mathrm{sq} . \mathrm{km}$. , respectively.

\subsection{Enping Sag in Central NDZ (section 2)}

As indicated by profile B (Fig. 7), Enping Sag is an atypical half-graben. The faults in the south have a displacement of more than $200 \mathrm{~m}$, and the fault in the north can be attributed to syngeneic deposition. The profile can also be divided into three layers (Wenchang Fm., Enping Fm., and Zhuhai Fm.). In the Wenchang Fm. interval, we can distinguish between several seismic packages with a concave or lenticular shape at the bottom. The inner chaotic event shows a fast infilling process, which can be interpreted as a deposited fan delta or alluvial fan. The thickness became $80 \mathrm{~m}$ and is related to the volume of these pro-graded sediments. Then, upward to Enping Fm., according to the onlap seismic event in Fig. 7, we distinguish between three phases of the delta with an average thickness of $30-50 \mathrm{~m}$. 


\subsection{Huizhou Sag in Eastern NDZ (section 3)}

Journal Pre-proofs

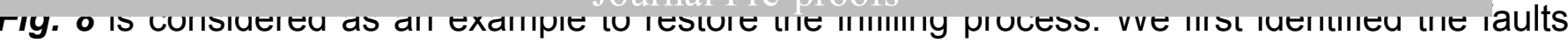
along the slope and calculated the broking distance at $20 \mathrm{~m}$ in Wenchang Fm. and $25 \mathrm{~m}$ in Enping Fm. Then, according to the well calibration and seismic reflection, the faults are divided into three layers: Wenchang Fm., Enping Fm., and Zhuhai Fm. In Wenchang Fm., the seismic facies with a clear concave and lenticular boundary exhibit an inner chaotic event, indicating the fast infilling process. Upward to the Enping Fm. interval, a series of pro-graded deltas can be observed from the south and north uplifts. The average thickness in the south is $57 \mathrm{~m}$, whereas that in the north is $35 \mathrm{~m}$.

\section{Results}

\subsection{Apatite/zircon FT data}

Refer to the form research in South China (Yi et al., 2009; Li et al., 2018), the FT thermochronometric method in this study can be used to reconstruct the rifting process and prove the paleo-morphology rebuilding. Based on the work conducted by Yi et al. (2009), the cooling temperature of zircon is $210 \pm 18{ }^{\circ} \mathrm{C}$ and that of apatite is $60^{\circ} \mathrm{C}-120^{\circ} \mathrm{C}$. The histogram of the fission track in wells $\mathrm{O}$ and $\mathrm{P}$ show multiple peaks, whereas that of the fission track in wells $\mathrm{H}, \mathrm{G}, \mathrm{J}$ and $\mathrm{L}$ is a one-peak pattern (Fig. 9), indicating that the thermal flow and rifting process of NDZ are heterogeneous in case of planar distribution.

All the grain ages of wells $L, H$, and $G$ pass the $x^{2}$ text $(5 \%)$; these ages can be calculated as pool age, which is estimated as the ratio of spontaneous track density to induced track density. This indicated that these grains may have annealed thoroughly during the Paleogene. The $P\left(x^{2}\right)$ of wells $O$ and $P$ is less than $5 \%$; these ages were the central age. Based on the thermal flow associated with PRMB (Yuan et al., 2009; Li et al., 2018), the grains in wells $\mathrm{O}$ and $\mathrm{P}$ may not reach the cooling temperature of the apatite and exhibit low thermal flow at the above well location (Enping Sag in Central NDZ).

The average of the AFT in NDZ range from 11.37 to $13.16 \mu \mathrm{m}$, and its standard deviation $(\sigma)$ is 1.14 3.01 $\mu \mathrm{m}$. The inversion results obtained using paired minerals indicate that the cooling rates of wells $\mathrm{L}, \mathrm{O}$, and $\mathrm{P} J, \mathrm{G}$, are $1.66,4.31,15.25,1.91$, and $2.50{ }^{\circ} \mathrm{C} / \mathrm{Ma}$, respectively. Then, as the geothermal gradient in various sags (Yuan et al., 2009), the uplifts of wells $L$ in the western NDZ 
character by the uplifting rate of $0.038 \mathrm{~km} / \mathrm{Ma}$ and the calculated basement-elevated height $(\eta(x))$ is

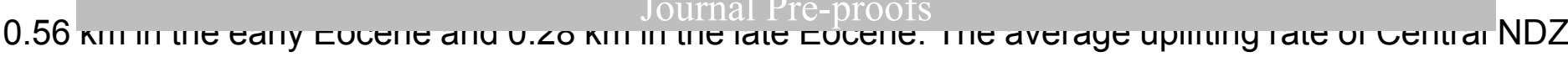
(the well $O 0.113 \mathrm{~km} / \mathrm{Ma}$ and $\mathrm{P} 0.48 \mathrm{~km} / \mathrm{Ma}$ ) is $0.30 \mathrm{~km} / \mathrm{Ma}$. Well $\mathrm{J}$ and $\mathrm{G}$ shows the uplifting rate in the Eastern NDZ, which is 0.057 and $0.089 \mathrm{~km} / \mathrm{Ma}$, respectively.

\subsection{U-Pb detrital zircon data}

Detrital zircons $\mathrm{U}-\mathrm{Pb}$ age data are used to constrain the potential source area of sediments deposited in the PRMB during the Eocene and Oligocene. Four samples selected and representative zircon Cathodoluminescence $(\mathrm{CL})$ images are shown on Fig. 10. Concordia plots in Fig.11 and individual age spectrums in Fig.12.

The zircon in the late Eocene is colorless and is mostly in an elliptical shape. According to the $\mathrm{CL}$ image, the long-axis zircon is $90-120 \mu \mathrm{m}$. According to the internal structures, zircon can be classified into three types (Fig. 10). The first type is a subangular shape with a length-to-width ratio of $1: 1$. This type of zircon shows a dark magmatic oscillatory zone that can be observed from the cathodoluminescence $(\mathrm{CL})$ images. This type accounts for $60 \%$ of each sample, and the age range is 145-23.3 Ma. The second type is a sub-round shape with a length-to-width ratio of $3: 1$. This type of zircon shows a clear magmatic oscillatory zone that can be observed in the CL images. The age is 443-145 Ma. The third type is a round shape with a length-to-width ratio of 2:1. The internal structure exhibits homogeneous or patchy zoning, and this type accounts for $20 \%$ of all the samples.

The age data associated with wells E, F, C, and B are presented in Appendix Tables 1-4. In this study, 345 detrital zircons were considered to be adequate. The zircon age data of the four samples can be classified into four groups: 100-200, 410-500, 250-280, and 2400-2500 Ma (Fig. 11).

The zircon of well F at a depth of $3917.5 \mathrm{~m}$ is the interval of Enping Fm. The U-Pb Concordia plots (Fig. 11) of all the grains display concordances of $>90 \%$. Its age spectrum shows that the zircon can be divided into five parts: 30-200, 200-300, 400-500, 600-750, and 750-1000 Ma (Fig. 12). Their corresponding peaks are 175, 245, 420, 710, and $880 \mathrm{Ma}$, respectively (Fig. 12). A sample of well E with a depth of $4155.5 \mathrm{~m}$ can be observed in Enping Fm., and all the grains show concordances of $>90 \%$ (Fig. 11). Its age can be divided into two parts: $150-400 \mathrm{Ma}(80 \%)$ and $400-500 \mathrm{Ma}(17 \%)$. The samples from well C (with a depth of $2581.1 \mathrm{~m}$ ) and well B (with a depth of $2580.1 \mathrm{~m}$ ) are in the interval 
of Enping Fm. In case of well B, the age spectrum is divided into two groups: $83-150 \mathrm{Ma}$ (35\% with a

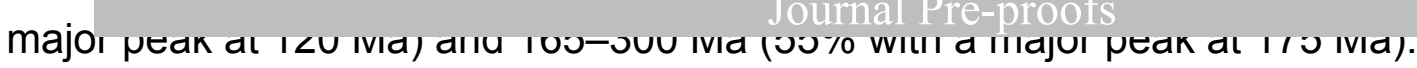

The thorium-to-uranium (Th/U) ratio can reflect the lithologies of the provenance area. As shown in Fig. 13, for the Th/U ratio of the Eocene, we refer to the study conducted by Wang et al. (2019), which indicates a range of $0.125-1.36$. For the Oligocene, the samples of wells $F, E$, B, and $C$ in Enping Fm. exhibit Th/U ratios of $0.015-0.165$. This condition indicates that a large volume of metamorphic rocks was injected into the sink area during the Oligocene.

\subsection{Rare earth element (REE) content}

In the Enping Fm. interval, the amount of $\operatorname{REE}\left(540.9 \times 10^{-6}-993.2 \times 10^{-6}\right)$ in the samples from wells $E$ and $F$ is high. The LREE/HREE (Light rare earth/ Heavy rare earth) value is 3.02-6.79, the $\delta(\mathrm{Eu})$ value is $0.855-0.901$, and the $\delta(\mathrm{Ce})$ value is $0.912-0.975$. As indicated by the chondritenormalized REE distribution patterns (Fig. 14), the REE in wells $E$ and F eastern and central of NDZ shows LREE enrichment and HREE deficiency. The Eu content shows a slightly negative anomaly, whereas $\mathrm{Ge}$ is normal. The amount of $\Sigma$ REE in the samples from wells $\mathrm{C}$ and $\mathrm{B}$ in the Western NDZ is $602.2 \times 10^{-6}-722.4 \times 10^{-6}$. The LREE/HREE value is $1.98-2.66$, the $\delta(\mathrm{Eu})$ value is $0.238-0.996$, and the $\delta(\mathrm{Ce})$ value is $0.940-1.00$. Similarly, as indicated by the chondrite- normalized REE distribution patterns (Fig. 14), the LREE in wells $C$ and $B$ are enriched, whereas HREE is deficient. The Eu and Ge contents are both normal.

In the Wenchang Fm. interval, the REE distribution data are obtained from the study conducted by Shao et al. (2018). The REE distribution in case of Eastern and Central NDZ shows that the LREE content is higher than the HREE content and that in case of the Western NDZ shows that the LREE content is less than the HREE content. Generally, the Eu content of the samples from NDZ shows a negative $\mathrm{V}$ shape.

\subsection{Heavy mineral assemblage}

1) Heavy mineral assemblage in Eastern and Central NDZ

As shown in Fig. 15, the HMA in the Eastern and Central NDZ is observed to vary. In the Xijiang Sag (well E), the HMA comprises zircon-titanite-anatase-tourmaline. The well M in the Huizhou Sag comprises zircon-apatite-magnetite-barite. The sediment of well $F$ has HMA comprising pyrite- 
zircon-rutile-titanite. In this study, we evaluated the sediment migration distance according to the value of $Z 1 \pi$.

During the Eocene, the ZTR values of wells $E, M$, and F show a spatial difference and they are $70 \%, 35 \%$, and $20 \%$, respectively. Up to the Oligocene, wells E, M and F showed a sharply increase in ZTR value and saw a rising of the zircon content, suggesting that an increasing distal sediment was dominant in this interval.

2) Heavy mineral assemblage in Western NDZ

The HMA values associated with wells $C$ and B show similar compositions, i.e., zircon-rutiletitanite-biotite. During the Eocene, the average ZTR index of Western NDZ was 30\%. In the Oligocene, the average ZTR index increased to $57 \%$. The ZTR index of well C increased drastically to $90 \%$, whereas that of well B changed gradually. This condition indicates that the distal sediment influences Western NDZ and that the sediments may accumulate in some proximal areas as well.

\section{Discussions}

\subsection{Rifting process reconstruction and classification}

As interpreted from the seismic profile presented in Fig. 16, we can identify the faults, i.e., F1 to F33. Then, we calculate the average broken displacement from the Eocene to the Oligocene. Accordingly, we classified that the Western NDZ as a uniform rifting system, the Central NDZ (Enping and Xijiang Sags) as a decelerated rifting system, and Eastern NDZ as an accelerated rifting system.

\subsubsection{Uniform rifting system}

The broken displacement in Wenchang "A" Sag remains at the same level during the riffing process (Fig.16 a). When compared with the thickness of Tg-T80, the average strata thickness of T80-T70 $(450 \mathrm{~m})$ does not change drastically. As the ZFT inversion results in well L (eastern NDZ), the timetemperature curve in Fig. 9 reflects a multistage uplifting process in eastern NDZ during 64.9-27. 3 Ma. Then, as indicated by the calculation of the rifting rate, the first rifting rate of $180 \mathrm{~m} / \mathrm{Ma}$ can be observed in the first rifting stage (Eocene) and a rifting rate of $160 \mathrm{~m} / \mathrm{Ma}$ can be observed in the second stage (Oligocene). Accordingly, this type of episodic rifting process can be referred to as a uniform rifting system.

\subsubsection{Decelerated rifting system}


The Enping and Xijiang Sags are typical multistage half-grabens, which are controlled by boundary

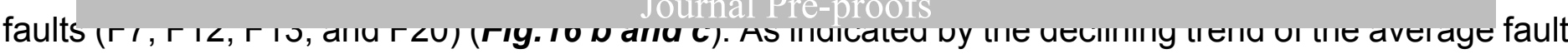
displacement associated with these sags (F7-F20), fewer fault displacements occur in the Oligocene when compared with those in the Eocene. The time-temperature curve of the wells $\mathrm{O}$, and $\mathrm{P}$ reflects the thermal evolution and uplift process of the Panyu Uplift (south of the Enping and Xijiang Sags) (Fig. 9). Fig. 16 shows a fast uplifting rate in the first stage and a slow uplifting rate or slight subsidence in the second stage. As indicated by T80 and T70 in the seismic profile of Figs. $\mathbf{3} \boldsymbol{b}$ and $\boldsymbol{c}$, considerable erosion can be observed at the interface. Accordingly, the rifting rates are $155 \mathrm{~m} / \mathrm{Ma}$ in the Eocene and $90 \mathrm{~m} / \mathrm{Ma}$ in the Oligocene.

Based on the tectonic characteristics of PRMB and their evolution history ( $L i$ and Rao, 1994), the center of NDZ is considered to be a decelerated rifting system.

\subsubsection{Accelerated rifting system}

Different from the aforementioned rifting processes, the structural framework of Huizhou Sag is controlled by two boundary faults (F21 and F33) and several sub-faults (F22-F32) (Fig.16 d). According to the time-temperature curve of well $G$, the uplift rate is gentle in the first stage and accelerates drastically during the Oligocene (Fig. 9). Thus, based on the uplift rate and strata thickness, the rifting rate in the Eocene is $55 \mathrm{~m} / \mathrm{Ma}$, whereas that in the Oligocene is $110 \mathrm{~m} / \mathrm{Ma}$. Furthermore, as indicated by the increasing displacement of the fault, this type of episodic rifting process can be defined as an accelerated rifting system.

\subsection{Source-to-sink system evolution during the rifting process}

\subsubsection{Provenance identification and its evolution process}

\section{1) Provenance area during the early Eocene}

(1) Wenchang Sag in western NDZ

As shown by the tectonic structure map (Fig. 1) and paleomorphology (Fig. 15), the Wenchang Sag was surrounded by the Yangchun low uplift in the north and Shenhu uplift in the south during the early Eocene interval. According to the study conducted by Shao et al. (2016) and Wang et al. (2019), the ratio of $\mathrm{Tu} / \mathrm{U}<1$ (Fig. 13) indicated that the intermediate source mainly dominates the sediments in Wenchang Sag during the early Eocene. The REE distribution shows abnormal Eu content, LREE 
enrichment, and HREE deficiency (Fig. 14). In comparison, it was considering the REE distribution

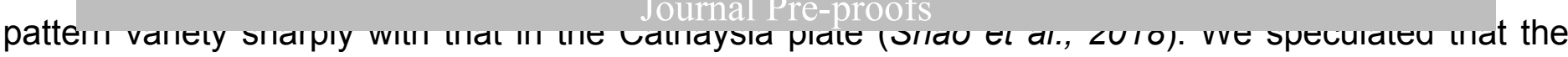
majority of the sediments are deposited in a proximal uplift area. Furthermore, the low ZTR index $(<30 \%)$ (Fig. 15) can also provide evidence for short-distance transport.

(2) Enping, Xijiang, and Huizhou Sags in the Central and Eastern NDZ

According to previous studies (Shao et al., 2016; Liu et al., 2017; Wang et al., 2019), as shown by the tectonic structure map in Fig. 1 and the paleomorphology in Fig. 15, majority of the sediments during the early Eocene interval were provided by the northern fault terrace zone and the Panyu and Dongsha uplift in the south. The REE distribution pattern and low ZTR index (except for well E in Xijiang Sag) can provide evidence with respect to the proximal provenance area.

\section{2) Provenance area during the late Eocene to Oligocene}

(1) Wenchang Sag in Western NDZ

In the age spectrum of wells B and C, the peak ages are 175 and $169 \mathrm{Ma}$, respectively. When these ages are compared with the peak age distribution in the Cathaysia plate (Liu et al., 2017), the peak age is similar to that in the Pearl River, as shown in Fig. 11. Besides that, As indicated by the REE distribution, the slightly abnormal Eu value indicated that some sediments are contributed by the upper crust, indicating that some deposits area eroded from the nearby uplift and injected into a proximal area. According to ZTR value in Fig. 15, well B and well C shows a variety of trending. Well C has an increasing ZTR value, whereas well B has a low ZTR index (52\%). Thus, we speculate that the deposits in Wenchang Sag may involve distal and proximal sediments.

(2) Enping and Xijiang Sags in Central NDZ

The peak age spectrum of the sediment from the Pearl River (including the northeastern and western Pearl River) and well E in Enping Sag (210 and 450 Ma) (Fig. 11) are observed in similar peak values. The ratio of $\mathrm{Th} / \mathrm{U}$ in well $\mathrm{E}$ (Fig. 13) shows that some sediment in Enping Sag is the intermediated source from the Cathaysia plate and surrounding uplift. Thus, we infer that more distal sediment from is deposited in the Central NDZ. Besides that, the normal content of Eu and the rising ZTR index can provide evidence to the distal sediment accumulation.

(3) Huizhou Sag in Eastern NDZ 
By comparing the age spectrum in the Huizhou Sag and that in the west Pearl River (Fig. 11), well

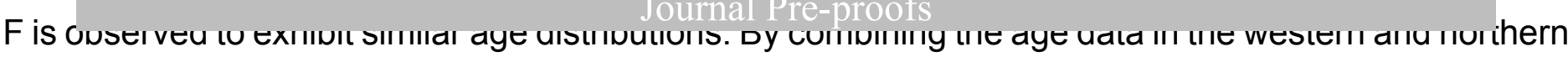
Pearl River (Wang et al., 2019), their peak values (275, 450, and $835 \mathrm{Ma}$ in the western Pearl River and 145 and $450 \mathrm{Ma}$ in the northern Pearl River) are observed to fit well with the grains in well F. Furthermore, the increasing ZTR index indicates that a considerable amount of the sediment is obtained from the distal area.

\subsubsection{Depositional environment spatial variability in sink area}

1) Depositional environment in the uniform rifting block

We build the S2S system (Figs. 17 and 19) distribution in Eastern NDZ by integrating the aforementioned study into our findings. During the Eocene, the coarse-grained fan infilled to the sag along the NE directional faults. The pro-graded delta was dominant in the gentle south slope (Fig. 18). Then, in the Enping Formation, as the geomorphology in Fig.15 shown, the area of the dispersal area increased during the second rifting process. Upper to Zhuhai Fm., increasing fine-grained sediments were observed in the paleo-Pearl River. Paleography map in Fig.18 shows the faults in the south also targeted coarse-grained sediment, and the distal fine-grained sediments mixed with the proximal coarse-grained fans.

\section{2) Depositional environment in the decelerated rifting block}

The Central NDZ shows the accretion pattern of the decelerated rifting block. During the interval of Wenchang Fm., Central NDZ is controlled by several faults in the south and north. The high-angled faults in the north triggered the development of alluvial deltas. In the Enping Fm., the second rifting process enlarged the dispersal area. Further, plain alluvial and large pro-graded deltas developed. With the rising sea level during the late Oligocene (Haq and Schutter., 2008; Xie et al., 2019), the reworking process became dominant, and tide- or wave-influenced delta could be observed. Then, at the end of the second rifting process (Wang et al., 2019; Xie et al., 2019), all the sags in the Central NDZ were filled by the distal fine sediment provided by the Pearl River.

\section{3) Depositional environment in the accelerated rifting block}

The Eastern NDZ is a typical accelerated rifting block exhibiting spatial variation with respect to the accretion pattern. During Wenchang Fm., the separated sag and limited dispersal area lead to the 
development of a small scale alluvial fan and pro-graded delta in these areas. In the Enping Fm. interval,

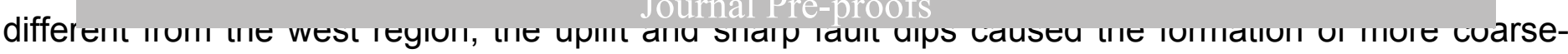
grained fans or braided deltas. Then, in the Zhuhai Fm., due to the uplift during the end of the second rifting stage, the sediment provided by the Pearl River mixed with the coarse fan. In addition, some carbonated platforms developed with less sediments (Fig. 18).

\subsection{Infilling process insights from the S2S system}

Michael et al., (2013) have studied the relation between the mass balance coordinate (or mass loss), grain size distribution, and moving boundary of the coarse-grained sediment. Based on the study on the mass balance coordinate and infilling process (Hampson et al., 2014), the mass balance

coordinate $X$ can serve as an index to evaluate the accretion pattern from upstream to downstream(Fig.17). Accordingly, after importing the above S2S parameters into Equation 3, we can generate the plot of the mass balance coordinate $X$ and its corresponding infilling process (Fig. 20).

\subsubsection{Infilling process and dominant factors associated with the uniform rifting system}

Western NDZ shows an infilling process of the uniform rifting system. In case of the Zhuqiong I stage tectonic movement, $x(x)$ shows a linear relation between the mass balance coordinate and deposition distance. $\mathrm{X}(\mathrm{x})$ is $0-0.7$, indicating different grain sizes (coarse-grained fan or sandy delta) distributed with a clear boundary. As the depositional environment stated above, a coarse-grained fan is developed in the proximal area, whereas the fine-grained sediment is deposited in the distal region. During the Zhuqiong II stage tectonic movement, the relation between the mass balance coordinate and deposition distance $\mathrm{x}(\mathrm{x})$ maintained a linear curve $(\boldsymbol{F i g}$. 20). $\mathrm{x}(\mathrm{x})$ was $0.2-0.7$, and its decline curve was observed to become gentle. More fine-grained sediments were injected into the depression because of the warm paleoclimate during the Eocene to the Oligocene (Zachos et al., 2008; Bijl et al., 2009). A comparison of the $x(x)$ curve of the two aforementioned rifting stages shows that the infilling process is not signification during the uniform rifting process.

Based on the statistical analysis of the S2S systems (Table 3), the following fitting formula can be obtained (Fig. 20):

$$
V=a A+b Q_{\text {total }}+c e^{H}+m
$$

where $V$ is the volume of the sink, $Q$ is the sediment supply, $A$ is the provenance area, and $H$ is the 
relative height of the pathway. The terms a, b, $c$ in the equation are fitting coefficients. According to the

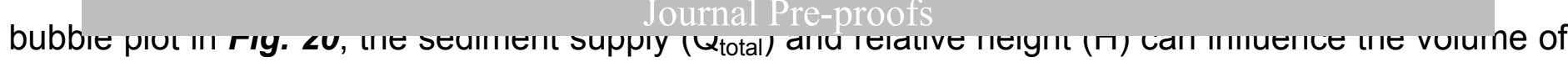
the S2S system in the uniform rifting system.

\subsubsection{Infilling process and dominant factors associated with the decelerated rifting block}

The Central NDZ shows the infilling process of the decelerated rifting system. In the first rifting stage (early Eocene), the accretion pattern is similar to that of Western NDZ. $X(x)$ is $0.2-1.0$. During the second rifting stage, the curve of $X(x)$ shows an under-concave shape, indicating that more coarsegrained sediments developed in the proximal area and that fine-grained sediments were deposited in limited area. The above comparison shows two curves; more fine-grained sediments accumulated in the second stage when compared with those in the first stage.

The analysis of the sequence stratigraphy showed the decelerating rifting process that resulted in the declining accommodation area from the Eocene to the Oligocene. With the increasing fine-grained sediment provided by the paleo-Pearl River during the Oligocene, the accommodation space was infilled by the fine-grained sediment. The volcanic moment associated with the Xijiang and SDZ and tuff and volcanic clastic rocks can provide fine-grained sediment in the depression (Sun et al., 2008; Sun et al., 2010).

Based on a statistical analysis of the S2S systems (Table 3), the following fitting formula can be obtained:

$$
V=b H+c A \cdot e^{Q t o t a l}+m
$$

(Equation 5)

As shown in Fig. 20, $e^{\text {Qtotal }}$ is the dominant part of the S2S volume in Equation 5.b, and $c$ and $m$ are the fitting coefficients. Thus, the sediment supply is the key factor associated with the S2S developed in the decelerated rifting basin. Furthermore, Gawthorpe et al. (1994); Chen et al. (2019); Zhuo et al. (2019) found that the latter rework process, including the tidal or wavy current, reduces the impact factor of the relative height.

\subsubsection{Infilling process and dominant factors associated with the accelerated rifting block}

The Eastern NDZ is a typical accelerated rifting block. In this study, we consider Huizhou Sag as an example. During the first rifting stage, $X(x)$ shows a linear relation between the mass balance coordinate and migration distance. In the second rifting stage presented in Fig. $20, X(x)$ is an up- 
concave-shaped curve. As shown by the S2S pattern in Fig. 19, during this interval, coarse-grained

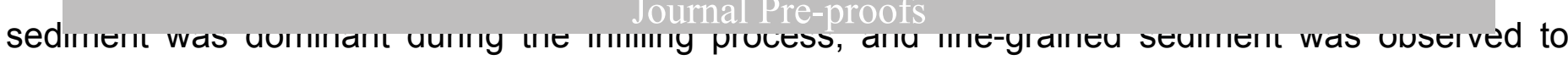
develop in a limited area.

The analysis of the insights obtained by applying the theory of sequence stratigraphy shows that the accelerating rate during the second rifting stage considerably contributes to the accommodation space. With the sharp increase in accommodation space, mass sediment must be injected into the depression area. Also, according to the paleoflow direction of the paleo-Pearl River, the accelerated rifting blocks are not in the main direction of the sediment supply, resulting in limited distal sediment supply. The HMA in Fig. 15 also provides evidence of this phenomenon. Thus, the ratio of accommodation space and sediment supply is increasing. According to Carroll and Bohacs (1999), based on the basin classification according to the balance between the sediment supply and accommodation rate, the coarse-grained mass sediment is dominant during the infilling process.

Based on a statistical analysis of the S2S systems (Table 3), the following fitting formula can be obtained:

$$
V=b A \cdot H+c \ln \left(Q_{\text {total }}\right)+m
$$

(Equation 6)

As shown by the balloon chart in Fig. 20 and Equation 6, $\mathrm{H}$ is the dominant factor in the S2S system volume apart from $Q_{\text {total. }}$

\subsection{S2S system evolution in case of an episodically rifting continental margin basin}

Combing previous studies (Buck., 1991; Brune et al., 2016; Ulvrova et al., 2019), the accelerated rifting system is characterized by a drastically increasing accommodation space. The decelerated rifting and uniform rifting systems exhibit different evolutionary processes, indicating the decreasing accommodation space in the sink area (Nottvedt et al., 1995; Gawthorpe and Leeder, 2008). Based on insights obtained globally, we can distinguish between episodically rifting basins such as the Victoria Land Basin, the Bohai Bay Basin, the East China Sea Basin, the Japanese Sea Basin, which mainly developed during the Cenozoic around the Pacific plate (Cooper and Davey, 1985; Hu et al., 2001; He and Wang., 2004), and the West Canada Basin, which developed around the North American plate (Cooper and Davey, 1985). We can also distinguish between the three rifting processes associated with these case studies. 
Royden and Keen (1980) indicated that the rifting process of the decelerated rifting basins could

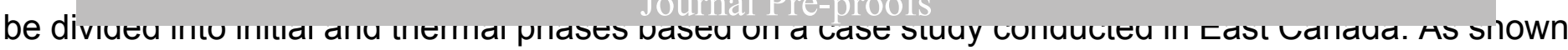
by the gentle slope of the depth-age curve, the decelerated rifting basin provides only limited amount of space during the second thermal stage. Thus, the sediment supply may be the dominant factor that influences the development of the S2S system. Cochran (1983) demonstrated that fine-grained sediments fill the basin during the second stage of the rifting process.

Based on the aforementioned observations, relative height is considered to be the dominant factor associated with the accelerated rifting process. Ren et al. (2002) and Li et al. (2009) presented an ideal case study of the East China Sea Basin, indicating a steep depth-age curve. By comparing the results of a sedimentology study conducted in the East China Sea (Li et al., 2018; Zhang et al., 2018) and the Huizhou Sag examined in this study, we find that the coarse-grained S2S system developed during the accelerated rifting process and that relative height is a dominant factor during sediment transportation.

\section{Conclusions}

In this study, we recovered the S2S system in the PRMB during the rifting interval and evaluated the infilling process using mass balance theory.

1) Based on the 2D seismic fault interpretation and FT inversion, we classified the episodic rifting into three systems: a uniform rifting system in Wenchang "A" Sag (Western NDZ), a decelerated rifting system in the Enping and Xijiang Sags (Central NDZ), and an accelerated rifting system in the Huizhou

\section{Sag(Eastern NDZ).}

2) We evaluated the amount of sediment provided from the source area by integrating the U-Pb data, REE data and heavy mineral data associated with the provenance area. During the early Eocene, NDZ sediments were deposited in a proximal area. Upper to the late Eocene and Oligocene, we speculated that more sediments from the paleo-Pearl River were injected into the dispersion area.

3) In case of the uniform rifting system, the proximal coarse-grained fan was dominant during the first rifting stage, whereas the fine-grained sediment from the proximal area infilled the sag during the second rifting stage. In case of the decelerated rifting system, we considered the coarse-grained sediment from the proximal area transferred to the fine-grained sediment from the distal area. The infilling process of the accelerated rifting system exhibited a filling process similar those exhibited by 
the two aforementioned types. During the second stage, the fine-grained sediment provided by the

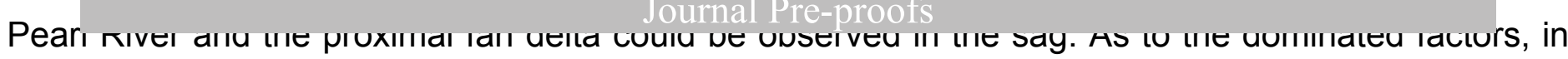
the decelerated rifting basin, the sediment supply was the major factor associated with S2S development, whereas the relative height was the major factor in case of the accelerated rifting basin.

\section{Acknowledgement}

This research was sponsored by the Major State Science and Technology Research Program (No. 2016ZX05024002-002) and the China Scholarship Council (No. 201906400071). The authors would like to thank CNOOC Shenzhen Company for providing the geological and seismic data used in this study. The authors would also like to acknowledge the Paleo-2D team at Université de Rennes 1 and the Sedimentology team at China University of Geoscience, Beijing. Finally, the authors wish to thank the journal reviewer and handling editor for their thoughtful and insightful comments, which have helped us to improve the quality of this manuscript.

\section{References}

Anell, I. and Midtkandal, I., 2015. The quantifiable clinothem - types, shapes and geometric relationships in the Plio - Pleistocene giant foresets formation, Taranaki basin, New Zealand. Basin Research, 29: 277-297.

Bijl, P. K., S. Schouten, A. Sluijs, G. Reichart, J. C. Zachos, and H. Brinkhuis, 2009. Early Palaeogene temperature evolution of the southwest Pacific Ocean. Nature, 461(7265): 776-779.

Brune, S., Williams, S.E., Butterworth, N.P. and Müller, R.D., 2016. Abrupt plate accelerations shape rifted continental margins. Nature, 536(7615): 201-204.

Buck, W.R., 1991. Modes of continental lithospheric extension. Journal of Geophysical Research: Solid Earth, 96(B12): 20161-20178.

Cao, L., Shao, L., Qiao, P., Zhao, Z. and van Hinsbergen, D.J.J., 2018. Early Miocene birth of modern Pearl River recorded low-relief, high-elevation surface formation of SE Tibetan Plateau. Earth and Planetary Science Letters, 496: 120-131.

Carroll, A.R. and Bohacs, K.M., 1999. Stratigraphic classification of ancient lakes: Balancing tectonic and climatic controls. Geology, 27(2): 99.

Chen, S., Steel, R., Wang, H., Zhao, R. and Olariu, C., 2019. Clinoform growth and sediment flux 
into late Cenozoic Qiongdongnan shelf margin, South China Sea. Basin Research, 32: 302-319.

Joumal Pre-proofs

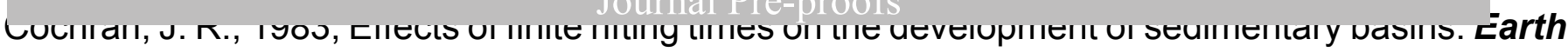
and Planetary Science Letters, 66: 289-302.

Cooper, A.K. and Davey, F.J., 1985. Episodic Rifting of Phanerozoic Rocks in the Victoria Land Basin, Western Ross Sea, Antarctica. Science, 229(4718): 1085-1087.

Deng, K., S. Yang, C. Li, N. Su, L. Bi, Y. Chang, and S. Chang, 2017. Detrital zircon geochronology of river sands from Taiwan: Implications for sedimentary provenance of Taiwan and its source link with the east China mainland. Earth-Science Reviews, 164: 31-47.

Dong, D., Zhang, G., Zhong, K., Yuan, S. and Wu, S., 2009. Tectonic evolution and dynamics of deepwater area of Pearl River Mouth basin, northern South China Sea. Journal of Earth Science, 20(1): 147-159.

Engebretson, D.C., Cox, A. and Gordon, R.G., 1984. Relative motions between oceanic plates of the Pacific Basin. Journal of Geophysical Research: Solid Earth, 89(B12): 10291-10310.

Fu, C., Li, S., Li, S., Fan, X. and Xu, J., 2020. Sedimentary characteristics, dispersal patterns, and pathway formation in Liaoxi Sag, Liaodong Bay Depression, North China: Evolution of source - to sink systems in strike - slip tectonics belt. Geological Journal, 55(7), 5119-5137.

Gawthorpe, R.L. and Leeder, M.R., 2008. Tectono - sedimentary evolution of active extensional basins. Basin Research, 12(3 - 4): 195-218.

Gawthorpe, R.L., Fraser, A.J. and Collier, R.E.L., 1994. Sequence stratigraphy in active extensional basins: implications for the interpretation of ancient basin-fills. Marine and Petroleum Geology, 11(6): 642-658.

Gawthorpe, R.L., Hardy, S. and Ritchie, B., 2003. Numerical modelling of depositional sequences in half - graben rift basins. Sedimentology, 50(1): 169-185.

Ge, J., Zhu, X., Yu, F., Jones, B.G. and Tao, W., 2018. Controls of faulting on synrift infill patterns in the Eocene PY4 Sag, Pearl River Mouth Basin, South China Sea. Australian Journal of Earth Sciences, 66(1): 111-132.

Ge, J. W., X. M. Zhu, X. T. Zhang, B. G. Jones, F. S. Yu, Z. C. Niu, and M. Li, 2017. Tectonostratigraphic evolution and hydrocarbon exploration in the Eocene Southern Lufeng Depression, Pearl 
River Mouth Basin, South China Sea. Australian Journal of Earth Sciences, 64(7): 931-956.

Joumal Pre-proofs

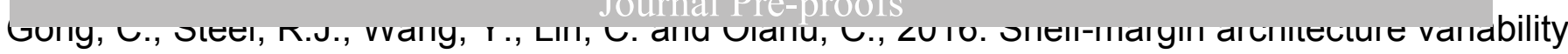
and its role in sediment-budget partitioning into deep-water areas. Earth-Science Reviews, 154: 72101.

Green, P.F., Duddy, I.R., Gleadow, A., Tingate, P.R. and Laslett, G.M., 1985. Fission-track annealing in apatite: track length measurements and the form of the Arrhenius plot. Nuclear Tracks and Radiation Measurements, 10(3): 323-328.

Hampson, G.J., Duller, R.A., Petter, A.L., Robinson, R.A.J. and Allen, P.A., 2014. Mass-Balance Constraints On Stratigraphic Interpretation of Linked Alluvial-Coastal-Shelfal Deposits From Source To Sink: Example From Cretaceous Western Interior Basin, Utah and Colorado, U.S.A. Journal of Sedimentary Research, 84(11): 935-960.

Haq, B.U. and Schutter, S.R., 2008. A Chronology of Paleozoic Sea-Level Changes. Science, 322(5898): 64-68.

He, L. and Wang, J., 2004. Tectono-thermal modelling of sedimentary basins with episodic extension and inversion, a case history of the Jiyang Basin, North China. Basin Research, 16(4): 587599.

He, J., Garzanti, E., Cao, L. and Wang, H., 2020. The zircon story of the Pearl River (China) from Cretaceous to present. Earth-Science Reviews, 201: 103078.

Hu, G., W. Hu, J. Cao, S. Yao, X. Xie, Y. Li, Y. Liu, and X. Wang., 2012. Deciphering the Early Cretaceous transgression in coastal southeastern China: Constraints based on petrography, paleontology and geochemistry. Palaeogeography, Palaeoclimatology, Palaeoecology, 317-318: 182-195.

Huang, W. and Wang, P., 2006. Sediment mass and distribution in the South China Sea since the Oligocene. Science in China Series D: Earth Sciences, 49(11): 1147-1155.

Hurford, A.J. and Green, P.F., 1983. The zeta age calibration of fission-track dating. Chemical Geology, 41: 285-317.

Jiao, Y., Li, S., Xie, X. and Ren, J., 1997. Manifestation of multistage episodic rifting- take western Pearl River Mouth Basin and its peripheral area as an example. Experimental Petroleum Geology 
(with English abstract), 3(19): 222-227.

Journal Pre-proofs

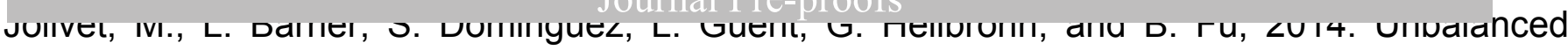
sediment budgets in the catchment-alluvial fan system of the Kuitun River (northern Tian Shan, China): Implications for mass-balance estimates, denudation and sedimentation rates in orogenic systems. Geomorphology, 214: 168-182.

Keen, C.E. and Dehler, S.A., 1993. Stretching and subsidence: Rifting of conjugate margins in the North Atlantic Region. Tectonics, 12(5): 1209-1229.

Li, C., Z. Zhou, H. Ge, and Y. Mao, 2009, Rifting process of the Xihu Depression, East China Sea Basin: Tectonophysics, 472(1-4): 135-147.

Li, C., X. Xu, J. Lin, Z. Sun, J. Zhu, Y. Yao, X. Zhao, Q. Liu, D. K. Kulhanek, J. Wang, T. Song, J. Zhao, N. Qiu, Y. Guan, Z. Zhou, T. Williams, R. Bao, A. Briais, E. A. Brown, Y. Chen, P. D. Clift, F. S. Colwell, K. A. Dadd, W. Ding, I. H. Almeida, X. Huang, S. Hyun, T. Jiang, A. A. P. Koppers, Q. Li, C. Liu, Z. Liu, R. H. Nagai, A. Peleo-Alampay, X. Su, M. L. G. Tejada, H. S. Trinh, Y. Yeh, C. Zhang, F. Zhang, and G. Zhang, 2014, Ages and magnetic structures of the South China Sea constrained by deep tow magnetic surveys and IODP Expedition 349: Geochemistry, Geophysics, Geosystems, 15(12): 4958-4983.

Li, C., J. Li, W. Ding, D. Franke, Y. Yao, H. Shi, X. Pang, Y. Cao, J. Lin, D. K. Kulhanek, T. Williams, R. Bao, A. Briais, E. A. Brown, Y. Chen, P. D. Clift, F. S. Colwell, K. A. Dadd, I. Hernández-Almeida, X. Huang, S. Hyun, T. Jiang, A. A. P. Koppers, Q. Li, C. Liu, Q. Liu, Z. Liu, R. H. Nagai, A. PeleoAlampay, X. Su, Z. Sun, M. L. G. Tejada, H. S. Trinh, Y. Yeh, C. Zhang, F. Zhang, G. Zhang, and X. Zhao, 2015, Seismic stratigraphy of the central South China Sea basin and implications for neotectonics: Journal of Geophysical Research: Solid Earth, 120(3): 1377-1399.

Lin, C., J. Jiang, H. Shi, Z. Zhang, J. Liu, C. Qin, H. Li, H. Ran, A. Wei, H. Tian, Z. Xing, and Q. Yao, 2018. Sequence architecture and depositional evolution of the northern continental slope of the South China Sea: responses to tectonic processes and changes in sea level. Basin Research, 30: 568-595.

Lin, C., Zhang, Y., Li, S., Ren, J. and Zhang, Y., 2004. Episodic Rifting Dynamic Process and Quantitative Model of Mesozoic-Cenozoic Faulted Basins in Eastern China. Earth Science- Journal 
of China Universtiy of Geosciences (with English abstract), 5(29): 583-588.

Joumal Pre-proofs

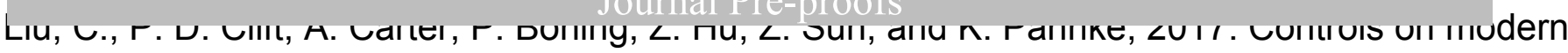
erosion and the development of the Pearl River drainage in the late Paleogene. Marine Geology, 394: $52-68$.

Li, S., Wang, Y. and Wu, S., 2018. Meso-Cenozoic tectonothermal pattern of the Pearl River Mouth Basin: constraints from zircon and apatite fission track data. Earth Science Frontiers (with English abstract), 1(25): 095-107.

Li, S., X. Yu, R. Steel, X. Zhu, S. Li, B. Cao, and G. Hou, 2018. Change from tide-influenced deltas in a regression-dominated set of sequences to tide-dominated estuaries in a transgression-dominated sequence set, East China Sea Shelf Basin. Sedimentology, 65(7): 2312-2338.

Li, P. and Rao, C., 1994. Tectonic characteristics and evolution history of the Pearl river mouth basin. Tectonophysics, 235(1): 13-25.

Li, Y., Z. Jiang, H. Liu, C. Shi, Y. Huang, and H. Zhang, 2020, Using element geochemistry and detrital zircon geochronology to constrain provenance of the Eocene sediments in the deep-water area of the Pearl River Mouth Basin, South China Sea: Journal of Asian Earth Sciences, 204: 104501.

Liu, Z., Y. Zhao, C. Colin, K. Stattegger, M. G. Wiesner, C. Huh, Y. Zhang, X. Li, P. Sompongchaiyakul, and C. You, 2016, Source-to-sink transport processes of fluvial sediments in the South China Sea: Earth-Science Reviews, 153: 238-273.

Liu, Z., Wang, S., Yin, B., Zhang, Y. and Xiao, L., 2013. Different distribution of lacustrine facies and its controlling factors during rifting stage, Zhu I and Zhu III Depressions, Pearl River Mouth Basin. Experimental Petroleum Geology (with English abstract), 5(35): 523-533.

Ma, M., G. Chen, C. Lv, G. Zhang, C. Li, Z. Zhao, and H. Shen ., 2016. Eocene-low Oligocene sedimentary environment and mudstone provenance in Baiyun Sag, Pearl River Mouth Basin. Acta Petrolei Sinica (with English abstract), 37(05): 610-621.

Ma, M., J. Qi, Y. Zhang, Q. Miao, W. Chen, and S. Zhang., 2019. An analysis of subsidence characteristics and affecting factors in the Pearl River Mouth Basin in Cenozoic. Geological in China (with English abstract), 2(46): 269-289.

Maill, A.D., 1978. Fluvial sedimentology: an historical review. Fluvial Sedimentology, Canadian 
Society of Petroleum Geologist, memoir, 5: 1-47.

Joumal Pre-proofs

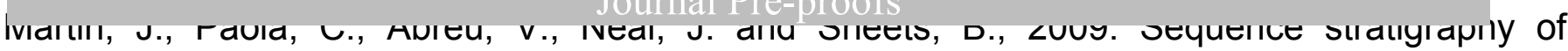
experimental strata under known conditions of differential subsidence and variable base level. AAPG Bulletin, 93(4): 503-533.

Mi, L., G. Zhang, H. Shen, Z. Liu, R. Guo, K. Zhong, and J. Tian, 2008. Eocene-Lower Oligocene sedimentation characteristics of Baiyun Sag in the deep-water area of Pearl River Mouth Basin. Acta Petrolei Sinica (with English abstract), 29(1): 29-34.

Michael, N.A., Carter, A., Whittaker, A.C. and Allen, P.A., 2014. Erosion rates in the source region of an ancient sediment routing system: comparison of depositional volumes with thermochronometric estimates. Journal of the Geological Society, 171(3): 401-412.

Michael, N.A., Whittaker, A.C. and Allen, P.A., 2013. The Functioning of Sediment Routing Systems Using a Mass Balance Approach: Example from the Eocene of the Southern Pyrenees. The Journal of Geology, 121(6): 581-606.

Michael, N.A., Whittaker, A.C., Carter, A. and Allen, P.A., 2014. Volumetric budget and grain-size fractionation of a geological sediment routing system: Eocene Escanilla Formation, south-central Pyrenees. Geological Society of America Bulletin, 126(3-4): 585-599.

Merle, O., 2011, A simple continental rift classification: Tectonophysics, 513(1-4): 88-95.

Morley, C.K., 2002. A tectonic model for the Tertiary evolution of strike-slip faults and rift basins in SE Asia. Tectonophysics, 347(4): 189-215.

Morley, C.K., 2016. Major unconformities/termination of extension events and associated surfaces in the South China Seas: Review and implications for tectonic development. Journal of Asian Earth Sciences, 120: 62-86.

Mugisha, F., Ebinger, C.J., Strecker, M. and Pope, D., 1997. Two-stage rifting in the Kenya rift: implications for half-graben models. Tectonophysics, 278(1): 63-81.

Nottvedt, A., Gabrielsen, R.H. and Steel, R.J., 1995. Tectonostratigraphy and sedimentary architecture of rift basins, with reference to the northern North Sea. Marine and Petroleum Geology, 12(8): 881-901.

Nyberg, B., W. Helland-Hansen, R. L. Gawthorpe, P. Sandbakken, C. H. Eide, T. Sømme, F. 
Hadler-Jacobsen, and S. Leiknes, 2018. Revisiting morphological relationships of modern source-to-

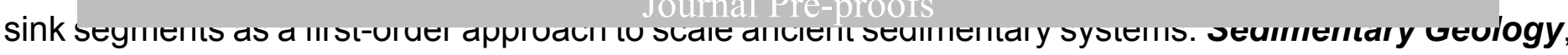
373: 111-133.

Nyberg, B. and Howell, J.A., 2016. Global distribution of modern shallow marine shorelines. Implications for exploration and reservoir analogue studies. Marine and Petroleum Geology, 71: 83104.

Paola, C. and Martin, J.M., 2012. Mass-Balance Effects In Depositional Systems. Journal of Sedimentary Research, 82(6): 435-450.

Pascucci, V., Costantini, A., Martini, I.P. and Dringoli, R., 2006. Tectono-sedimentary analysis of a complex, extensional, Neogene basin formed on thrust-faulted, Northern Apennines hinterland: Radicofani Basin, Italy. Sedimentary Geology, 183(1): 71-97.

Pavelić, D., 2015. Tectonostratigraphic model for the North Croatian and North Bosnian sector of the Miocene Pannonian Basin System. Basin Research, 13(3): 359-376.

Peng, J., X. Pang, H. Peng, X. Ma, H. Shi, Z. Zhao, S. Xiao, and J. Zhu., 2017. Geochemistry, origin, and accumulation of petroleum in the Eocene Wenchang Formation reservoirs in Pearl River Mouth Basin, South China Sea: A case study of HZ25-7 oil field. Marine and Petroleum Geology, 80: 154-170.

Reid, I. and Frostick, L.E., 1987. Flow dynamics and suspended sediment properties in arid zone flash floods. Hydrological Processes, 1(3): 239-253.

Ren, J., Liu, W., Lin, C. and Li, S., 1996. Features of late Mesozoic rifting in east China and its episodic extension. Geoscience (with English abstract), 4(10): 526-531.

Ren, J., K. Tamaki, S. Li, and Z. Junxia, 2002, Late Mesozoic and Cenozoic rifting and its dynamic setting in Eastern China and adjacent areas: Tectonophysics, 344(3): 175-205.

Royden, L. and Keen, C.E., 1980. Rifting process and thermal evolution of the continental margin of eastern Canada determined from subsidence curves. Earth and Planetary Science Letters, 51(2): 343-361.

Saneyoshi, M., Nakayama, K., Sakai, T., Sawada, Y. and Ishida, H., 2006. Half graben filling processes in the early phase of continental rifting: The Miocene Namurungule Formation of the Kenya 
Rift. Sedimentary Geology, 186(1-2): 111-131.

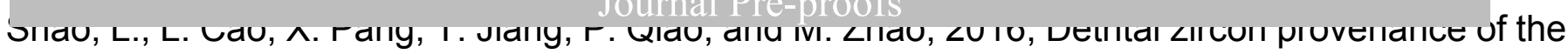
Paleogene syn-rift sediments in the northern South China Sea: Geochemistry, Geophysics, Geosystems, 477: 97-107.

Shao, L., L. Cao, P. Qiao, X. Zhang, Q. Li, and D. J. J. van Hinsbergen, 2017, Cretaceous-Eocene provenance connections between the Palawan Continental Terrane and the northern South China Sea margin: Earth and Planetary Science Letters, 17(2): 255-269.

Shao, L., Y. Cui, K. Stattegger, W. Zhu, P. Qiao, and Z. Zhao, 2018, Drainage control of Eocene to Miocene sedimentary records in the southeastern margin of Eurasian Plate: GSA Bulletin, 131(34): 461-478.

Sheets, B.A., Hickson, T.A. and Paola, C., 2002. Assembling the stratigraphic record: depositional patterns and time-scales in an experimental alluvial basin. Basin Research, 14(3): 287-301.

Sømme, T.O., Jackson, C.A. and Vaksdal, M., 2013. Source-to-sink analysis of ancient sedimentary systems using a subsurface case study from the Møre-Trøndelag area of southern Norway: Part 1 - depositional setting and fan evolution. Basin Research, 25(5): 489-511.

Steel, R.J., Olariu, C., Zhang, J. and Chen, S., 2019. What is the topset of a shelf - margin prism?

\section{Basin Research.}

Sun, Z., Z. Zhong, D. Zhou, X. Pang, C. Huang, C. Chen, M. He, and H. Xu, 2008, Dynamics Analysis of the Baiyun Sag in the Pearl River Mouth Basin, North of the South China Sea: Acta Geologica Sinica-English edition, 82(1): 73-83.

Sun, Z., D. Zhou, L. Sun, C. Chen, X. Pang, J. Jiang, and H. Fan, 2010. Dynamic analysis on rifting stage of Pearl River Mouth basin through analogue modeling. Journal of Earth Science, 21(4): 439-454.

Suo, Y., S. Li, C. Jin, Y. Zhang, J. Zhou, X. Li, P. Wang, Z. Liu, X. Wang, and I. Somerville, 2019, Eastward tectonic migration and transition of the Jurassic-Cretaceous Andean-type continental margin along Southeast China: Earth-Science Reviews, 196: 102884.

Peng, J., X. Pang, H. Peng, X. Ma, H. Shi, Z. Zhao, S. Xiao, and J. Zhu., 1990. The Ailao Shan/Red River metamorphic belt: tertiary left-lateral shear between Indochina and South China. Nature, 
343(6257): 431.

Journal Pre-proofs

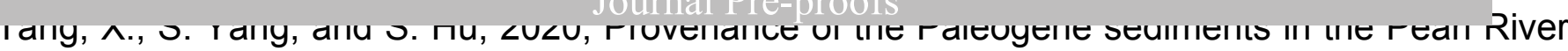

Mouth Basin, northern South China Sea: Insights from zircon U-Pb and fission track double dating: Journal of Asian Earth Sciences, 200: 104494.

Torsvik, T. H., B. Steinberger, G. E. Shephard, P. V. Doubrovine, C. Gaina, M. Domeier, C. P. Conrad, and W. W. Sager., 2019. Pacific - Panthalassic Reconstructions: Overview, Errata and the Way Forward. Geochemistry, Geophysics, Geosystems, 20(7): 3659-3689.

Ulvrova, M.M., Brune, S. and Williams, S., 2019. Breakup Without Borders: How Continents Speed Up and Slow Down During Rifting. Geophysical Research Letters, 46(3): 1338-1347.

Wang, W., J. Ye, T. Bidgoli, X. Yang, H. Shi, and Y. Shu, 2017, Using Detrital Zircon Geochronology to Constrain Paleogene Provenance and Its Relationship to Rifting in the Zhu 1 Depression, Pearl River Mouth Basin, South China Sea: Geochemistry, Geophysics, Geosystems, 18(11): 3976-3999.

Wang, W., Yang, X., Bidgoli, T.S. and Ye, J., 2019. Detrital zircon geochronology reveals sourceto-sink relationships in the Pearl River Mouth Basin, China. Sedimentary Geology, 388: 81-98.

Wang, Y., 2015. Major Unconformities and sedimentary system evolution in Pearl River Mouth Basin. Acta Sedimentologica Sinica (with English abstract), 3(33): 557-594.

Wu, D., H. Li, L. Jiang, S. Hu, Y. Wang, Y. Zhang, and Y. Liu, 2019, Diagenesis and reservoir quality in tight gas bearing sandstones of a tidally influenced fan delta deposit: The Oligocene Zhuhai Formation, western Pearl River Mouth Basin, South China Sea: Marine and Petroleum Geology, 107: 278-300.

Wu, Y., W. Ding, P. D. Clift, J. Li, S. Yin, Y. Fang, and H. Ding, 2019. Sedimentary budget of the Northwest Sub-basin, South China Sea: controlling factors and geological implications. International Geology Review: 1-18.

Wu, Z., Zhu, W., Shao, L. and Xu, C., 2016. Sedimentary facies and the rifting process during the late Cretaceous to early Oligocene in the northern continental margin, South China Sea. Interpretation, 4(3): SP33-SP45.

Xie, X., Cheng, S. and Lu, Y., 1996. Epsodic tectonic cyclyes and in ternal architectures of 
squences in continental basin. Earth Science- Journal of China Universtiy of Geosciences (with Enghsil ansuact), I(1yyo). $\angle 1-00$.

Xie, X., Ren, J., Pang, X., Lei, C. and Chen, H., 2019. Stratigraphic architectures and associated unconformities of Pearl River Mouth basin during rifting and lithospheric breakup of the South China Sea. Marine Geophysical Research, 40(2): 129-144.

Yi, Y., A. Carter, B. Xia, L. Ge, S. Brichau, and H. Xiaoqiong, 2009, A fission-track and (U-Th)/He thermochronometric study of the northern margin of the South China Sea: An example of a complex passive margin: Tectonophysics, 474(3-4): 584-594.

Yuan, Y., W. Zhu, L. Mi, G. Zhang, S. Hu, and L. He, 2009. "Uniform geothermal gradient" and heat flow in the Qiongdongnan and Pearl River Mouth Basins of the South China Sea. Marine and Petroleum Geology, 26(7): 1152-1162.

Zachos, J.C., Dickens, G.R. and Zeebe, R.E., 2008. An early Cenozoic perspective on greenhouse warming and carbon-cycle dynamics. Nature, 451(7176): 279-283.

Zhang, J., Y. Lu, W. Krijgsman, J. Liu, X. Li, X. Du, C. Wang, X. Liu, L. Feng, W. Wei, and H. Lin, 2018, Source to sink transport in the Oligocene Huagang Formation of the Xihu Depression, East China Sea Shelf Basin: Marine and Petroleum Geology, 98: 733-745.

Zhuo, H., Y. Wang, Z. Sun, Y. Wang, Q. Xu, P. Hou, X. Wang, Z. Zhao, W. Zhou, and S. Xu, 2019. 2019. Along - strike variability in shelf - margin morphology and accretion pattern: An example from the northern margin of the South China Sea. Basin Research, 31(3): 431-460.

Ziegler, P.A. and Cloetingh, S., 2004. Dynamic processes controlling evolution of rifted basins. Earth-Science Reviews, 64(1-2): 1-50.

\section{Figure Captions}

Fig. 1

Tectonic division of the Pearl River Mouth Basin (PRMB). PRMB can be divided into five parts: northern fault terrace zone, northern depression zone (NDZ), central uplift zone, southern depression zone (SDZ), and southern-northern fault zone. The red dot line indicates 2D seismic profiles, whereas the orange dot line shows the location of $3 \mathrm{D}$ profiles. B is a generalized stratigraphic column; The 
Shenhu $\left(E_{1} s\right)$, Wenchang $\left(E_{2} w\right)$, Enping $\left(E_{2} e\right)$, Zhuhai $\left(E_{3} z\right)$, Zhujiang $\left(N_{1} z\right)$, and Haijiang $\left(N_{2} h\right)$

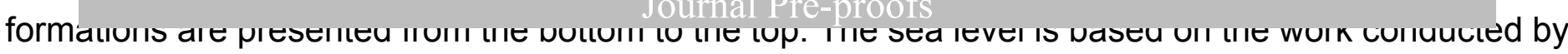
Haq and Schutter. (2008), and the tectonic stage is based on the study conducted by Li and Rao, (1994); Shao et al. (2018); and Wang et al. (2019). F,m stands for formation, M.b. is the member, SBF is the seismic reflection boundary, and Tec is the tectonic stage.

Fig. 2

Seismic profile around the PRMB. The polar stereographic projection indicates the faults in the northwest part of the basin developed in the northwest direction and those in the east part developed in the northern direction. In the SDZ, the main faults developed in the northeast direction.

Fig. 3

Geological map of PRMB at present time(a) and the tectonic movement stage division(b) (Li and Rao, 1994). The age dating of the granite refer to the study of (Wang et al., 2017; Wang et al., 2019; Suo et al., 2019). As indicated by the profile, the Paleocene to the Eocene indicates the interval of the first rifting stage, whereas the Oligocene corresponds to the second rifting stage.

Fig. 4

Collection of lithofacies description and grain size of the wells $D, B, E, F, I, J, K, M$, and Q, indicating the late Eocene to the Oligocene stratigraphic units in the PRMB. Wells $D$ and $B$ belong to Zhu III depression (Western NDZ). Wells E, F, I, and X are located in Zhu I Depression (Eastern and Central NDZ). Wells K, M, and Q show the strata in Zhu II depression (ZIID).

Fig. 5

Lithofacies templates. Six types of lithofacies associations are provided on the right side and detail description in Table.2.

Fig. 6

3D seismic profile of Wenchang Sag and its interpretation.

Fig. 7

3D seismic profile of Enping Sag and its interpretation.

Fig. 8

3D seismic profile of Huizhou Sag and its interpretation. 
Fig. 9

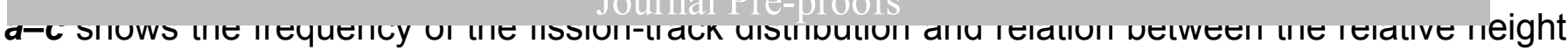

and ZFT age value. On the right are the representative plots of the fission track. Dark gray shading indicates the better-fitting cooling paths obtained from Monte Carlo trials. Light gray shading outlines the population of "acceptable" defined by a less stringent goodness-of-fit criterion of 0.05 .

Fig. 10

Representative zircon $(\mathrm{CL})$ images. The small white circles represent the sites of $\mathrm{U}-\mathrm{Pb}$ age analyses, and the measured ages are shown in Ma.

Fig. 11

Zircon $\mathrm{U}-\mathrm{Pb}$ age spectra of the Paleocene sediments in wells $\mathrm{C}, \mathrm{B}, \mathrm{E}$, and $\mathrm{F}$. The potential source areas are the northeastern Pearl River, western Pearl River, Panyu Uplift, and Hainan island (Liu et al., 2017; Shao et al., 2017; Wang et al., 2019).

Fig. 12

Concordia plot of the detrital zircon of wells $E(a), F(b), B(c)$, and $C(d)$. The data influenced by the case of $\mathrm{Pb}$ loss and inclusion have been deleted. Only analyses with concordances of $>90 \%$ are included.

Fig. 13

Intersection diagrams between the ratio of $\mathrm{Th} / \mathrm{U}$ and the age distribution. (a) presents the data of Eocene (Wang et al., 2019), whereas (b) shows the data of Oligocene.

Fig. 14

REE distribution pattern of NDZ. The REE data are standardized with the chordate.

Fig. 15

Paleomorphology of NDZ during the Eocene (a) and Oligocene (b). All the well locations and their corresponding HMA are presented as a pie chart. In the left column are the HMA and ZTR index of the wells $C, B, E, F$, and $M$.

Fig. 16

Tectonic framework of PRMB as a $2 \mathrm{D}$ seismic profile and its interpretation (the profile location is in Fig. 1). We calculated the broken displacement associated with each profile. Wenchang Sag shows 
a typical half-graben, and its fault displacement does not exhibit a drastic change. The fault

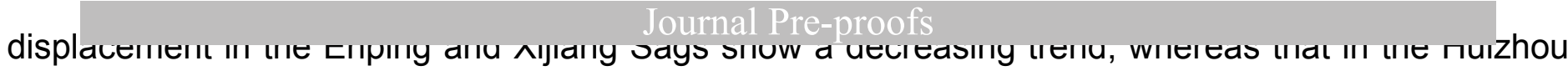
Sag increases from the Eocene to the Oligocene. Thus, we classified the rifting process into three stages: uniform, decelerated, and accelerated rifting systems.

\section{Fig. 17}

Various S2S patterns and their corresponding infilling pattern with multiprovenance. The charts below the S2S patterns reflect the relation between the migration distance and mass balance coordinate $x$. In this study, the mass balance coordinate (mass loss) $x(x)$ can be classified into three parts: dominated by a coarse-grain fan $(x(x)<0.25)$, dominated by sandy pro-graded delta $(0.25<x(x)$ $<0.75)$, and dominated by reworking sediments $(0.75<x(x)<1.0)$. The curve $(x(x))$ has three patterns to show various infilling patterns: a linear relation, an under-concave shape, and a down-concave shape. According to previous research (Paola. and Martin M., 2012; Michael et al., 2013; Hampson et al., 2014), the different curves can quantitatively present the various infilling processes.

\section{Fig. 18}

The pattern of evolution of the three-stage infilling process from the Eocene to the late Oligocene. A separate sag developed during the first rifting stage. The mass sediment is deposited in a proximal area. With the extension of the basin, more distal sediment was injected into the DNZ during the second rifting stage.

\section{Fig. 19}

Facies association distribution of PRMB. The facies distribution in SDZ is based on the work conducted by Mi et al. (2008). The Miocene facies association (d) is modified from Huang and Wang (2006) and Liu et al. (2016).

Fig. 20

The evolution of mass balance coordinate (mass loss) $x(x)$ during the two-stage tectonic movement. From left to right are the two-stage rifting model modified from Michael et al. (2013), the mass balance coordinate (mass loss) $\mathrm{X}(\mathrm{x})$ curve, and balloon pilots. In the two-stage rifting model, we show the three types of rifting process: $(a)$ is the uniform rifting system, $(b)$ is the decelerated rifting basin, and (c) is the accelerated rifting system. 


\section{Table Caption}

i avie I

Apatite/zircon FT data of the Pearl River Mouth Basin.

\section{Table 2}

Facies association descriptions.

\section{Table 3}

Parameters of the S2S system. The data used in this study were statistically obtained based on the seismic information. We obtained the dip angle with a dip along the slope. The provenance area was determined as the truncation area of the seismic package. The dispersal areas were calculated according to the truncation of the seismic events.

\section{Appendix Table Caption}

\section{Appendix Table 1}

The detrital zircon age date in well $\mathrm{E}$ at a depth of $4155.5 \mathrm{~m}$.

\section{Appendix Table 2}

The detrital zircon age date in well $\mathrm{F}$ at a depth of $3917.5 \mathrm{~m}$.

\section{Appendix Table 3}

The detrital zircon age date in well $\mathrm{C}$ at a depth of $2580.1 \mathrm{~m}$.

\section{Appendix Table 4}

The Detrital zircon age date in well B at a depth of $2581.2 \mathrm{~m}$. 


\section{Table1}

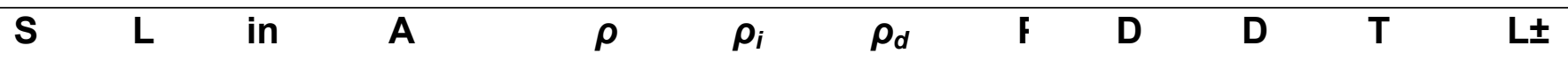

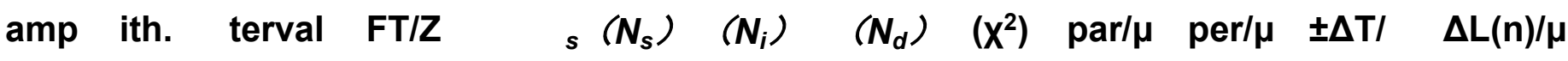
$\begin{array}{lllllllll}\text { le } & \text { FT } & /\left(10^{6} c\right. & /\left(10^{6} c\right. & /\left(10^{6} c\right. & \mathrm{m} & \mathrm{m} & \mathrm{Ma} & \mathrm{m}\end{array}$

No.

$\left.\left.\left.m^{-2}\right) \quad m^{-2}\right) \quad m^{-2}\right)$

5.

G J

$W$ ranit urassi ell L e c

G J

W Z ell L ranit urassi e c FT 7 $\begin{array}{lll}.61(2 & .06(7 & 219(4\end{array}$ 2 $30.6 \pm$ 615) 08) 881)

6.8

C

W D

ell $\mathrm{H}$ iorite $\mathrm{FT}$ ous
$1 \quad 1$

5.

$4.22(9.38(720(6$

80) 109) 780)

62

0.

$.64(3 \quad .34(1 \quad 219(4$

32)

17)

881)

5.

A $3.48(\quad 0.41(\quad 720(6$

ell O iorite FT 6 ous

G

W $\quad T$

ell $P$ neis riassic FT $\mathrm{s}$

W $\quad$ G $\quad$ T
557) 842) 780)

21

5. $0.15(7.33(720(6$ 529) 455) 708)
7

11.

$6.4 \pm 2 . \quad 63 \pm 3.0$

3
0.

1 


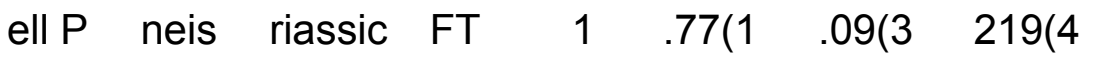

$31.7 \pm$

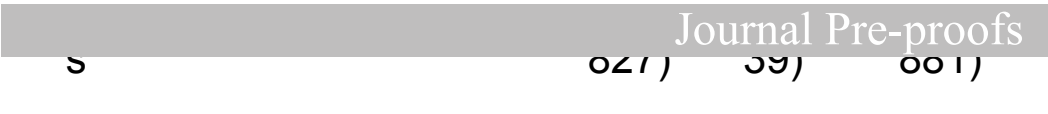

y.u

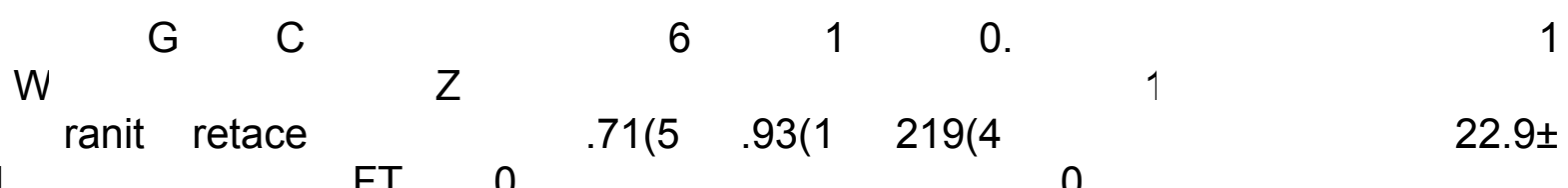

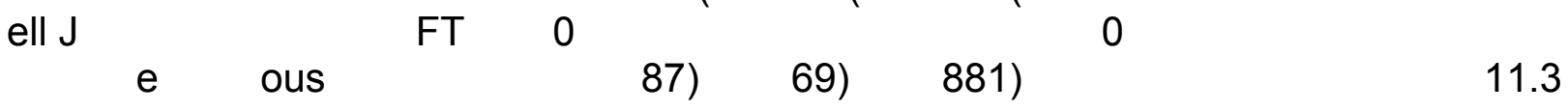

5.
G C

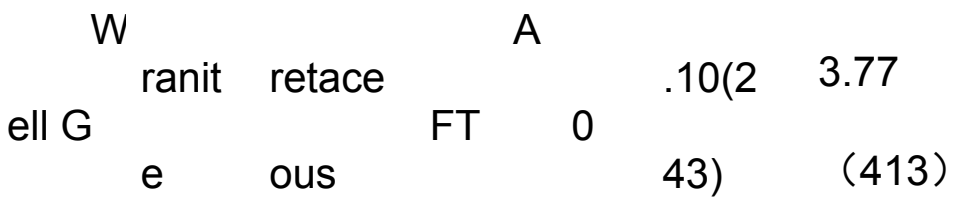
$\begin{array}{lllll}8 & 1 & & \end{array}$
13.
4.0 $0.5 . \quad 02 \pm 1.1$
$\left(\begin{array}{llll}678 & 8 & .84 & .48\end{array}\right.$
0)
4
$4(20)$

G $\quad C \quad 6 \quad 1 \quad 0$.

1

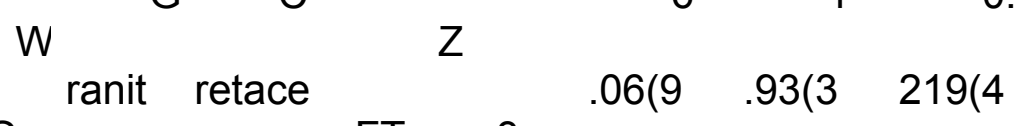

ell G FT 3

e ous

85) 14) 881)

$11.1 \pm$

7.9

W

ell $\mathrm{K}$

Refe G C

$\begin{array}{lll}7 & 2 & 0\end{array}$

1

$r$ to ranit retace

$\begin{array}{lllll} & & .31(1 & .01(5 & 219(4\end{array}$

$28.7 \pm$

Li et e ous

827） 02) 881)

7.5

al.,

(201

8)) 
TABLE 2

IrIterrea

Facies

\section{Association}

\section{Lithofacies}

\section{Association}

Lithofacies
A (LFA)
Lithofacies
B (LFB)
Lithofacies
(LFC)

Lithofacies

D (LFD)

M

Sc-Gm-Sp

Scc-Scm

Sm-Sc-

Moderately sorted homogeneous

sandstone in bottom and regularly

lamellar crossing bedding in the top

Planar cross-bedded gravel in

the middle, and the planar

crossbedding at the top

Coarsening upward sandstone.

Mud clast and deformed structure can

Sb-Sc-Sm-

Sp-Sm

be distinguished in the bottom, and

the coarse-grained sandstone

crossbedding in the upper part

Meandering rivers setting (Maill., 1978)

Imbricate-supported gravel in the

Sc-Gp-Sd-

middle. The mud layer and

deformation at the top

Short-term high-

density and high

Froude-number traction flow (Reid and Frostick., 1987) (Shortterm flooding setting)

Multi-layers of the moderately

Lithofacies Sm-M-Sb-

$E(L F E)$

M-Sm

sorted fine-grained sediment with

cross bedding and the mudstone

Mass mudstone in the bottom,

Lithofacies

F (LFF)

depositional

environment

Bidirectional

traction flow deposited

(Tidal environment)

Braided traction

flow
$M-S d-S b$

and fine-grained climbing-ripple

laminations in the middle. Compound-

graded bedding fine sand and parallel-

s


waved bedding sandstone in the

upper pall.

Gravel-supported conglomerate

Lithofacies

Gp-Gm-

with regular imbedded layers. Upper

G (LFG)

(Gm)

to the top, matrix-supported

conglomerate shows an imbricated

Coarse-grained

debris flow

orientation

\section{TABLE 3}

No.

pro-

\begin{tabular}{llllll}
\multicolumn{1}{c}{ pro- } & & & & $A v$ \\
Block & graded & & & e. & Dip \\
& delta/F & m. & & & Angle \\
& an & & & &
\end{tabular}

Av

Provan Evaluati

Pathw
Dip ce Area on height Area $/ \mathrm{km}^{2}$ ay Cut Area $/ \mathrm{km}^{2}$

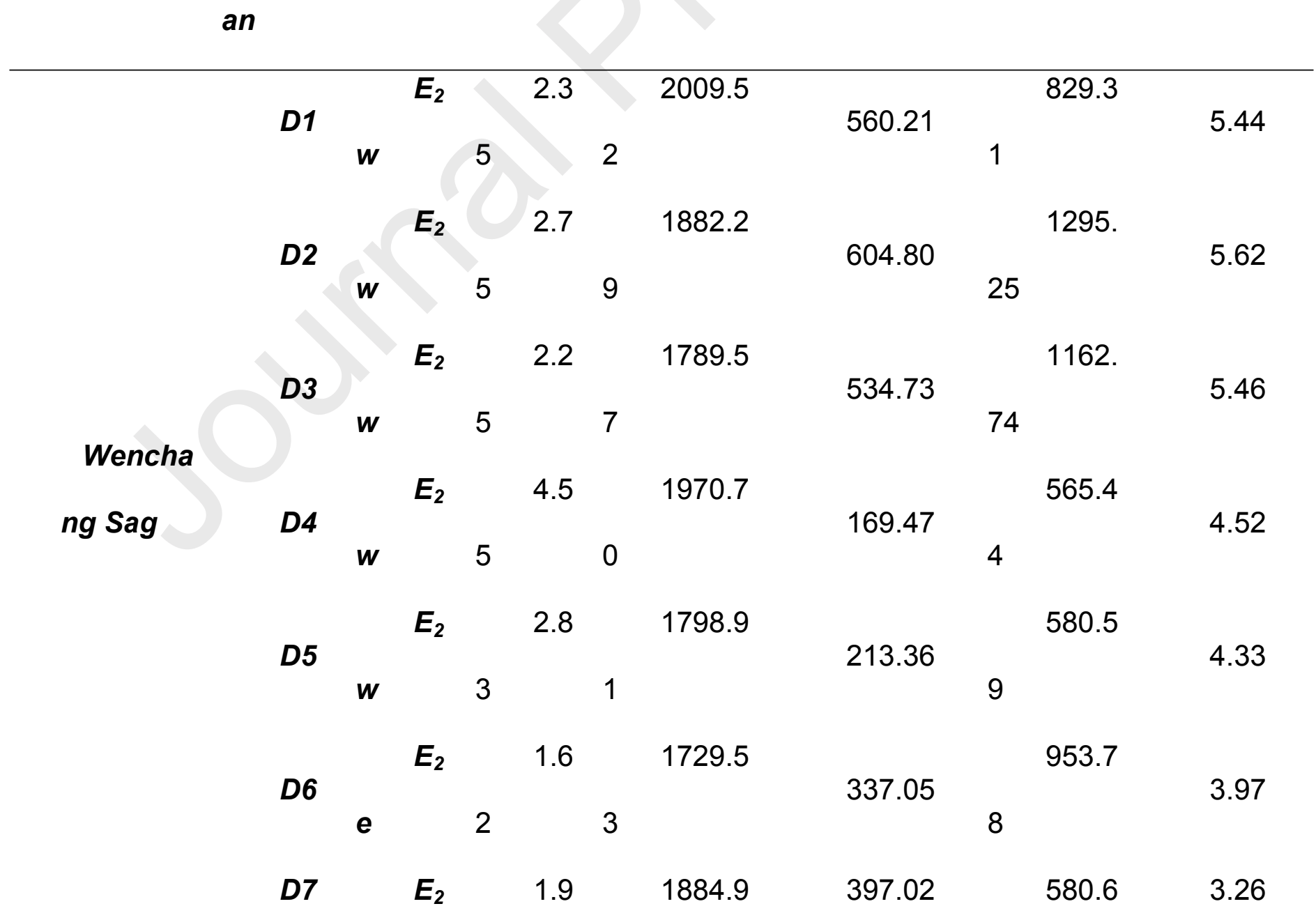




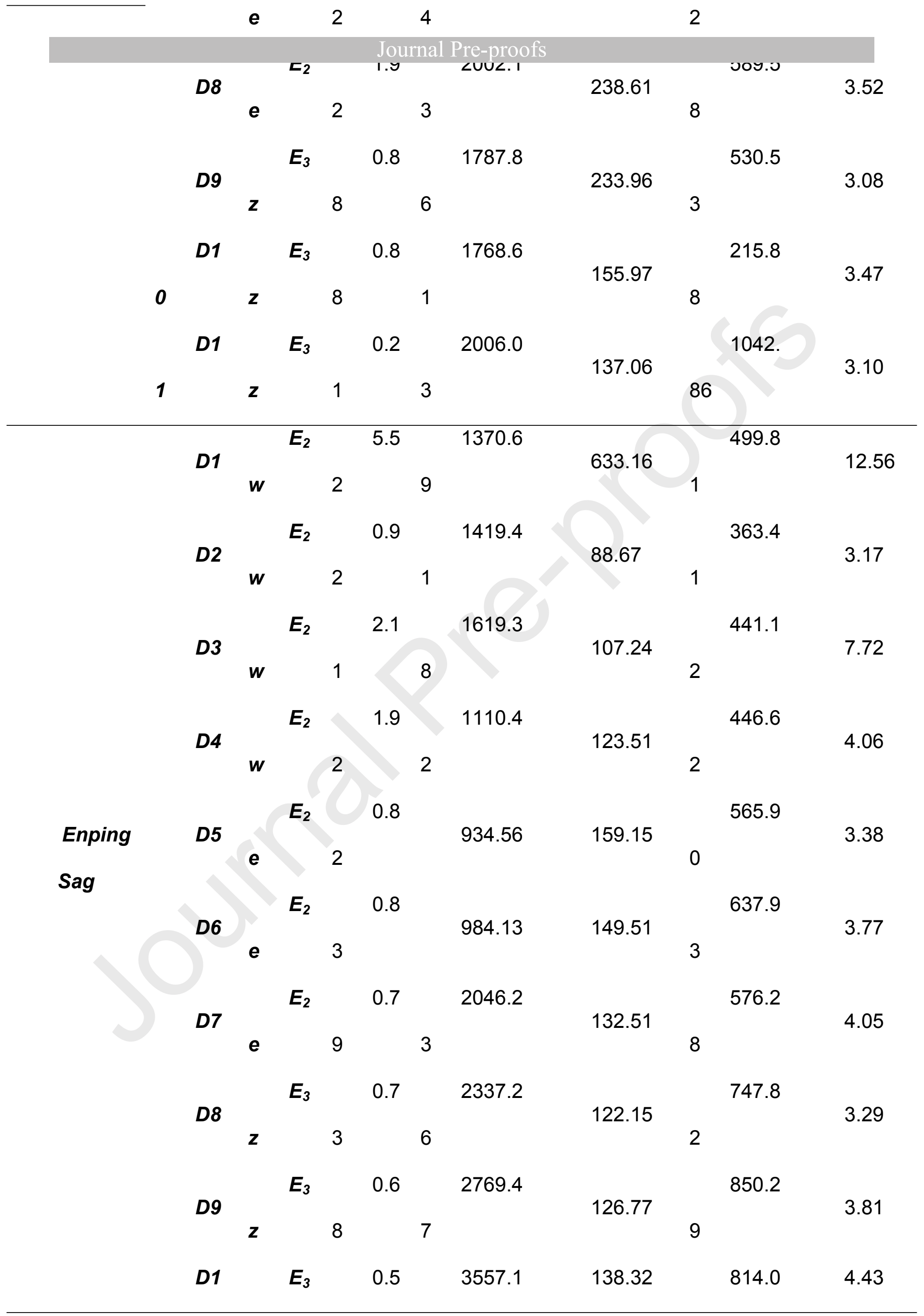




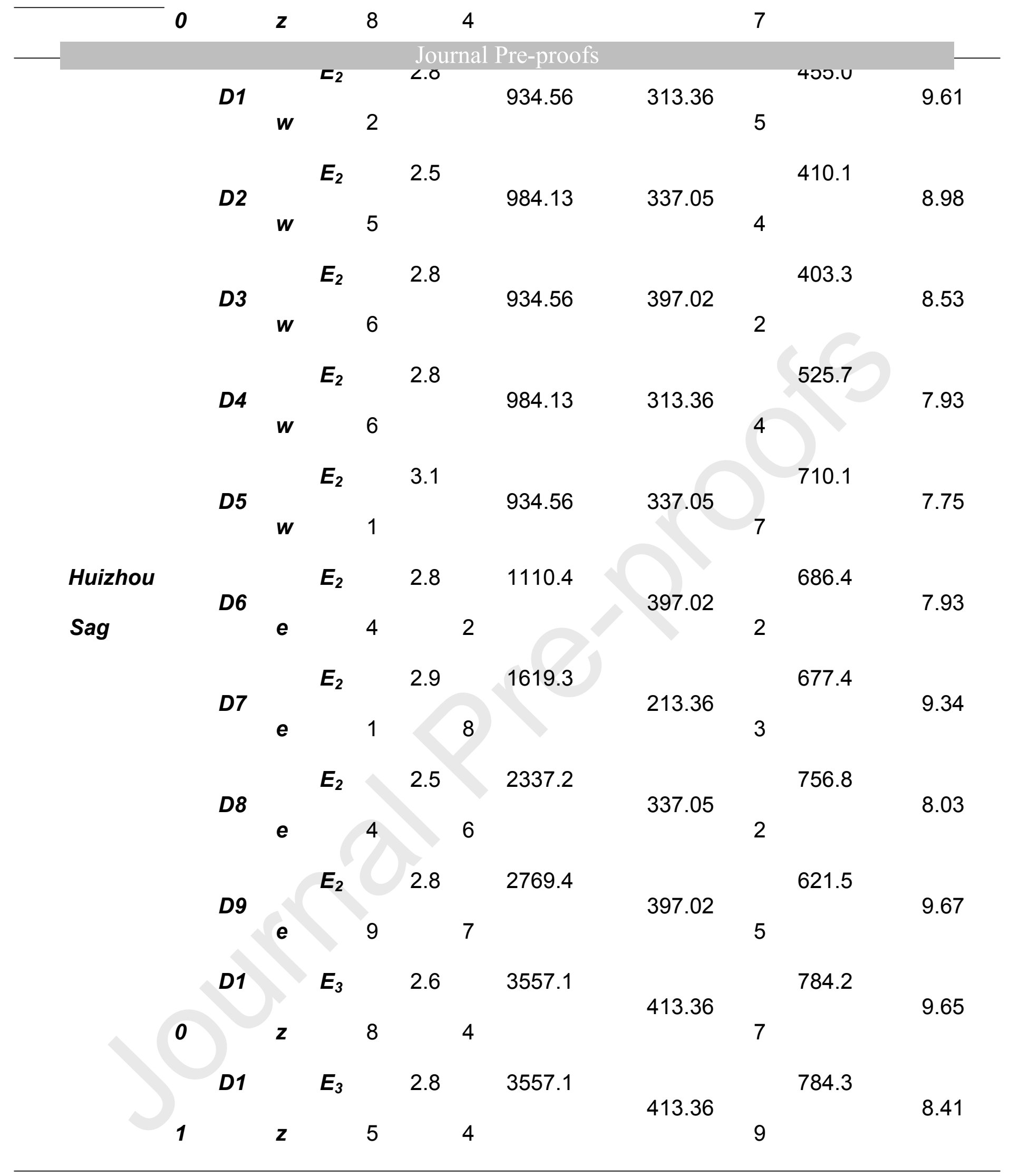


Appendix Table1 The Detrital zircon age date in Well E at the dePbh of $4155.5 m$

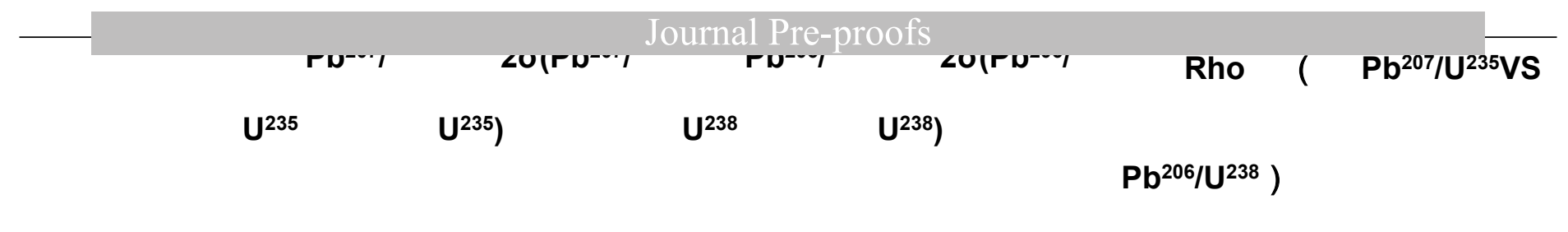

Well E-

1

165.7

5.7

160.3

2.4

0.19574

Well E-

2

168.5

3.9

165.1

2

0.29057

Well E-

3

166

11

165.3

2.7

0.013669

Well E-

4

175.9

5.2

162.9

2.7

0.096242

Well E-

171.6

4.5

167.7

2.2

$-0.08418$

Well E-

6

282

5.5

209.9

2

0.3539

Well E-

Well E-

149.8

0.25652

Well E-

9

168

4

164.1

1.7

0.15752

Well E-

206.8

1.9

0.31966

Well E-

Well E- 
Well E-

Well E-

14 164.1

9.3

164.8

2.5

0.18944

Well E-

15

151

12

145

3.4

$-0.046765$

Well E-

16

997

20

1002

15

0.27452

Well E-

17

155.3

4.3

151.5

1.8

0.31334

Well E-

18

170.2

4.2

157.9

1.7

0.27419

Well E-

19

152.3

4.7

149

1.7

0.0048404

Well E-

20

156.4

3.4

152.8

1.4

0.20135

Well E-

21

435.9

8

434.3

4.9

0.30965

Well E-

22

430

11

436.8

4.8

0.33766

Well E-

23

156.8

5.2

160.2

2

0.10962

Well E-

24

603

27

194

3

0.80949

Well E-

25

163.2

8.8

159.2

2.3

0.026785

Well E-

6.9

164

2.1

0.2745 
Well E-

27

$100.4 \quad 4.1$

$10<.0$

$0 . \angle 0010$

Well E-

28

169

6.1

163.4

2.5

0.11848

Well E-

29

2452

16

2499

24

0.46806

Well E-

30

216.3

5.6

163.3

1.6

$-0.00014542$

Well E-

31

448

13

458.6

5.2

$-0.078676$

Well E- 3354.

32

10

3191

20

0.74904

Well E-

33

166.1

4.4

167.1

2

0.16262

Well E-

34

774.1

9.2

681.6

6.8

0.41531

Well E-

35

158.9

5.3

150.8

1.7

$-0.018948$

Well E-

36

153.9

4.5

151.2

1.7

0.22939

Well E-

37

167.6

9.8

153.3

3.5

0.34635

Well E-

38

162

6.2

154.1

2.1

0.13535

Well E-

39

163.2

4.9

164.4

1.9

0.28495

Well E- 
Well E-

41

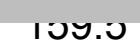

Well E-

42

788

14

784.5

8.1

0.018967

Well E-

43

$544 \quad 11$

428.5

4.3

0.085874

Well E-

44

183.3

5.1

162.9

1.7

0.15961

Well E-

45

$432.2 \quad 9.5$

433.7

5

0.12316

Well E-

46

$152.6 \quad 5.6$

157.6

1.9

0.12058

Well E-

47

195.3

5.8

157.1

2

0.28496

Well E-

48

149.8

5.7

146.5

2.2

0.12956

Well E-

49

274

11

160.3

1.9

0.46903

Well E-

50

650

11

616.1

7.8

0.40343

Well E-

51

2722

25

2677

35

0.82474

Well E-

52

156

3.8

153.9

1.7

0.30122

Well E-

53

1072

12

976.3

9.8

0.45734

Well E- 
Well E-

Well E-

56

189.2

5.6

151.5

1.8

0.23473

Well E-

57

165.7

7.7

154

2.9

0.0098553

Well E-

58

171.8

9.2

151.7

2.4

0.18594

Well E-

59 151.5

5.6

152.4

2.2

0.28114

Well E-

60 195.6

5.6

152.9

1.7

0.2323

Well E-

61

389.6

9.7

170.6

2.2

0.42791

Well E-

62

246.4

5.8

154.2

1.7

0.26066

Well E-

63

152.2

3.6

147.2

1.8

0.43509

Well E-

64

175.9

5

133.7

1.6

0.38403

Well E-

65

204.7

5.3

163.5

1.6

0.20468

Well E-

66

210.2

7.1

155.1

2.1

$-0.23976$

Well E-

67

167

4.6

161.4

2

0.16369

Well E- 
Well E-

69 100.0

Well E-

70

171

14

153.3

3

0.28974

Well E-

71

229.2

8.4

150.1

1.8

0.1906

Well E-

72 $167.3 \quad 7.6$

160.2

2.1

0.024542

Well E-

73

168.1

4.7

165.3

2.3

0.22936

Well E-

75

157.9

4.6

148.7

1.6

0.21955

Well E-

76

444

37

147.8

3

0.83587

Well E-

77

165.9

5.9

165.2

2.1

0.20289

Well E- 
Appendix Table2 The Detrital zircon age date in Well $F$ at the dePbh of $3917.5 m$

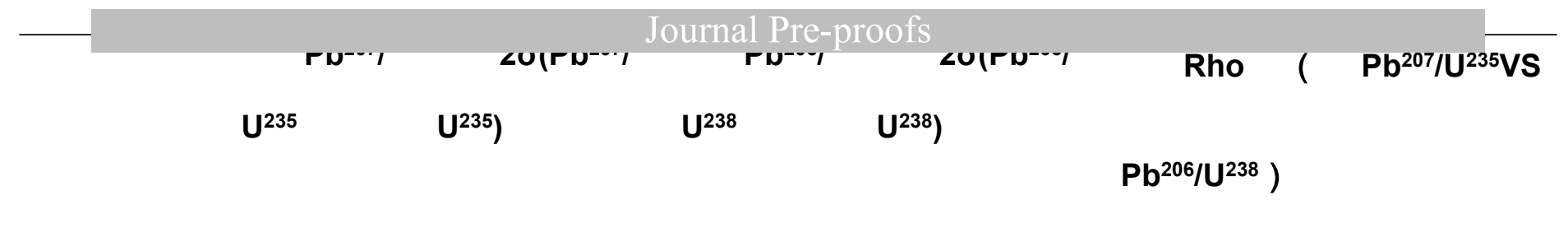

Well F-

1

136.1

6.7

134.1

1.8

$-0.029002$

Well F-

2

1880

12

1901

14

0.47298

Well F-

3

$444 \quad 10$

452.5

5.4

0.15649

Well F- 2424.

4

12

2360

21

0.59456

Well F-

5

2749

13

2714

22

0.65017

Well F- 2626.

6

9

12

2601

23

0.66477

Well F-

139.4

6.1

140

2

$-0.041381$

Well F-

8

156.8

6

158

1.9

$-0.040785$

Well F-

9

118.3

3.7

117.3

1.3

0.17285

Well F-

10

1438

15

1446

13

0.29409

Well F-

11 165

6.2

159.8

1.9

0.090403

Well F- 
Well F-

13

Well F-

14

1087

16

1099

11

0.16551

Well F-

15

131.5

6.8

135.2

1.9

$-0.10939$

Well F-

16

1055

19

1060

11

0.17088

Well F-

17

438.4

9.3

432.3

5

0.24424

Well F-

18

151

5.6

158.1

2

0.077932

Well F-

19

974

12

983.4

8.9

0.37888

Well F-

20

768

17

783.4

9.7

0.20129

Well F-

21

106

20

102.7

4.5

0.053367

Well F-

22

514

13

511

5.9

0.17424

Well F- 2114.

23

12

2086

16

0.50425

Well F-

24

$$
430.7
$$

10

442.1

4.2

0.07075

Well F-

247.2

2.8

0.18683

Well F- 
Well F-

27

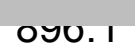

Well F-

28

421

15

433.5

4.9

0.18115

Well F-

29

233.7

7.6

234.4

2.8

0.25301

Well F-

30

338

13

327.9

4

0.055294

Well F-

31

$244.7 \quad 7.6$

248.4

2.5

0.079539

Well F-

32

2472

14

2413

21

0.46501

Well F-

33

$107.2 \quad 5.3$

99.1

1.4

0.054909

Well F-

34

143.9

6.8

140.5

2.2

0.14204

Well F-

35

422

11

428.1

4.2

0.17184

Well F-

36

219

11

227.1

3

0.072977

Well F-

37

93.4

5.3

96.8

1.4

$-0.020744$

Well F-

38

$$
939
$$

14

925.7

9.6

0.18859

Well F-

39

$435.6 \quad 8.6$

433.1

4.2

0.13007

Well F-

6.6

111.1 
Well F-

41

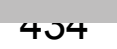

Well F-

42

943

25

942

12

0.045344

Well F-

43

2046

14

1838

18

0.60328

Well F-

44

2399

22

2333

24

0.38295

Well F-

45

441.6

9

438.5

4.6

0.28933

Well F-

46

150.2

6.7

146.3

1.8

0.090626

Well F-

47

444.3

9.5

436.4

4.5

0.27234

Well F-

48

1977

13

1967

15

0.4805

Well F-

49

1856

10

1849

14

0.57819

Well F-

50

$166.4 \quad 6.9$

166.9

2.2

0.004421

Well F-

1329.

1268.

51

3

9.4

3

8.5

0.46091

Well F-

52

$$
137.4
$$

7.3

139.1

2.1

$-0.009018$

Well F-

53

986

11

967.4

7.6

0.28445

Well F- 
Well F-

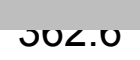

ग0<.0

U. 19140

Well F-

56

439

12

444.8

5.1

0.21985

Well F-

57

698.2

7.5

704.4

6.2

0.40134

Well F-

58

144.5

8.6

145.9

2.6

0.073232

Well F-

59

155.2

6

157.5

2.1

0.078864

Well F-

60 156.2

10

159

2.4

$-0.0049717$

Well F-

61 1461

13

1413

15

0.70695

Well F-

62

115.7

5.3

111.7

1.5

0.083661

Well F-

63 237.6

8

235.1

3

0.17525

Well F-

64

85.4

4.4

84.2

1.3

0.13501

Well F-

65

94.2

3.8

96.9

1.3

0.1212

Well F-

66 118.9

5.2

117

1.6

0.10087

Well F-

67

927

12

936

8.8

0.32514

Well F- 
Well F-

69

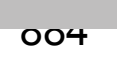

Well F-

70

260

16

256

4.5

0.24832

Well F-

71

704

12

712.4

7

0.22154

Well F-

72

778

20

774

9.5

0.15619

Well F-

73

815

22

819.1

9.4

0.063996

Well F-

74

270

11

264

4.8

0.29728

Well F-

75

$462.2 \quad 8.8$

462.9

4.4

0.2684

Well F-

76

2455

12

2421

17

0.44087

Well F-

77

164

16

145.8

4.7

0.34718

Well F-

78

30.5

2

31.54

0.5

0.1033

Well F-

79

938

22

928

12

0.10857

Well F-

80

$$
2456
$$

15

2454

21

0.3745

Well F-

81

$$
283
$$

11

285.8

3.5

0.11729

Well F-

82

278

12

282.8

3.6

0.041945 
Well F-

83

yo4 Journal Pre-proofs
yi L.y

U.4 IOUy

Well F-

84

721

12

714.2

6.3

0.39427

Well F-

452.2

6.2

0.082263 
Appendix Table3 The Detrital zircon age date in Well C at the dePbh of $2580.1 \mathrm{~m}$

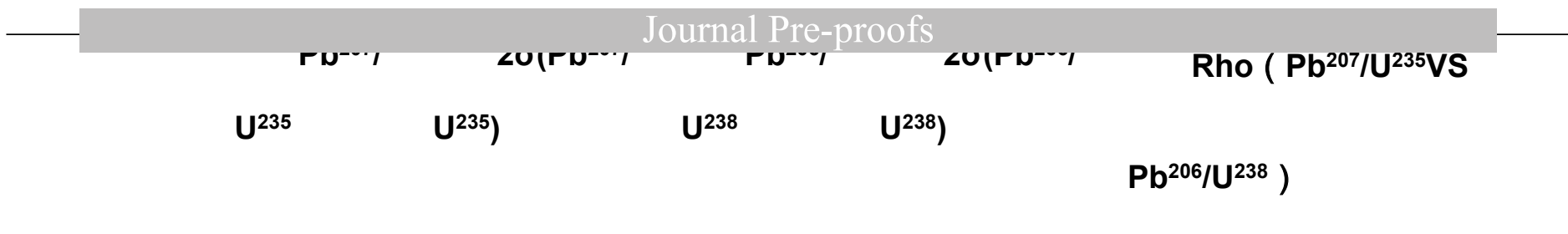

Well
C-1
152.7
6.8
151.7
2.2
0.10412

Well

C-2

217

12

144.9

2.1

0.26575

Well
C-3
Well

150.7

7.4

150.9

2.5

0.25865

C-4

165

13

143.6

3.4

0.14849

Well

C-5

158.5

8.3

153.3

2.6

0.004028

Well

C-6

145.6

5.3

151.5

2.2

0.10029

Well
C-7

164.3

7.1

152.5

2.2

0.16166

Well

C-8

155.7

7.3

154.3

2.7

0.084617

Well

C-9

148.1

10

155.2

2.8

0.11854

Well

C-10

154.1

4.3

152.7

1.9

0.16494

Well

$$
\text { C-11 }
$$

165

10

152.4

3.8

0.3283

Well

$$
\text { C-12 }
$$

185.4

7.8

148.9

2.3

0.27263 
Well

$$
\text { C-10 }
$$

Well

$$
\text { C-14 }
$$

Well

$$
\text { C-15 }
$$

156.9

3.7

148.1

1.8

0.34509

Well

$$
\text { C-16 }
$$

$$
1051
$$

17

1052

18

0.63805

Well

$$
\text { C-17 }
$$

Well

C-18

179

13

153

4.1

0.14686

Well

C-19

809

26

211

3.7

0.7308

Well

C-20

Well

C-21

159.5

7.3

150.6

3

0.17871

Well

C-22

158.3

5.2

157.5

2.2

0.14064

Well

C-23

262.9

6.7

256.6

3.1

0.12386

Well

$$
\text { C-24 }
$$

133.5

3.5

100.6

2.1

0.61182

Well

$$
\text { C-25 }
$$

158.5

4.4

153.2

2.1

0.19748

Well

C-26

152.8

7.2

151.5

2.2

0.027579 
Well

$$
\begin{aligned}
& \text { C-2 } \\
& \text { Well }
\end{aligned}
$$

C-28

158.1

4.6

151.5

1.8

0.20468

Well

C-29
Well

$$
\text { C-30 }
$$

152.9

5.4

155.3

2

0.18985

Well

C-31

152.4

6.5

155.3

2.3

$-0.028276$

Well

$$
\begin{aligned}
& \text { C-32 } \\
& \text { Well }
\end{aligned}
$$

160.5

8.4

154.8

2.2

0.20486

$$
\text { C-33 }
$$

146.1

6.8

155.2

2.2

0.055897

Well

C-34

Well

C-35

Well

C-36

Well

C-37

Well

C-38

156

114.9

4.2

114.7

1.6

0.22461

281.7

5.8

0.16108

0.13231

154.7

2.4

159.7

2.6

0.13301

13

11

158.4

2.9

0.018326

Well

C-39

154.9

6.1

154.1

2.1

0.10318

Well

C-40

157.2

5.9

154.9

2.1

0.12826 
Well

$$
\begin{aligned}
& \text { C-4 } 1 \\
& \text { Well }
\end{aligned}
$$

$$
\text { C-42 }
$$

156.1

5.3

155.8

2.1

0.1871

Well

$$
\begin{aligned}
& \text { C-43 } \\
& \text { Well }
\end{aligned}
$$

165.2

4.6

153

1.9

0.35908

$$
\text { C-44 }
$$

164.3

5.9

152.9

2.1

0.23104

Well

C-45

Well

C-46

Well

C-47

Well

C-48

154

6.7

157.6

2.4

$-0.071891$

Well

C-49

456.8

7.9

456.2

4.9

0.3462

Well

$$
\text { C-50 }
$$

168.5

7

160.6

3.6

0.30921

Well

C-51

Well

C-52

170.5

6.9

155.7

2.4

0.16501

Well

C-53

273

7.3

264.3

3.2

0.11396

Well

C-54

161.9

5.7

160.2

2.1

0.12102 
Well

C-5o $\angle \angle 1$

Well

C-56

155.4

7.1

150.9

2.4

0.046622

Well

C-57

285

14

268.1

7.8

0.27921

Well

C-58

189.9

6.9

157.1

2

0.13141

Well

C-59

633

19

183

2.6

0.3727

Well

C-60

149.3

7.7

157.1

2.5

$-0.078435$

Well

C-61

158.7

7.3

154.3

2.6

$-0.042675$

Well

C-62

153.2

6.6

152.7

2.1

$-0.045565$

Well

C-63

156.4

4.5

154.2

2

0.24869

Well

C-64

Well

C-65

Well

C-66

153.2

4.4

152.1

2

0.17424

Well

C-67

153

4.4

152.1

1.9

0.24534

Well

C-68

161

15

153.5

5.2

0.5589 
Well

C-70

Well

C-71

Well

C-72

Well

C-73

Well

C-74

120.8

5.3

111.4

1.9

0.1055

Well

C-75

144

8.5

155.7

$151.1 \quad 2.4$

0.089637

1.9

0.17726

156.9

$$
1.9
$$

0.096665

Well

C-76

153.1

5.1

148.5

2

$-0.035399$

Well

C-77

147.1

5.2

138.4

2

0.33871

Well

C-78

246

19

106.2

3.7

0.69298

Well

C-79

149.3

6.7

156.4

2.4

0.024926

Well

C-80

154.4

6.3

154.3

2.3

0.17582

Well

C-81

Well

C-82

8

1233

14

0.24855 
Well

$$
\text { C-8o }
$$$$
\text { 500.4 }
$$$$
9.0
$$
1089.

C-84

8

13

1082

13

0.47024

Well

C-85

Well

C-86

234.1

5

221.9

2.8

0.38338

Well

C-87

Well

C-88

163.6

7.7

159.2

2.5

0.070388

Well

C-89

151

6.1

150.5

2.2

0.12064

Well

5.8

155.5

2.1

0.10844 
Appendix Table4 The Detrital zircon age date in Well B at a dePbh of $2581.1 \mathrm{~m}$

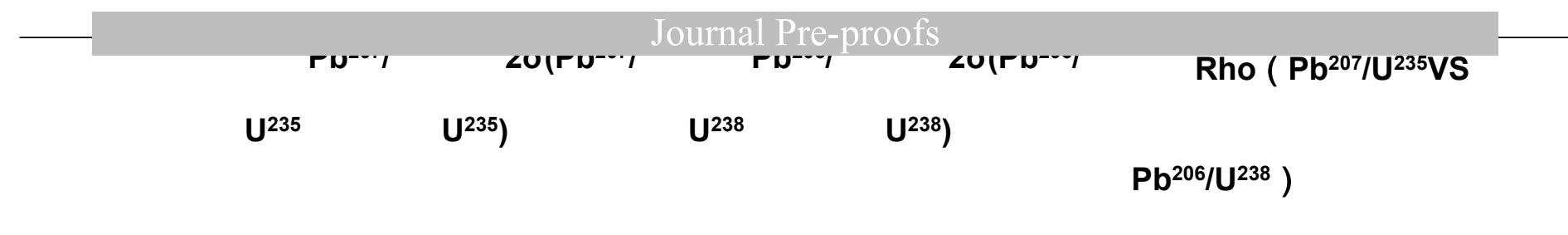

Well B-

1

$256.8 \quad 5.5$

257

3

0.31433

Well B-

2

514

15

517.2

6.7

0.26838

Well B-

3

160.1

6.5

154.7

2.1

0.088934

Well B-

4

120.4

7.7

118.1

2.1

0.041076

Well B-

5

154.3

9.6

154.8

2.7

0.068807

Well B-

6

$151.1 \quad 5.5$

152.7

1.8

0.21063

Well B-

152

6.7

152.6

2.3

0.028421

Well B-

8

147.2

3.3

146.8

1.9

0.41794

Well B-

9

113.7

4.4

112.2

1.5

0.16471

Well B-

10

126.4

8.6

129.8

2.4

0.044932

Well B-

153.9

1.8

0.18988

Well B-

8.4

149.4

2.4

0.010026 
Well B-
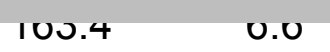

100

$$
\angle . \angle
$$

$-0.044400$

Well B-

14

155.5

6.6

157.1

2.4

0.0011161

Well B-

15

160.8

6.2

154.6

2.1

0.14127

Well B-

16

$$
165.4
$$

5.5

163.6

2.6

0.18778

Well B-

17

156.7

4.3

153.8

2

0.22712

Well B-

18

150.1

6.5

154.2

2.2

0.091504

Well B-

19

158.6

6.8

153.3

2.2

0.085955

Well B-

20

152.9

4.1

150.6

2

0.30177

Well B-

21

156.6

6.3

156.9

2.3

0.028828

Well B-

22

158.4

7.6

160.5

2.7

0.19981

Well B-

23

164.5

9.4

158.9

2.5

0.091353

Well B-

24

123.1

9.3

119.7

2.3

$-0.018192$

Well B-

25

161.4

5.6

157.9

2

0.056426

Well B- 
Well B-

27

104.1

0.1

104.4

$-0.000010$

Well B-

28

165.8

5.2

159.3

1.9

0.13786

Well B-

29

121.9

9.1

122.1

2.4

0.14114

Well B-

30

121

10

125.5

2.3

0.11655

Well B-

31

$162.2 \quad 6.4$

155.2

2.3

0.049175

Well B-

32

159.9

8.7

160.2

2.4

0.18671

Well B-

33

166.3

3.9

157.1

1.7

0.34102

Well B-

34

153.7

4.4

152.6

1.8

0.23184

Well B-

35

163.8

5.5

162

2

0.051079

Well B-

36

156.5

4.6

156.4

1.8

$-0.036668$

Well B-

37

314

11

256.6

3.7

0.17362

Well B-

38 161

6.8

155.1

2

$-0.021977$

Well B-

39

159.6

8

161.3

2.4

0.16092

Well B- 
Well B-

41

$1<1.0 \quad 1.4$

$1<0.1$

U. 1100

Well B-

42

157.5

8.3

154.5

2.2

$-0.0032929$

Well B-

43

155

10

119.1

2.2

0.0064158

Well B-

44

146.3

7.4

151.9

2.4

0.18071

Well B-

45

179.4

5.5

176.1

0.2199

Well B-

46

160.6

6.7

152.9

1.9

0.041994

Well B-

47

130.1

5.2

128.7

1.5

0.09287

Well B-

48

116.2

8.1

119.9

2.1

0.030523

Well B-

49

153.4

8

154

2.4

0.21461

Well B-

50

$152 \quad 6.6$

152.2

2.1

0.028025

Well B-

51

123.7

9.7

119.1

2.7

0.018176

Well B-

52

151.4

4.9

152.5

2

0.1739

Well B-

53

150

4.3

148.7

1.7

0.16887

Well B- 
Well B-

Well B-

56

123.6

6.7

123.9

2.3

$-0.099418$

Well B-

57

162.2

6.2

161.3

2.5

0.27309

Well B-

58

148.4

3.6

150.3

2.1

0.26268

Well B-

59

154.6

6.9

158.5

2.8

0.20458

Well B-

60 113.5

5.3

113

1.9

0.14798

Well B-

61

233.9

9.3

238

3.8

0.28797

Well B-

62

158.8

4.7

154

2.2

0.20432

Well B-

63

166.6

7.9

156.8

3.1

0.14802

Well B-

64

156.7

6.4

152.6

2.4

0.14015

Well B-

65

113.5

4.9

113.3

1.9

0.12314

Well B-

159.6

7

155.1

2.5

0.21887 

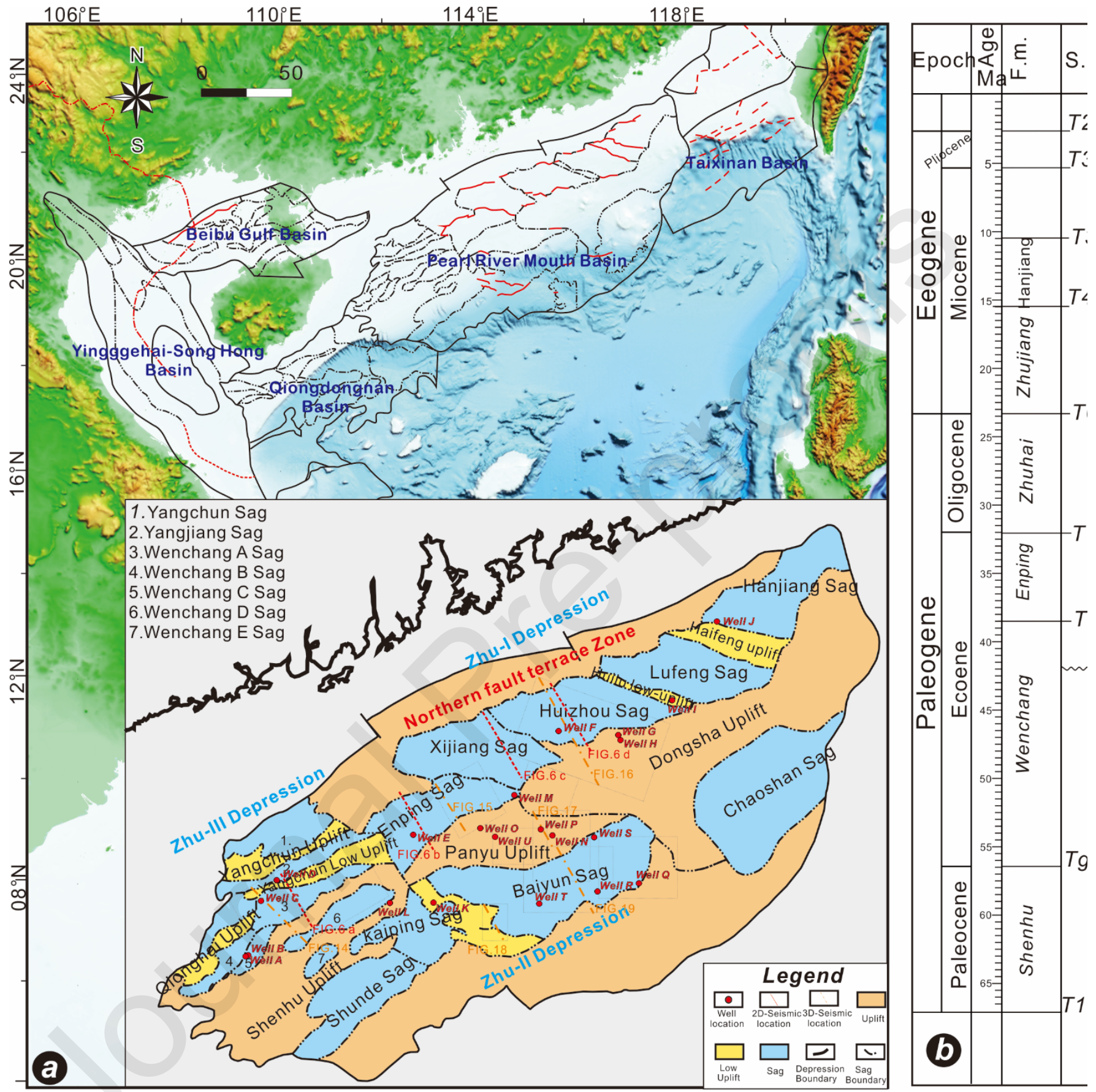

FIG 1 


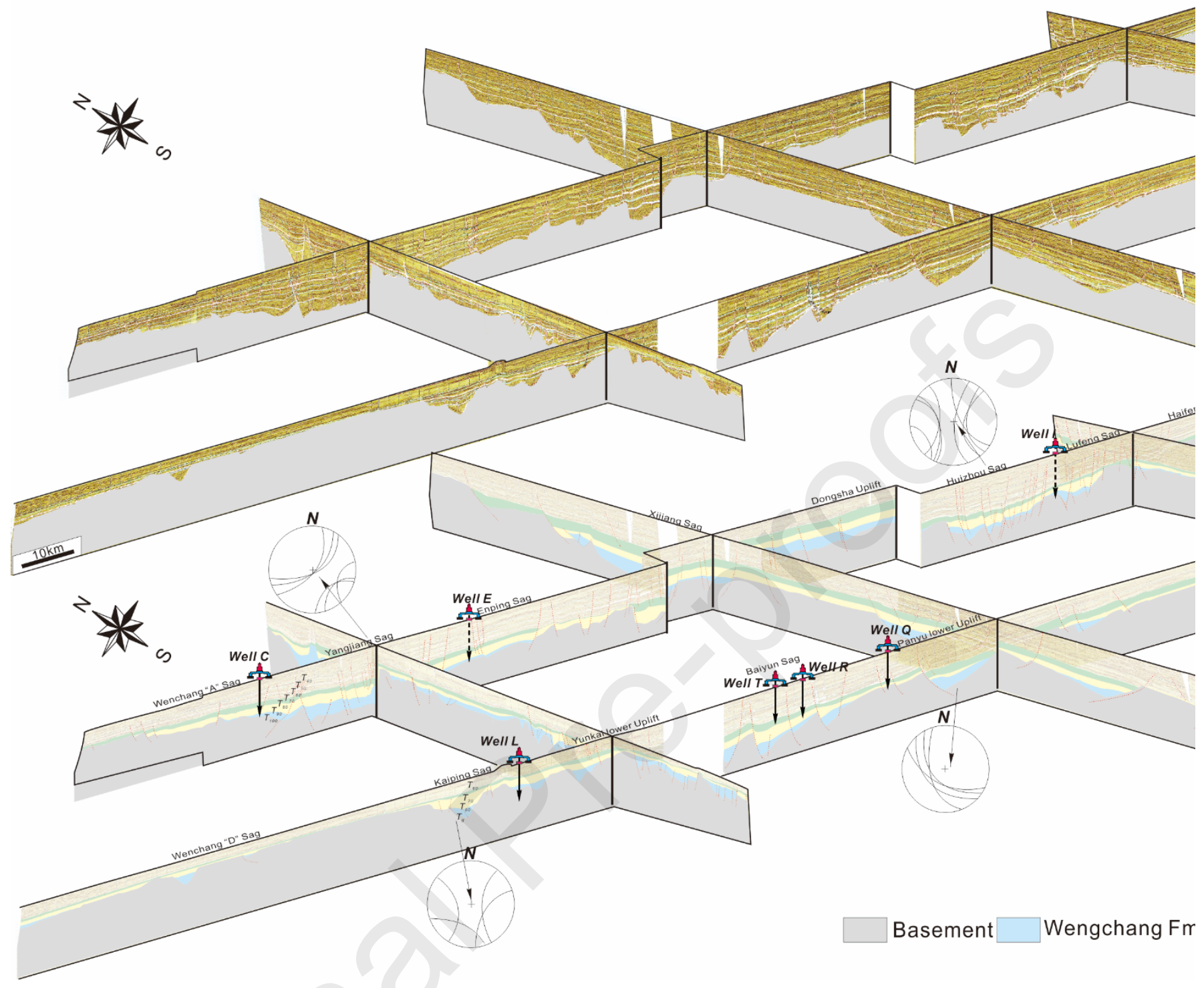

FIG 2 


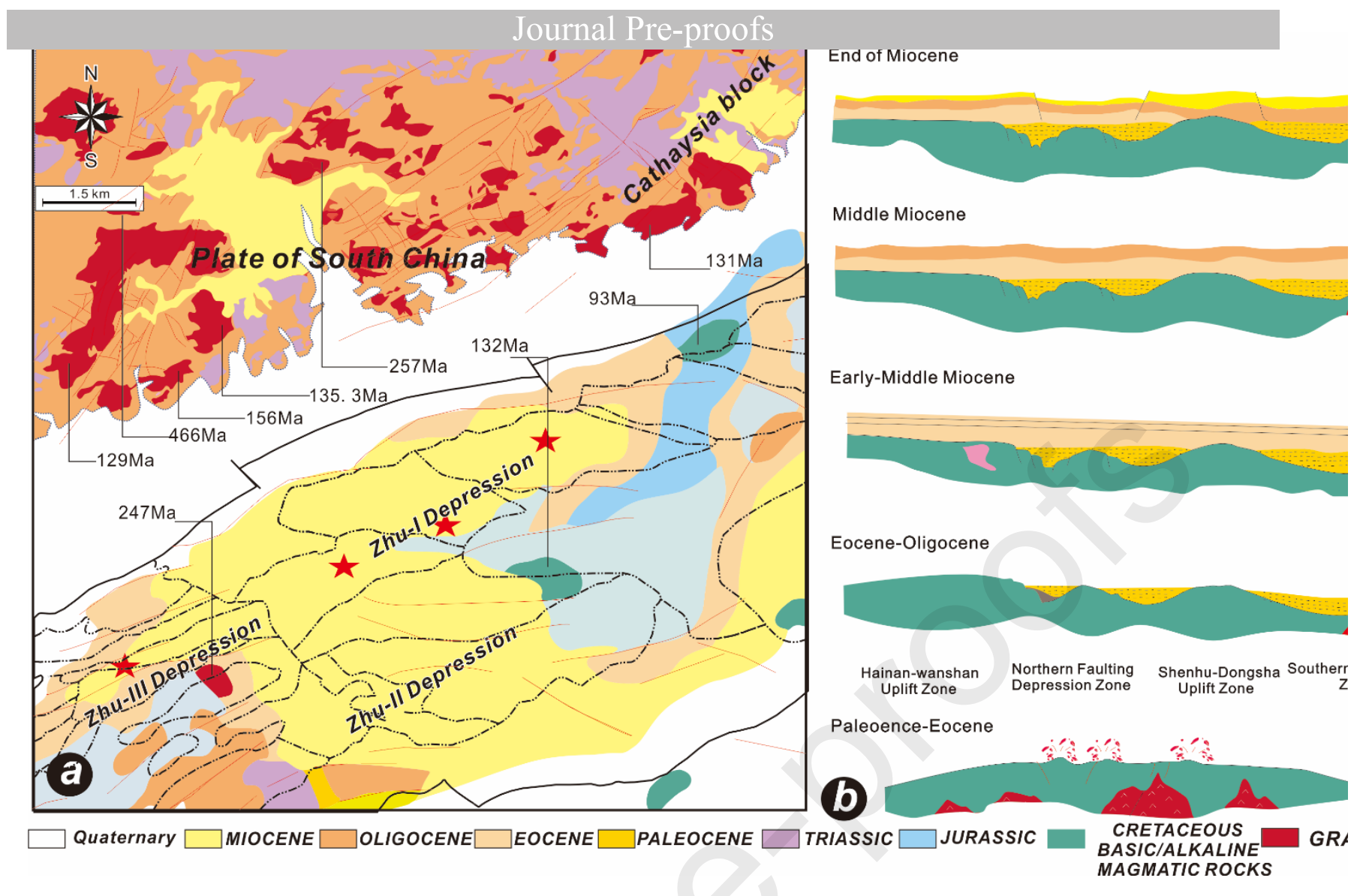

FIG 3 
Western North Depression Zone

Yangchun Uplift Wenchang C Sag

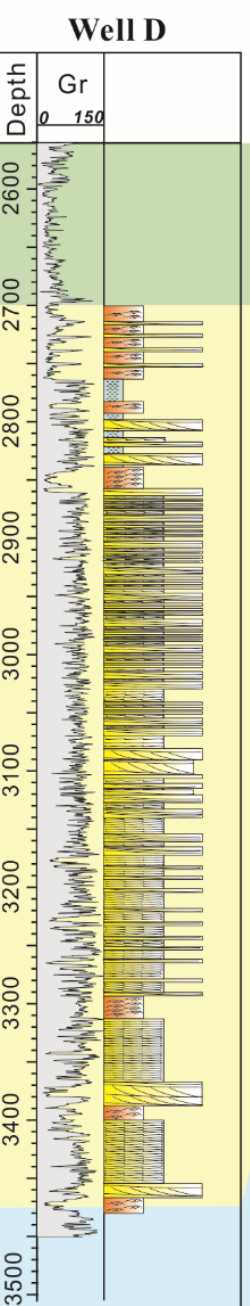

$$
\text { Well B }
$$

Central North Depression Zone

Enping Sag Panyu Uplift

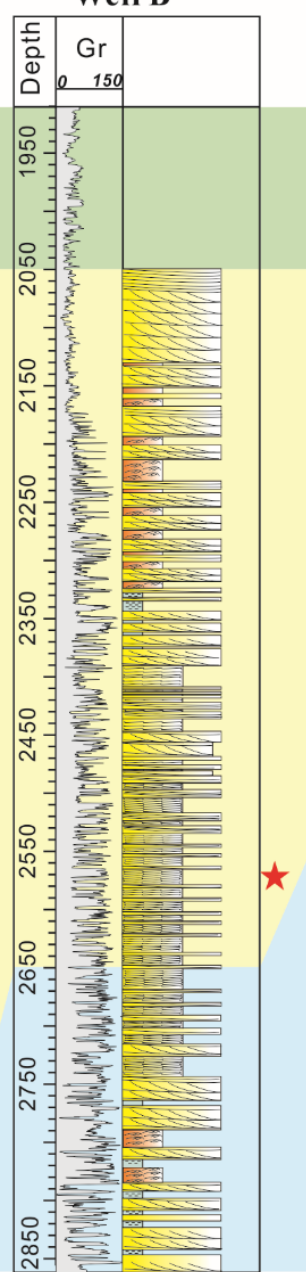

Well E

Well M

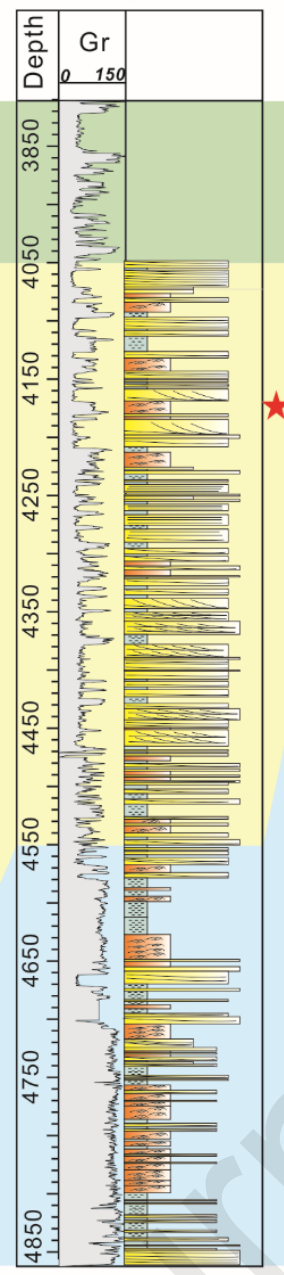

ren
Eastern North Depression Zone

Huizhou Sag Huizhou Sag Well F

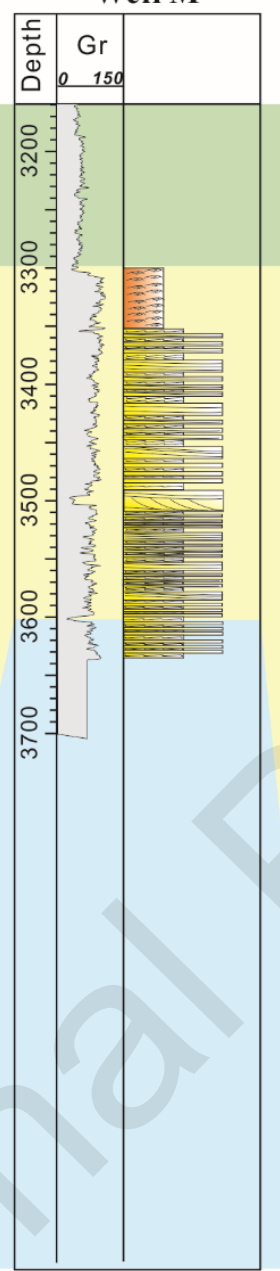

Well I

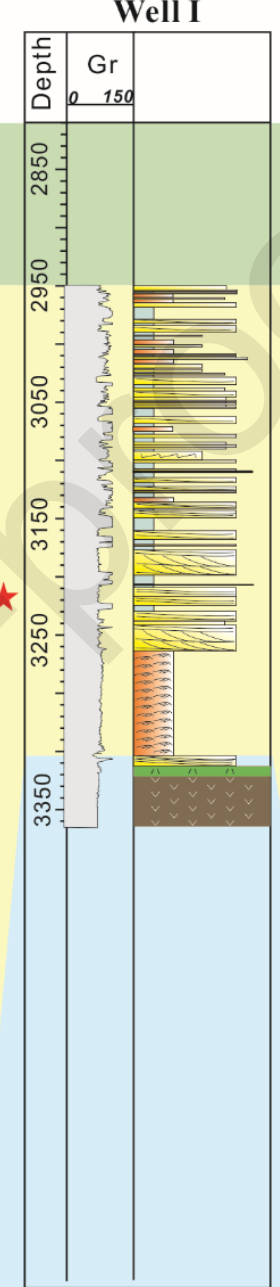

Hanjiang Sag

Well J

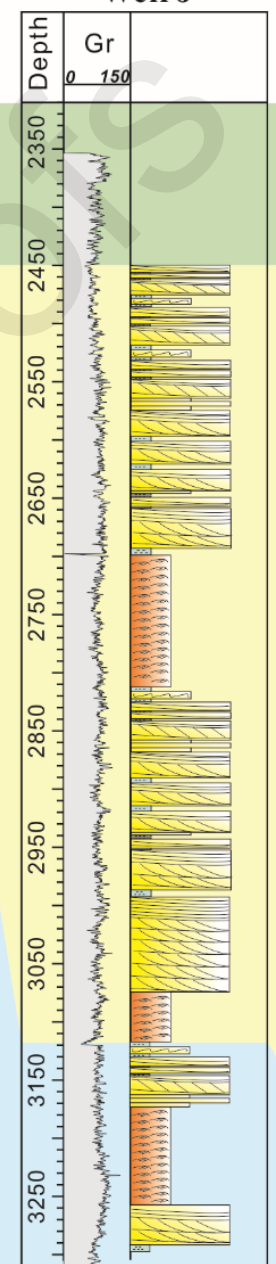

South Depression Zone

Kaiping Sag Baiyun Sag

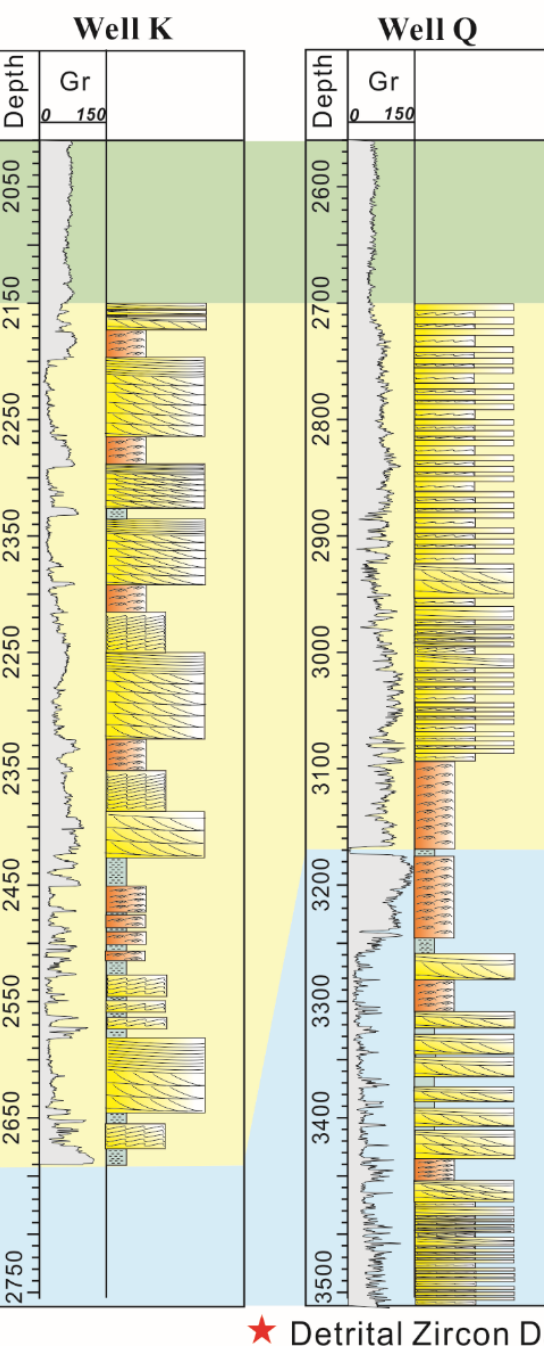

FIG 4 


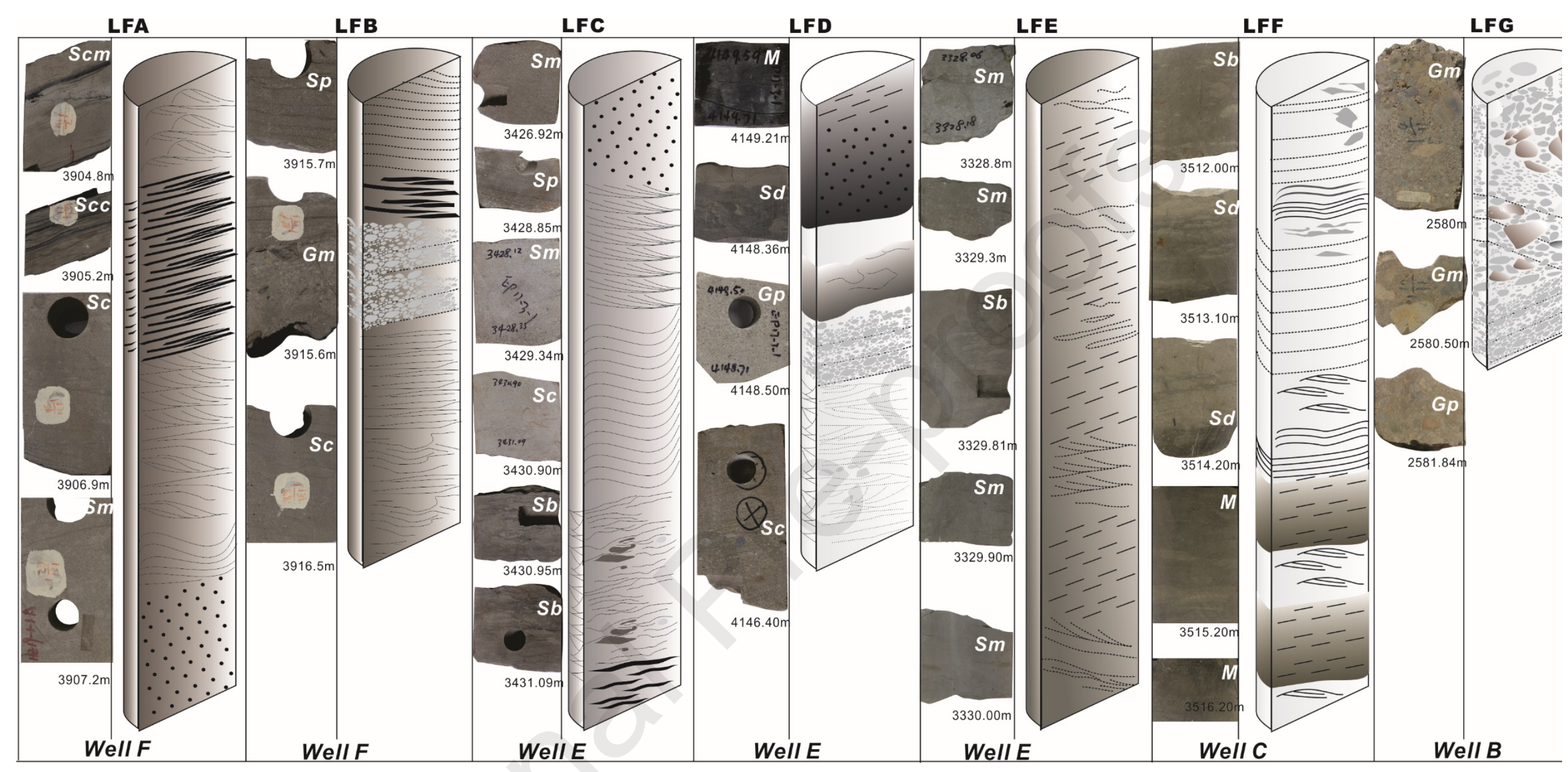

FIG 5 

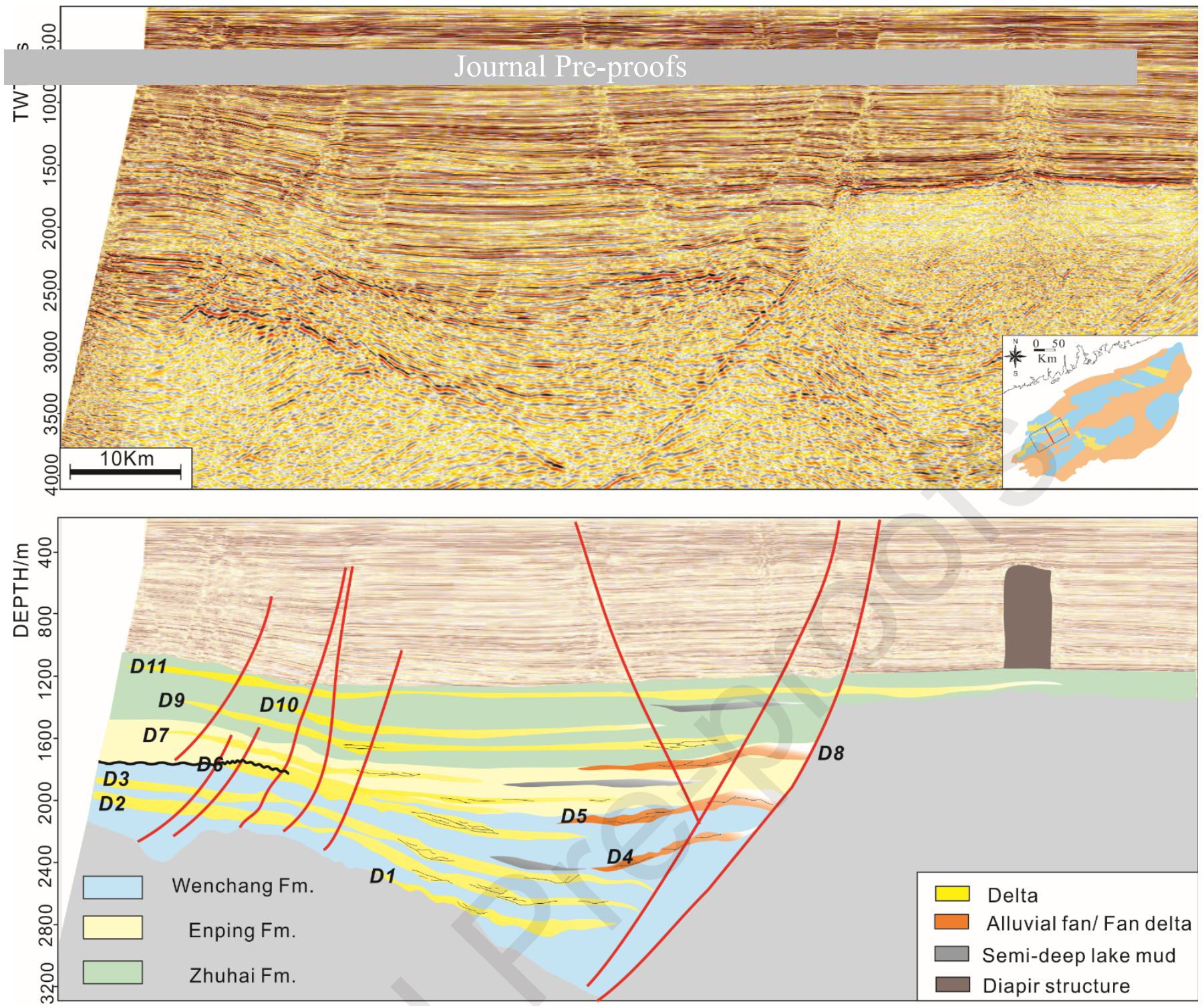

FIG 6 

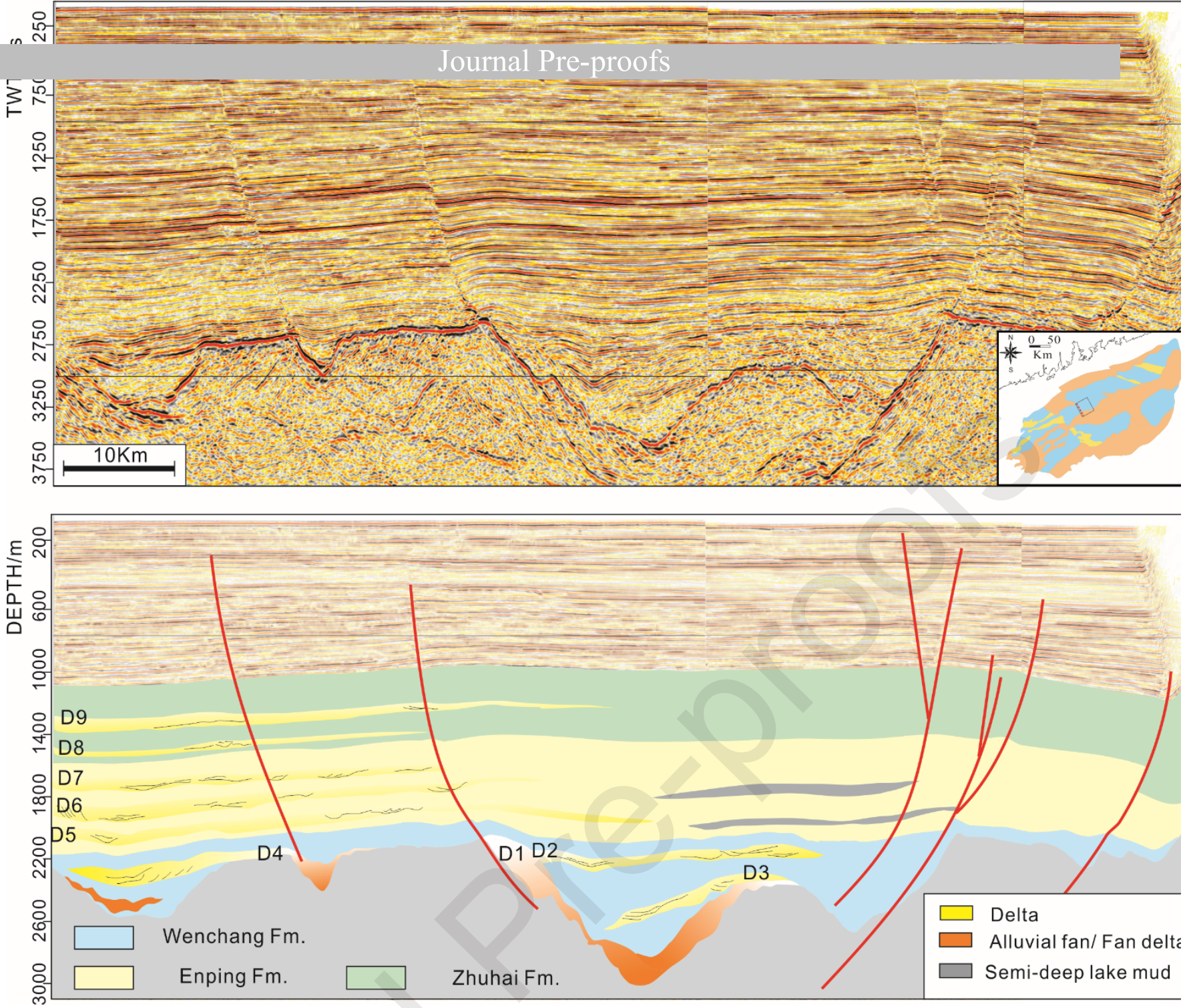

FIG 7 


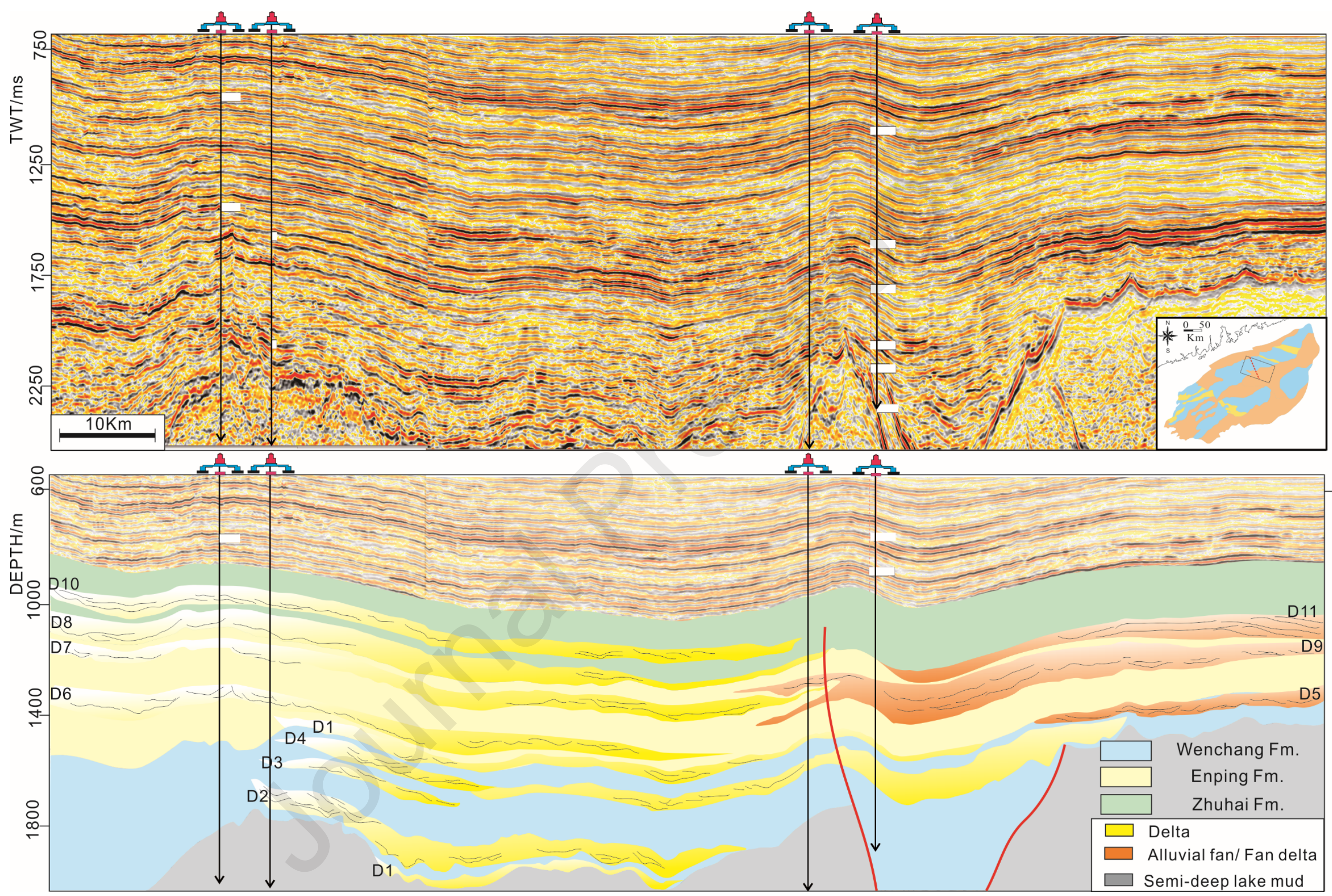


FIG 8
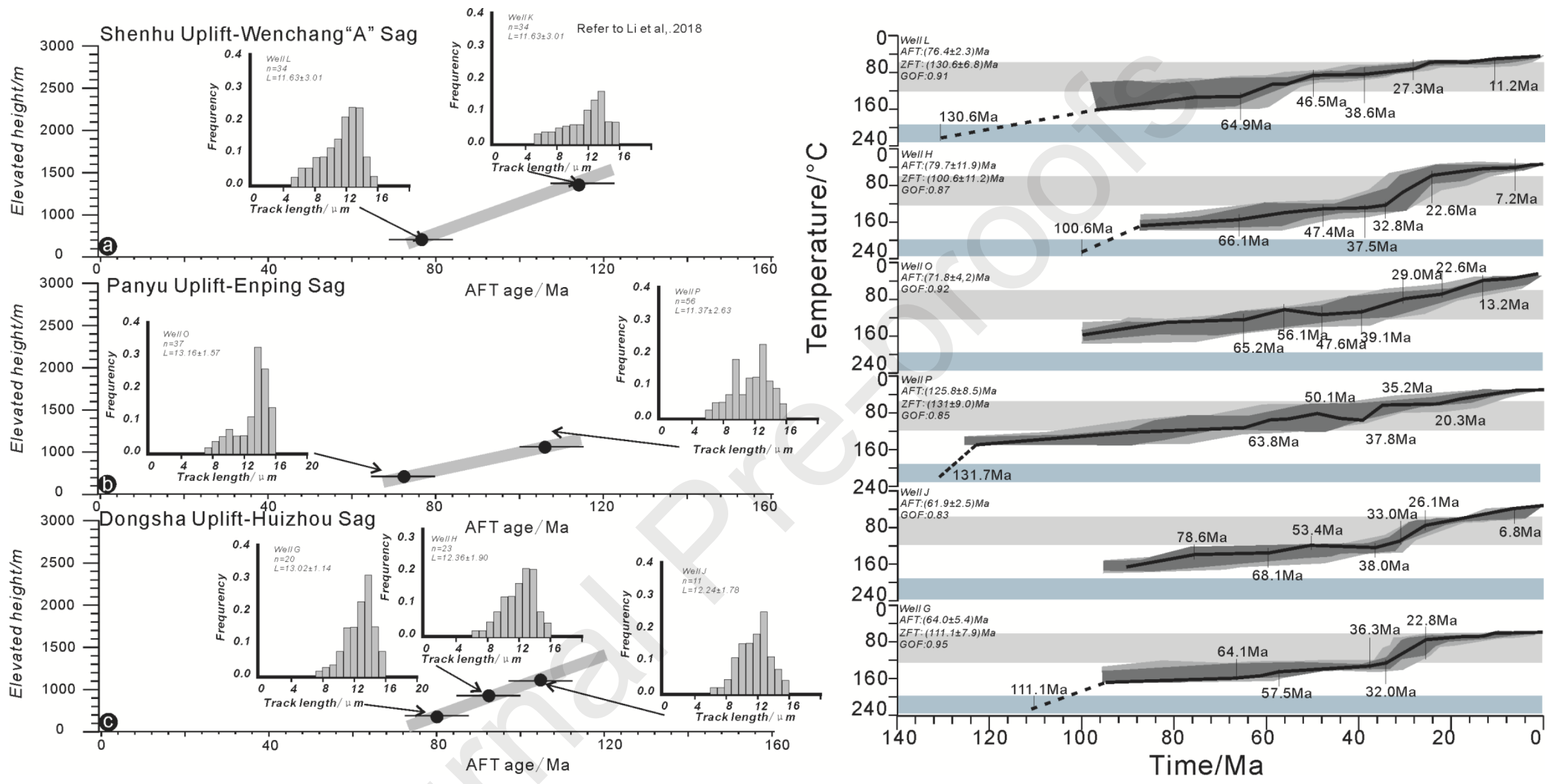

FIG 9 


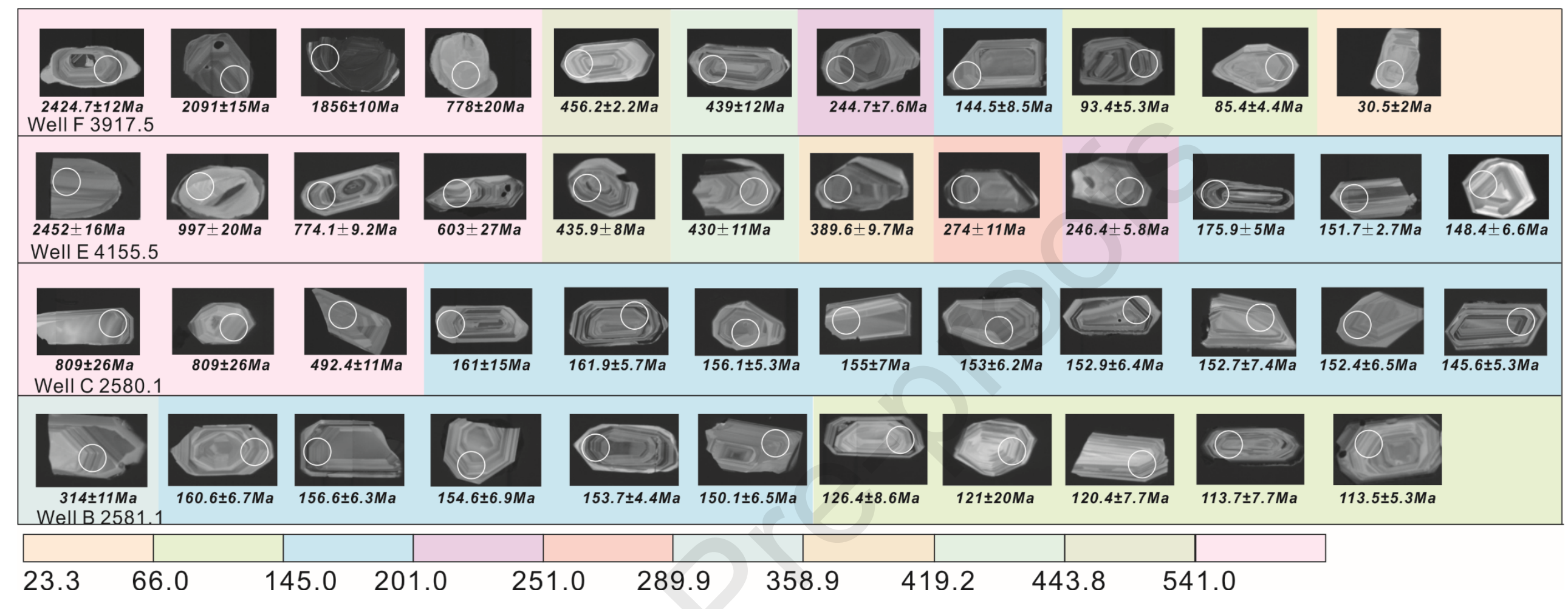

FIG 10 


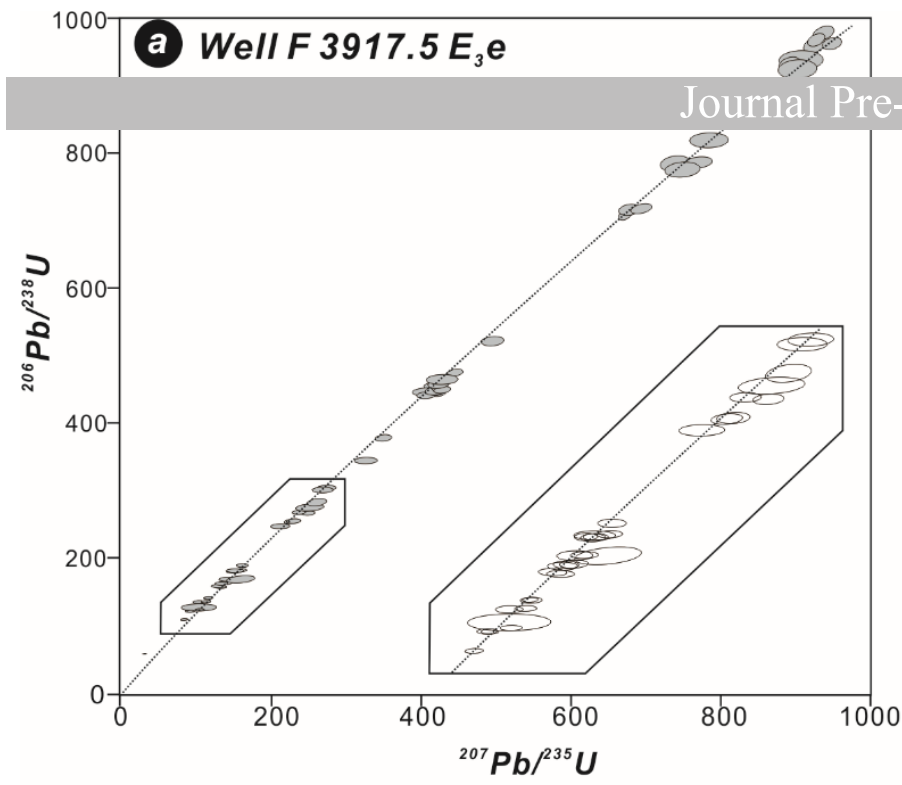

${ }^{1000}$ (b) Well E 4155. $5 E_{3} \mathrm{e}$
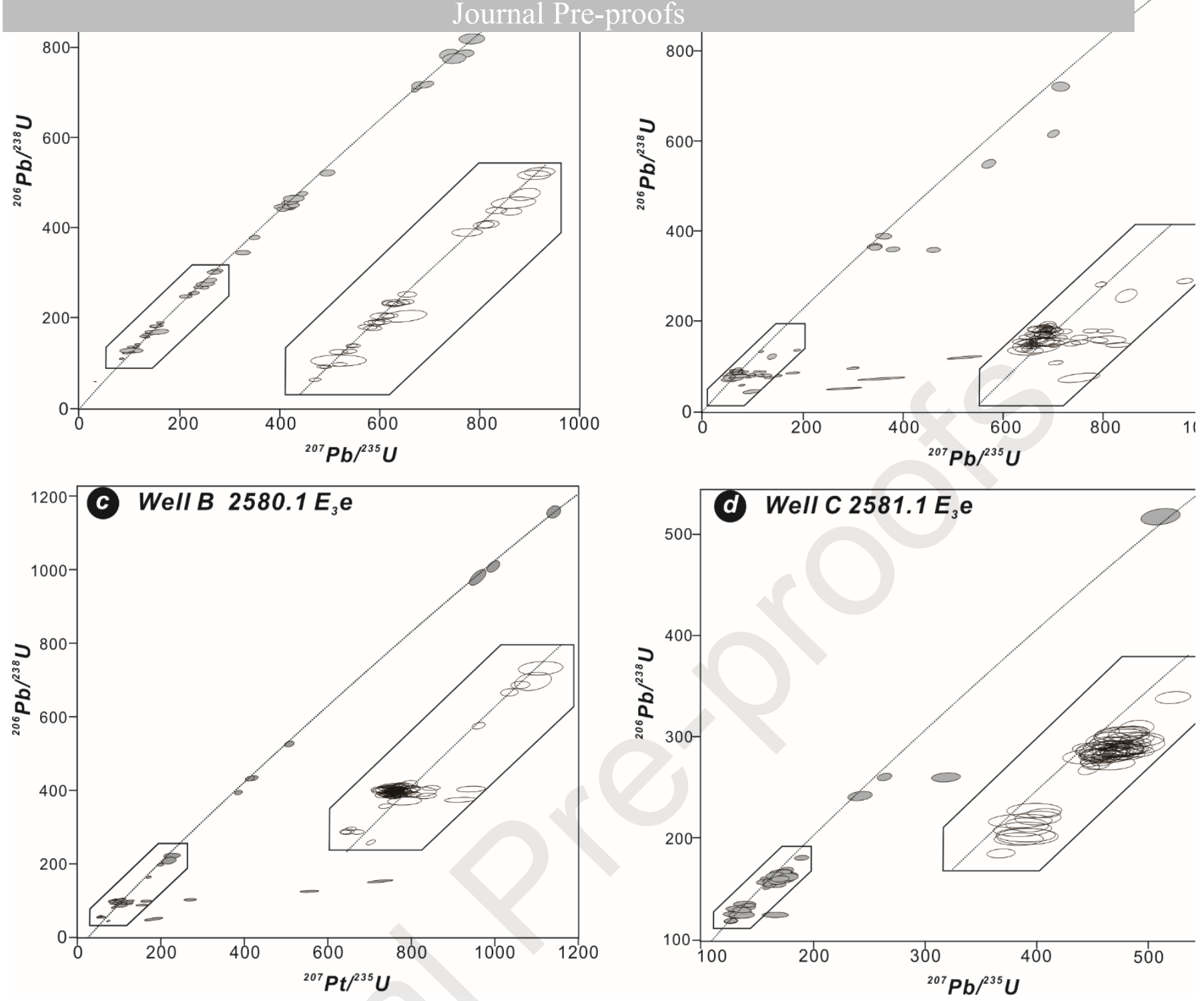

FIG 11 


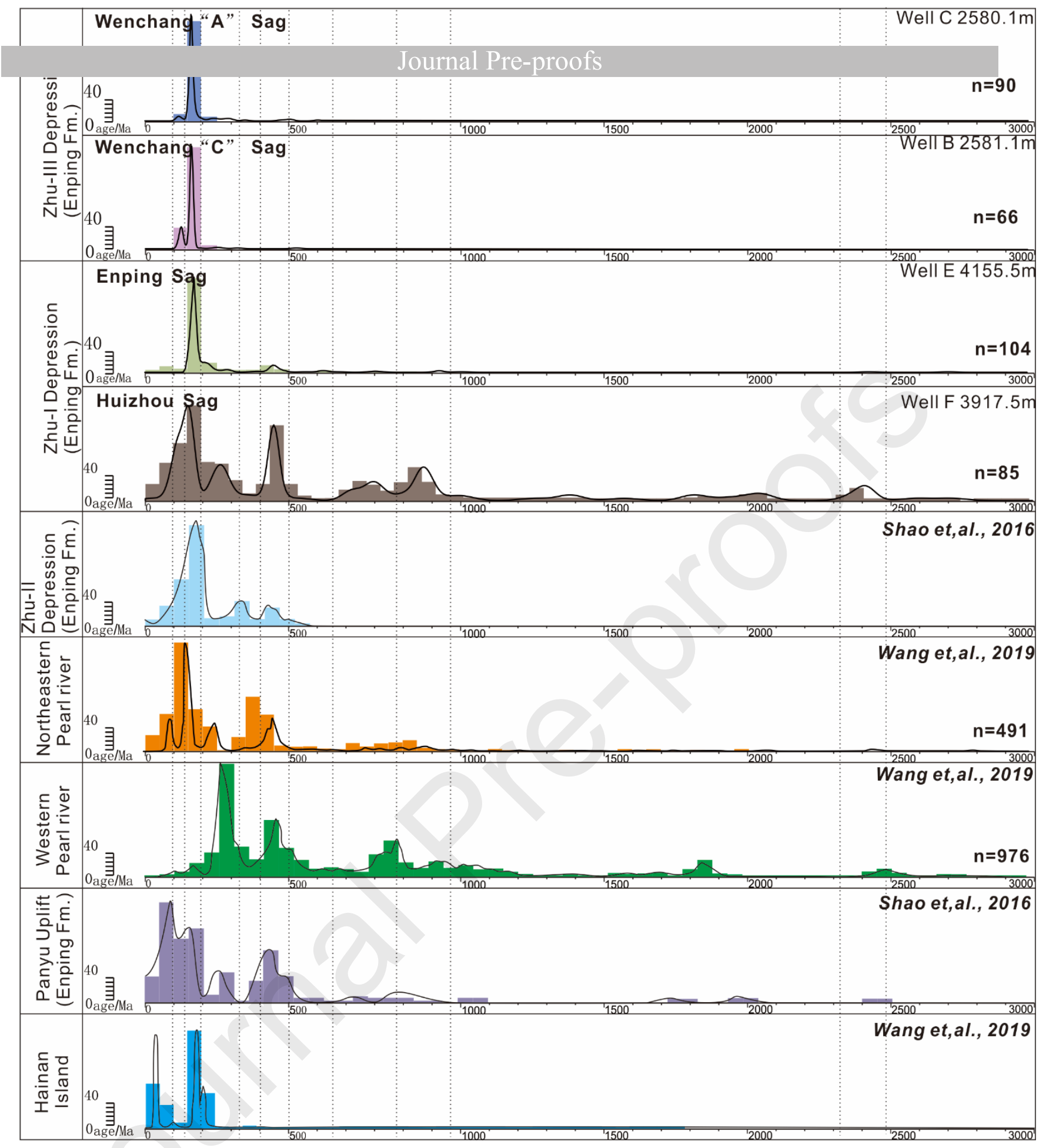

FIG 12 


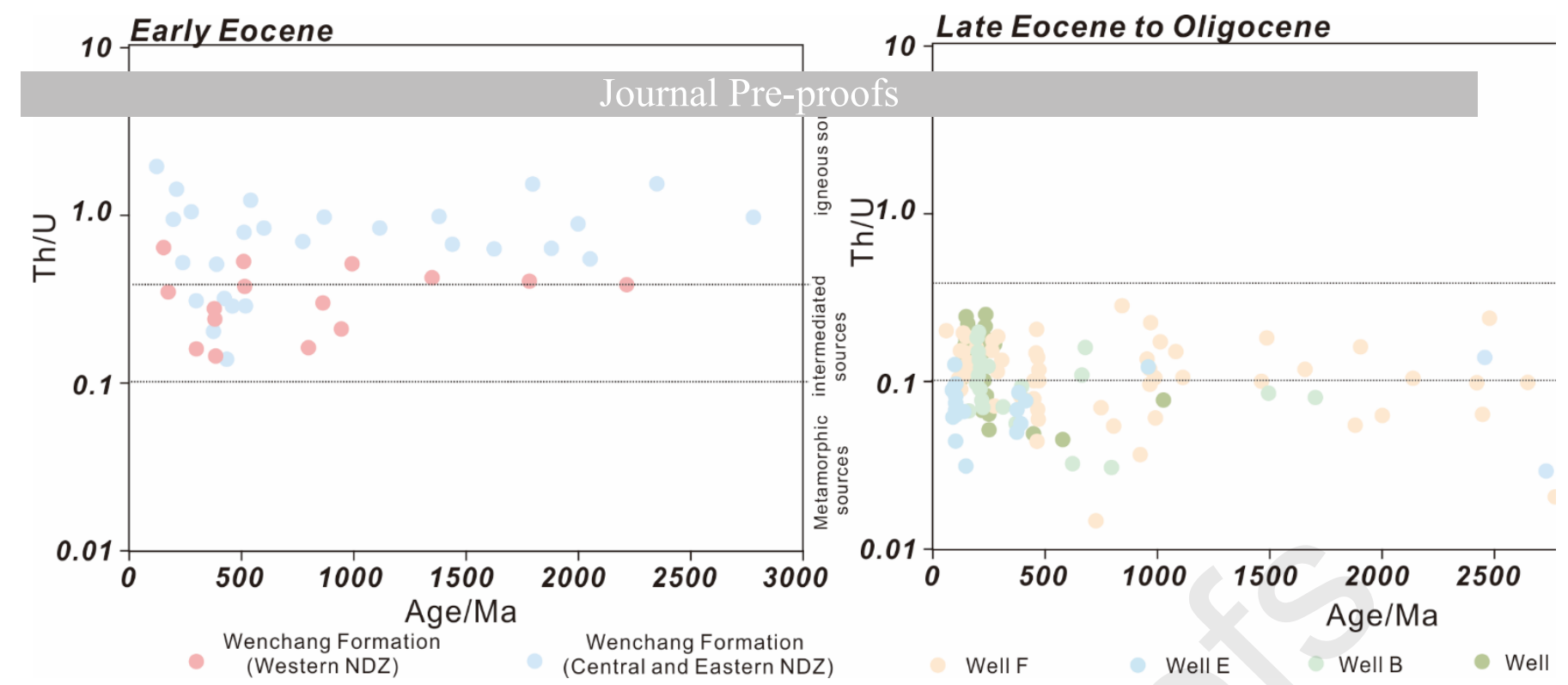

FIG 13
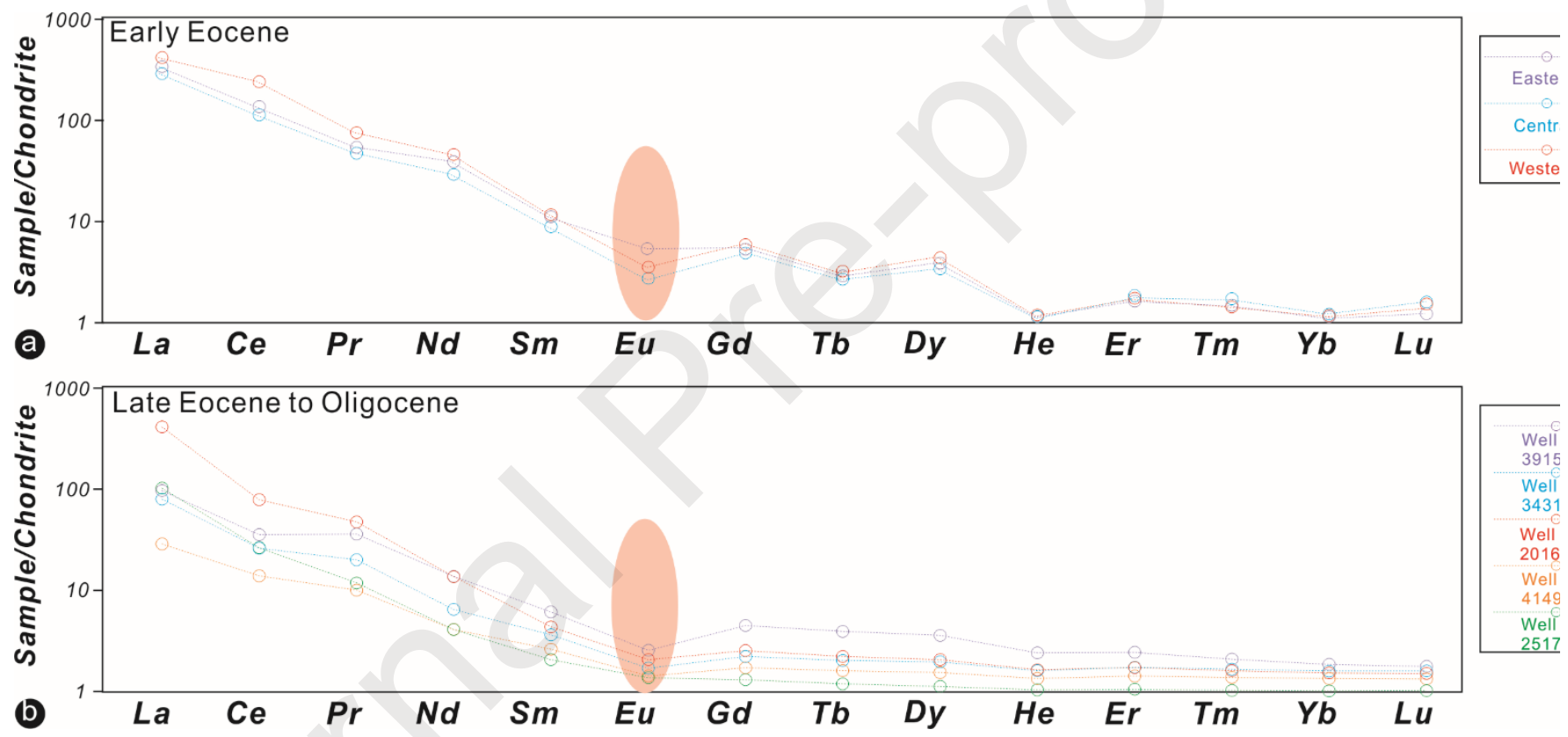

FIG 14 


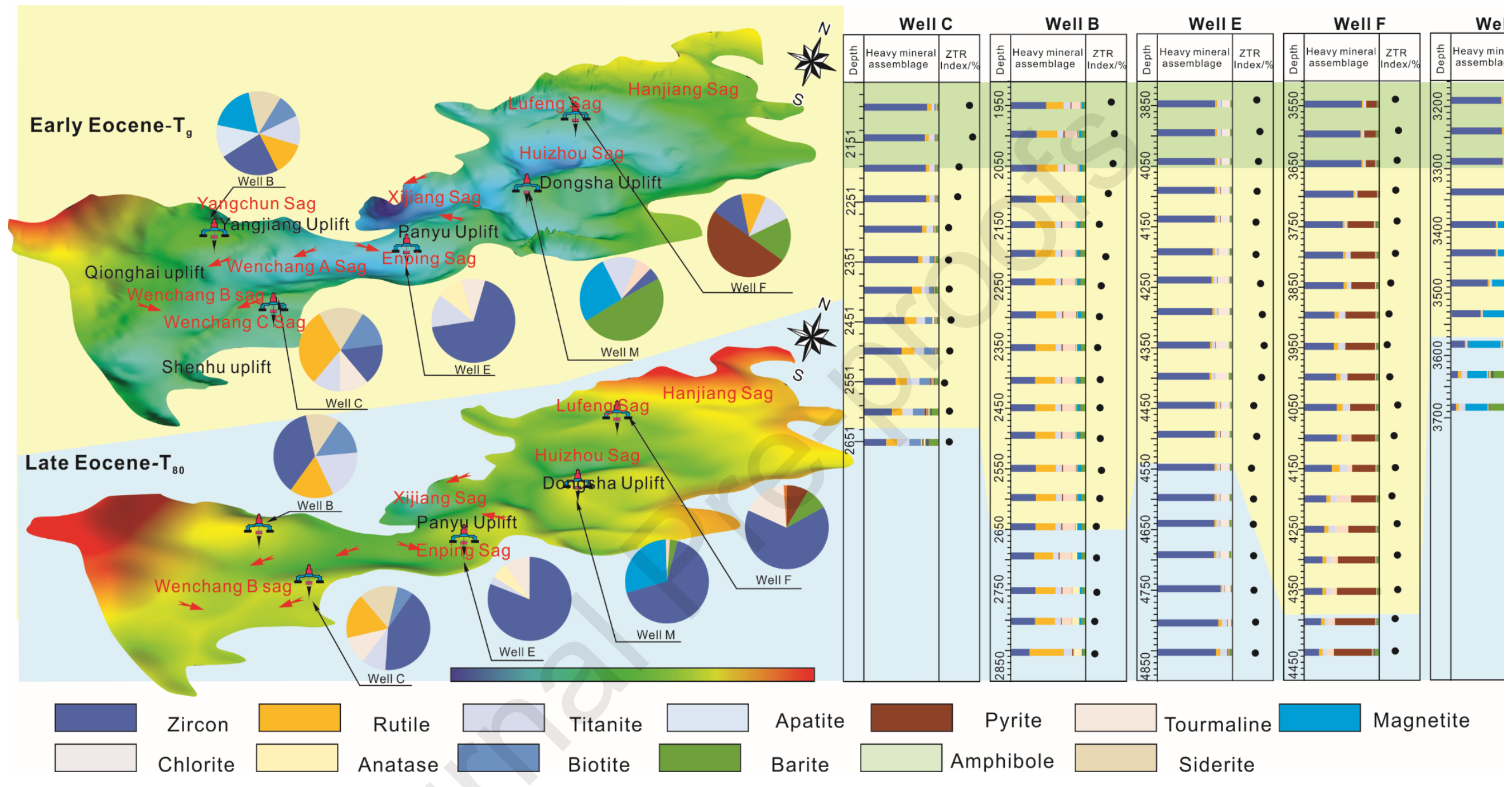

FIG 15 

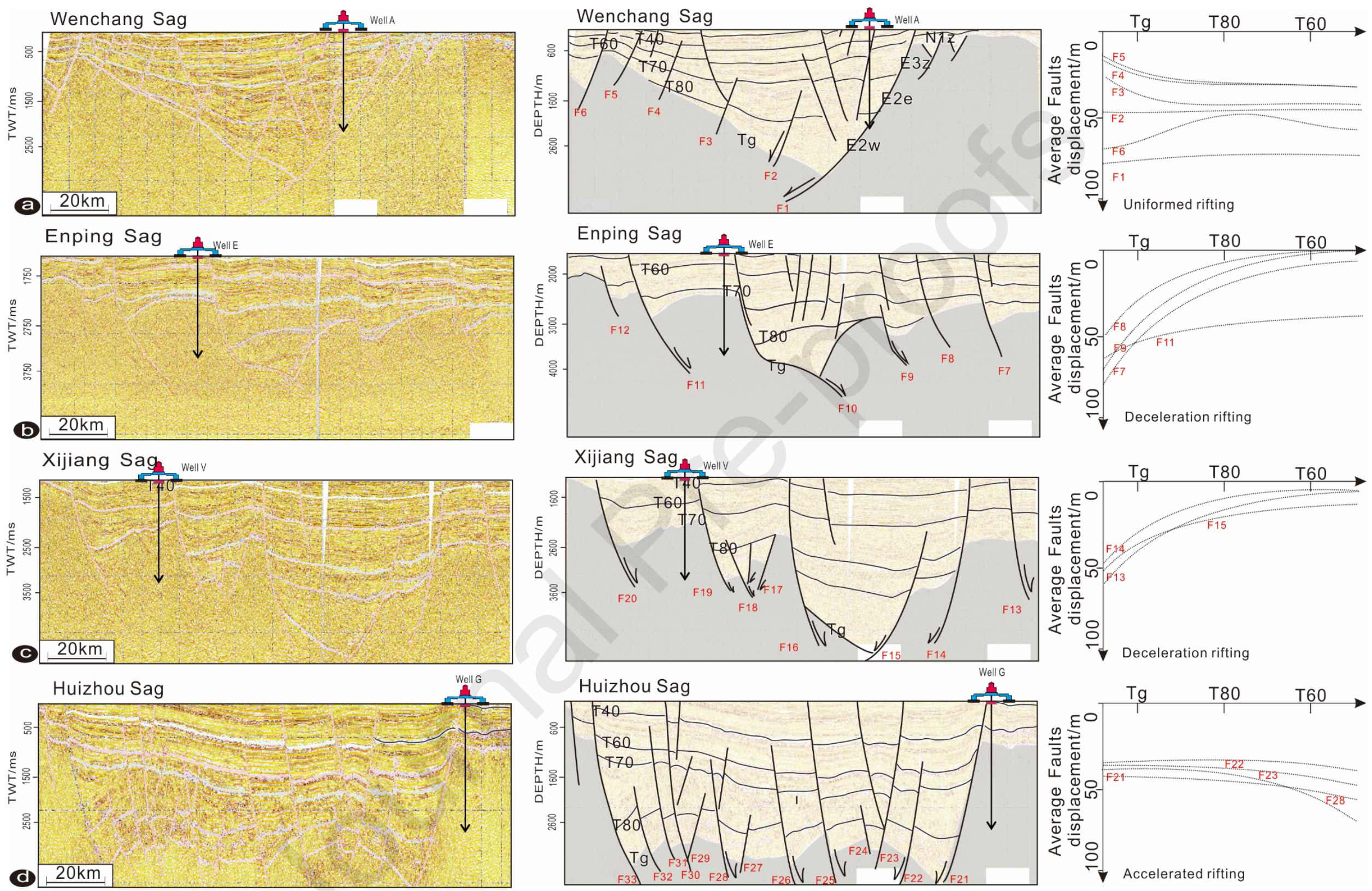

FIG 16 


\section{Source to sink system in Rifting Basin}

\section{Journal Pre-proofs}

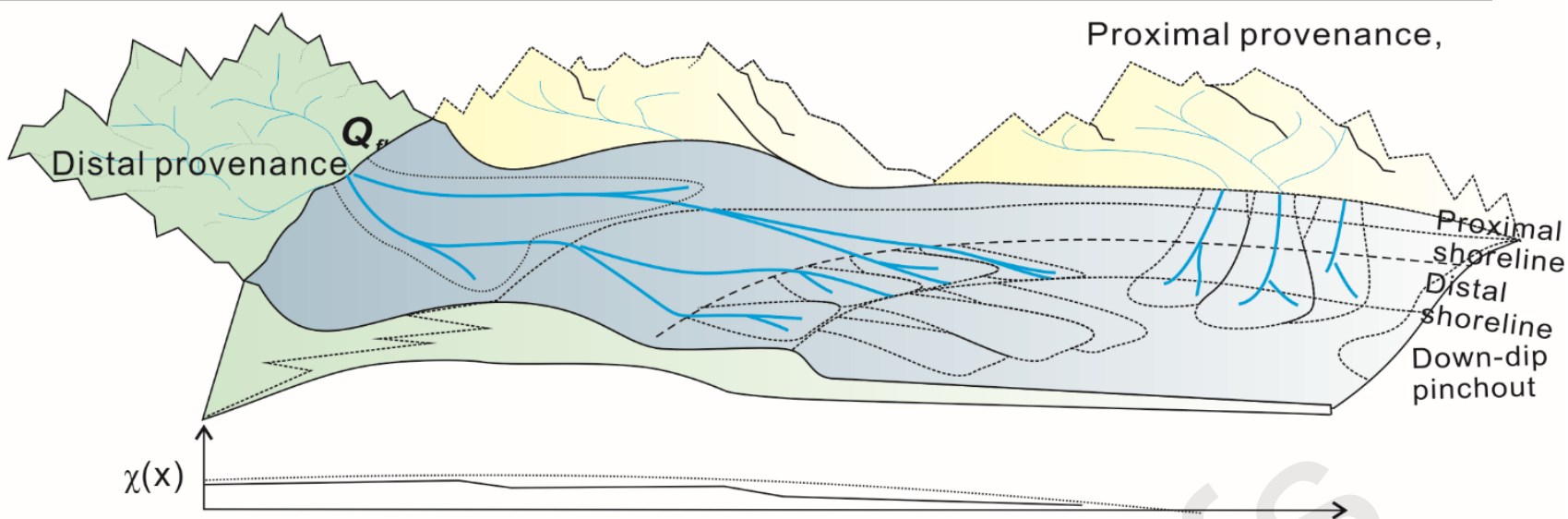

Medium rifting rate

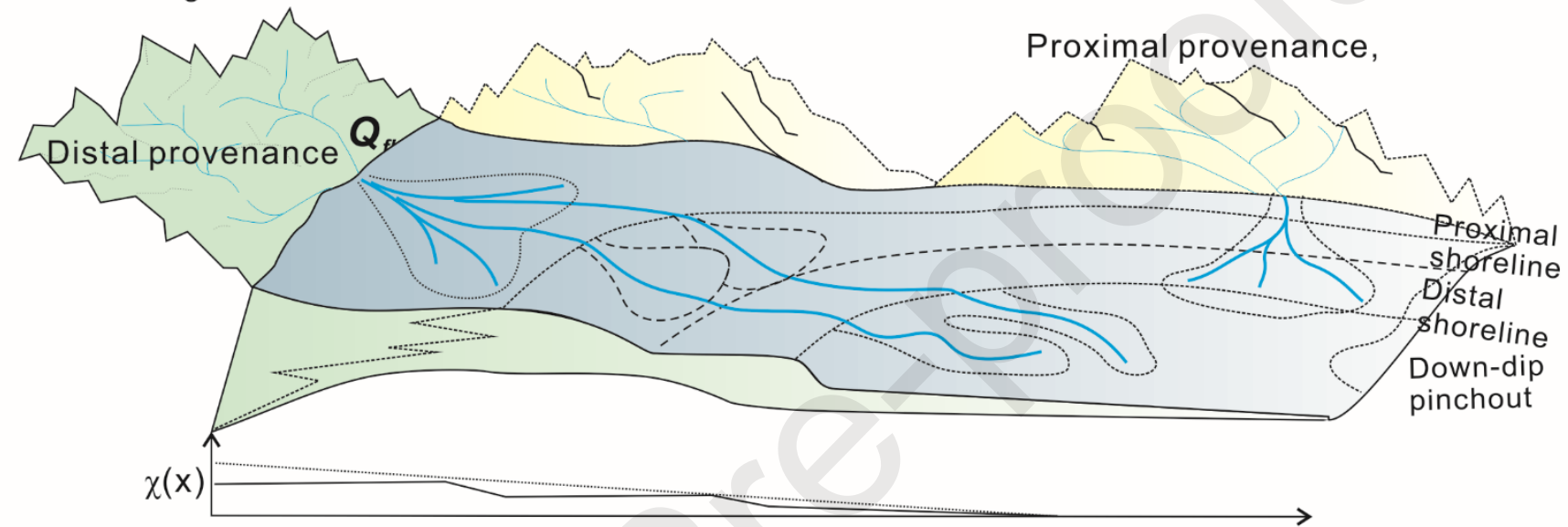

Low rifting rate

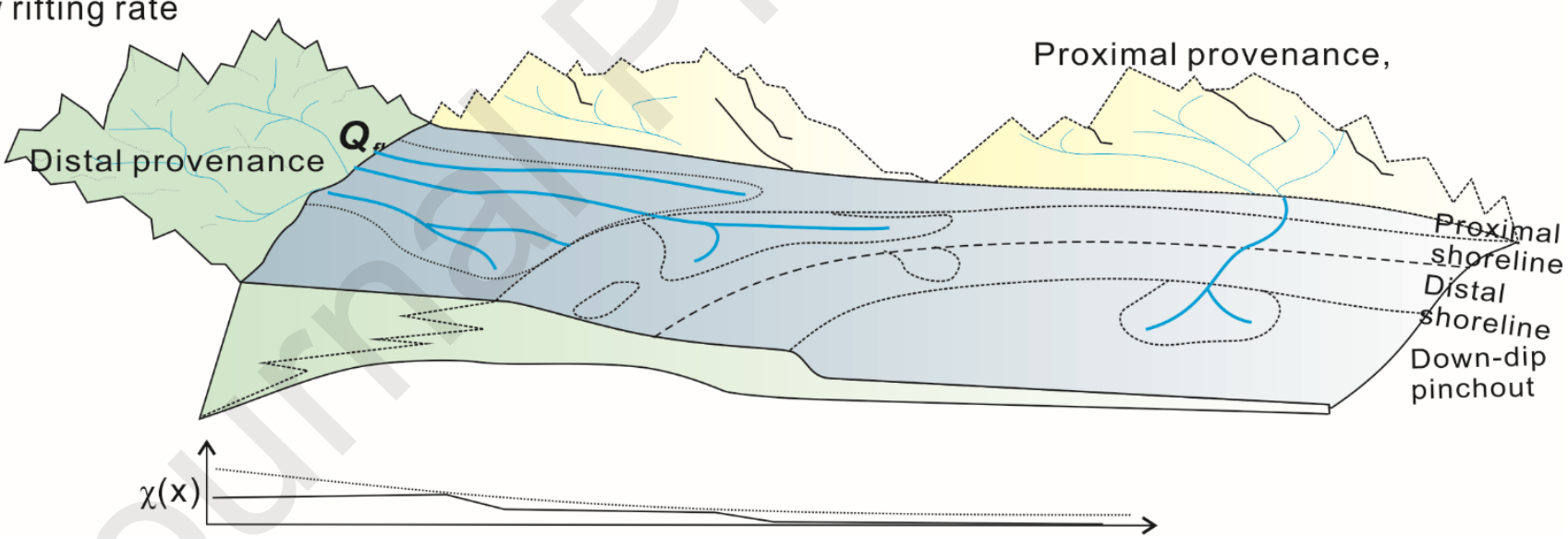

FIG 17 

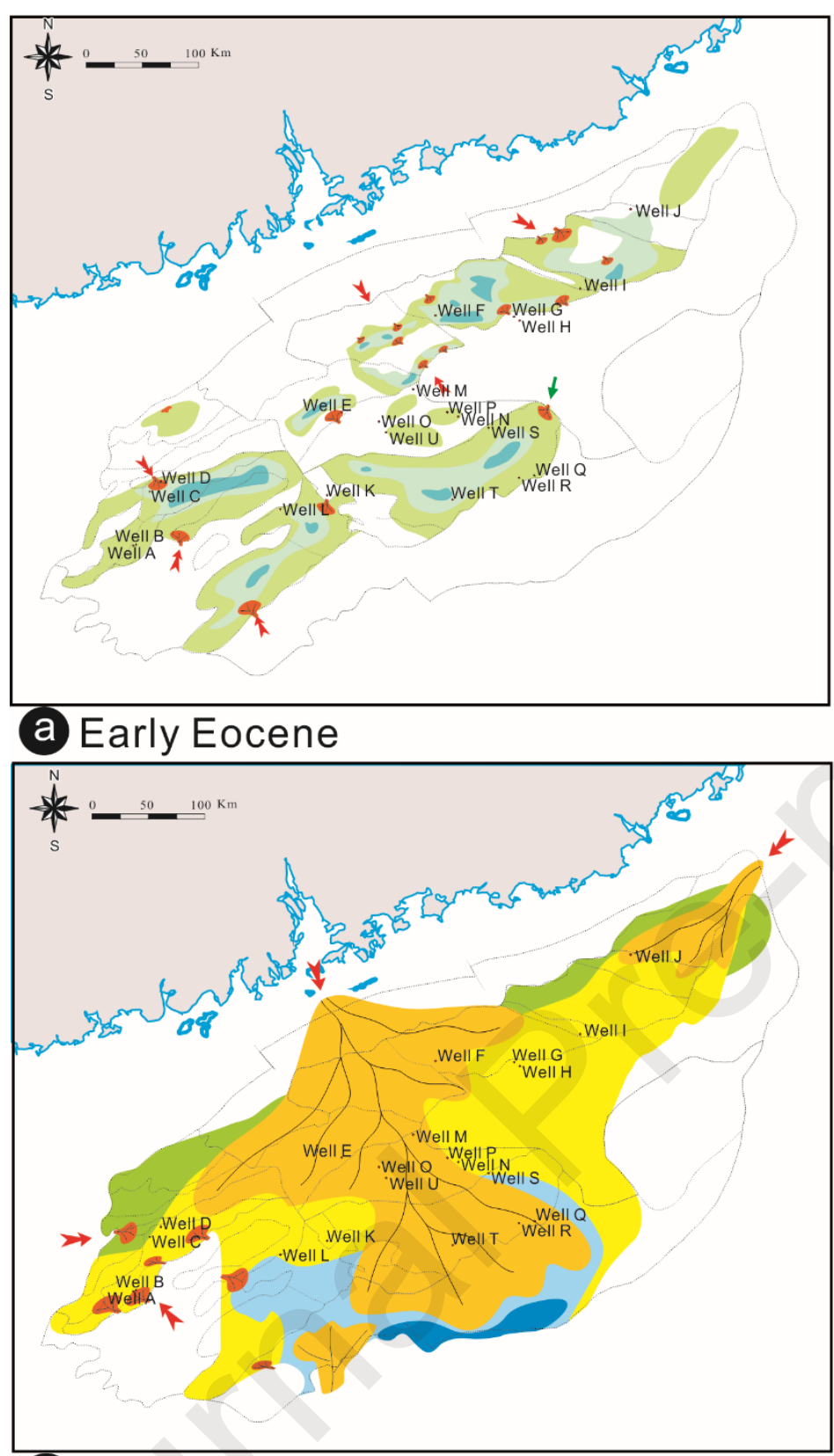

C Oligocene
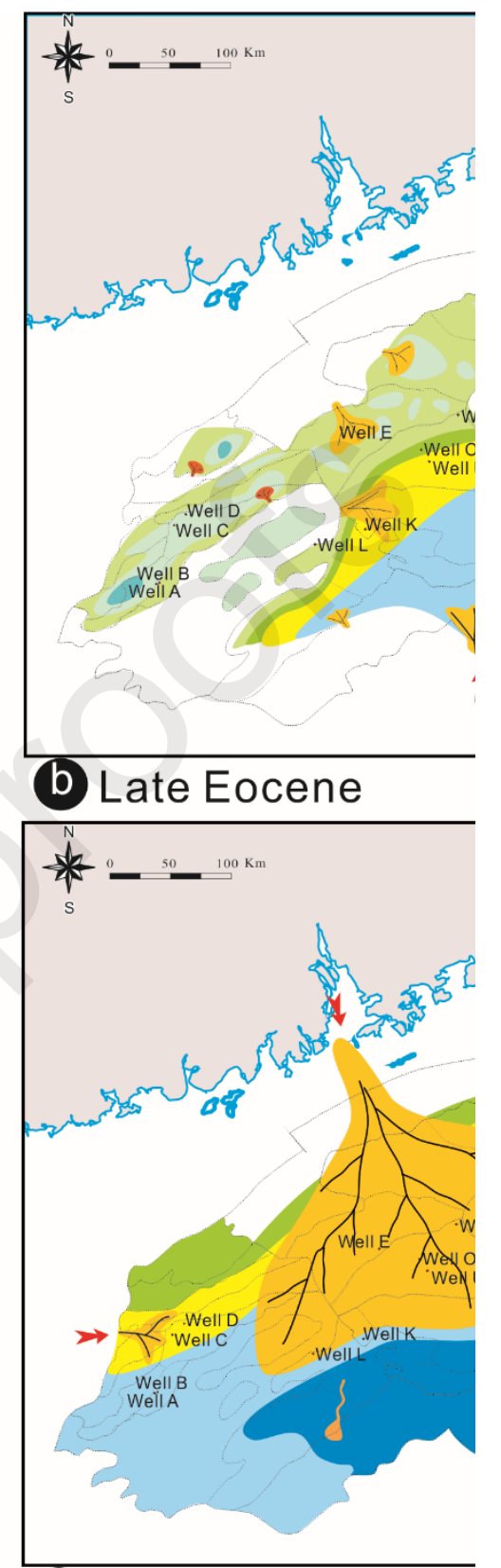

d Miocene

FIG 18 

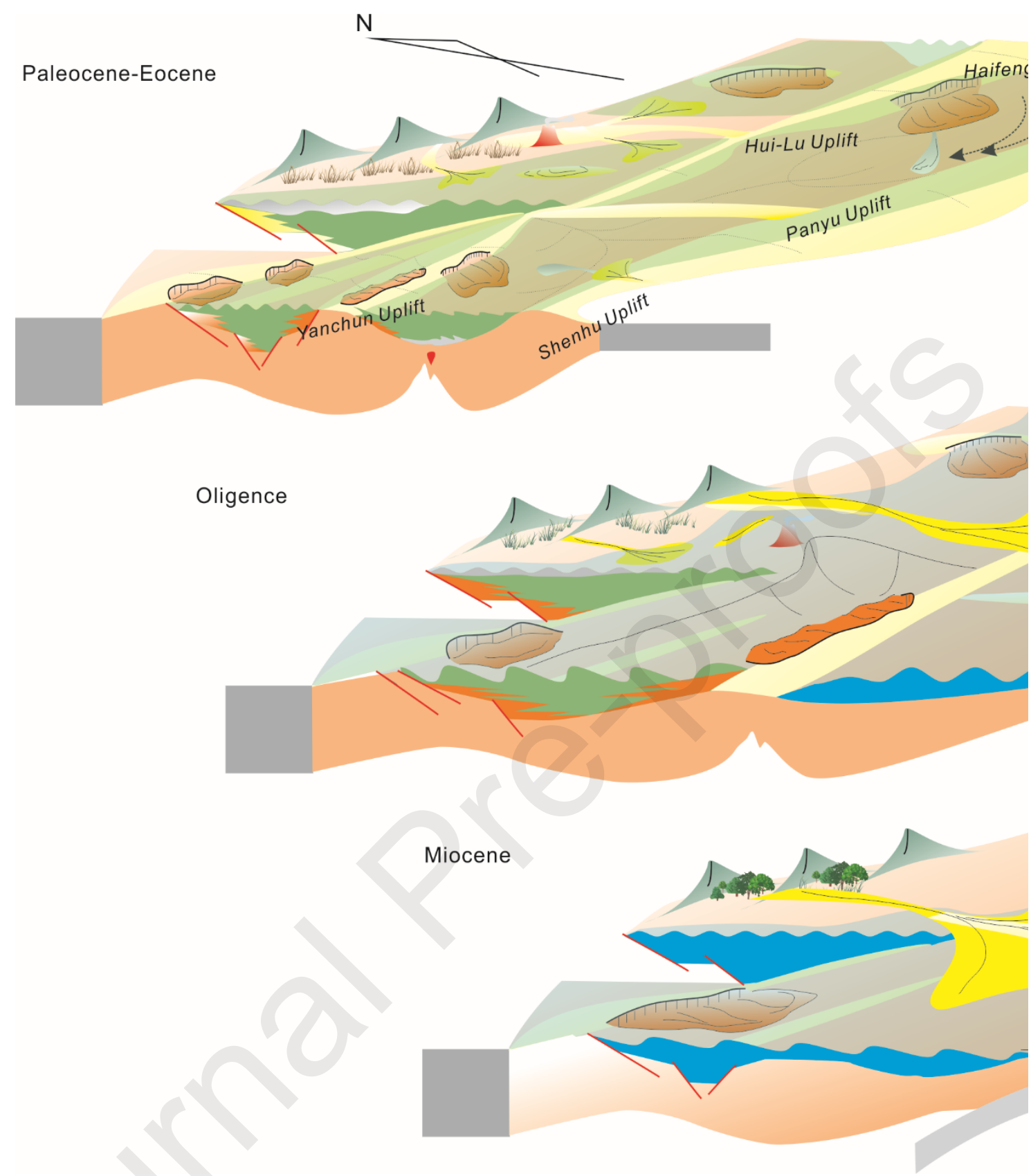

FIG 19 

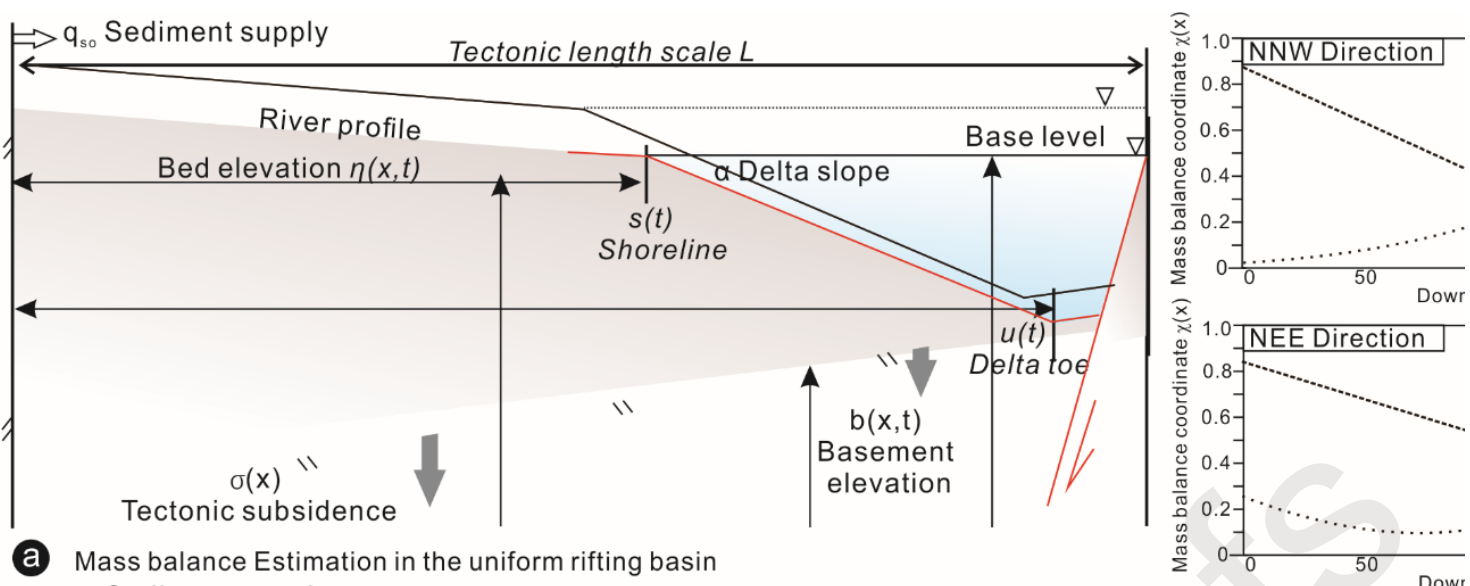

a Mass balance Estimation in the uniform rifting basin $\Leftrightarrow q_{\text {so }}$ Sediment supply

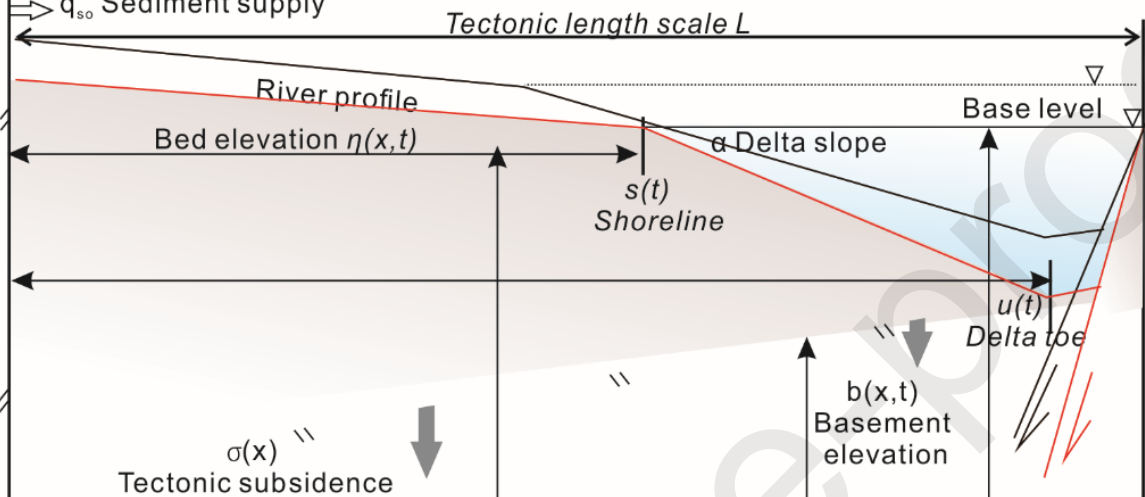

b Mass balance Estimation in the decelerated rifting basin

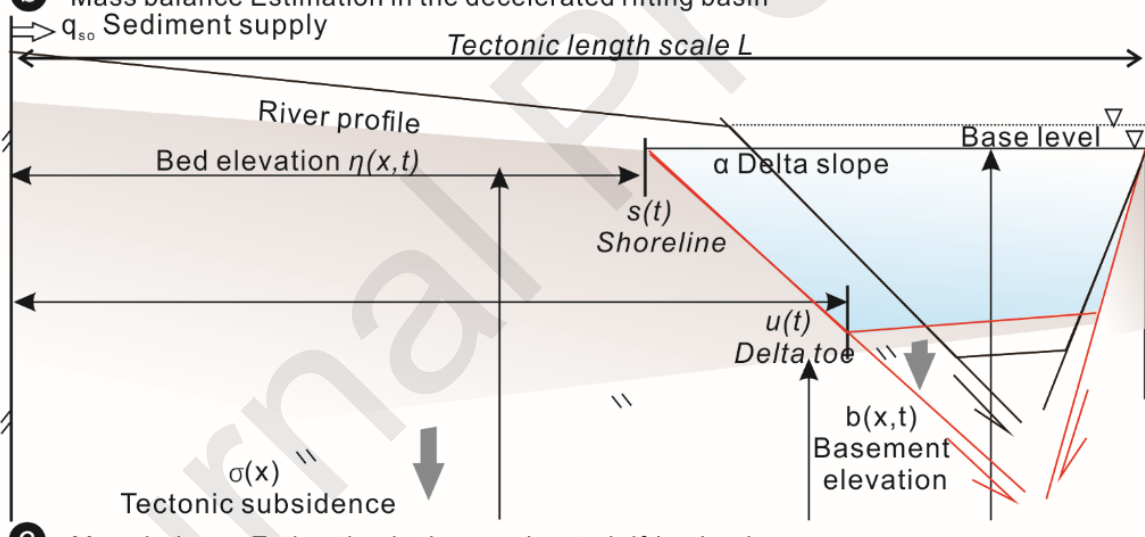

C Mass balance Estimation in the accelerated rifting basin

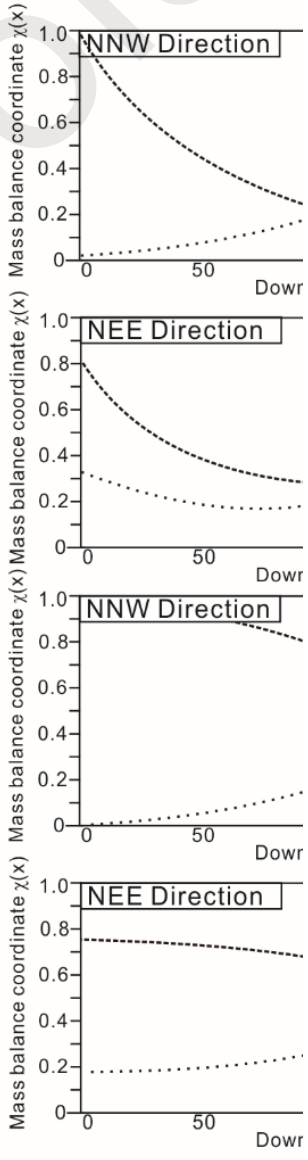

First rifting stage

Second rifting stage

FIG 20 
Uniform rifting system (Western part in northern depression zone of Pearl River Mouth Basin)

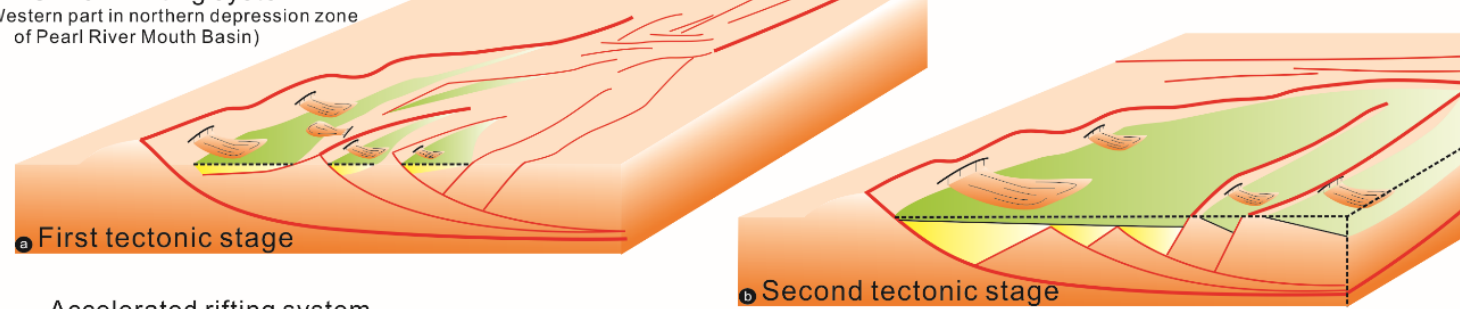

Accelerated rifting system

- Second tectonic stag

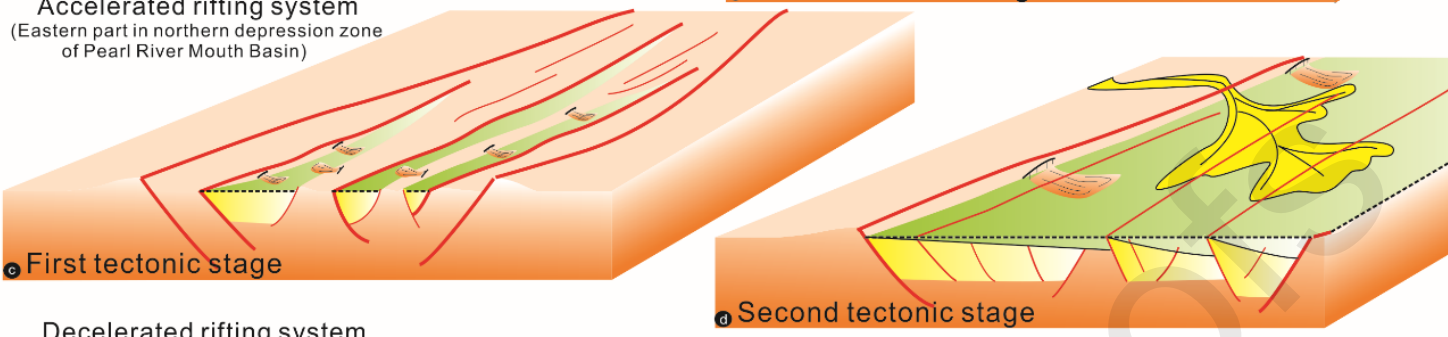

Decelerated rifting system
(Central part in northern depression zon

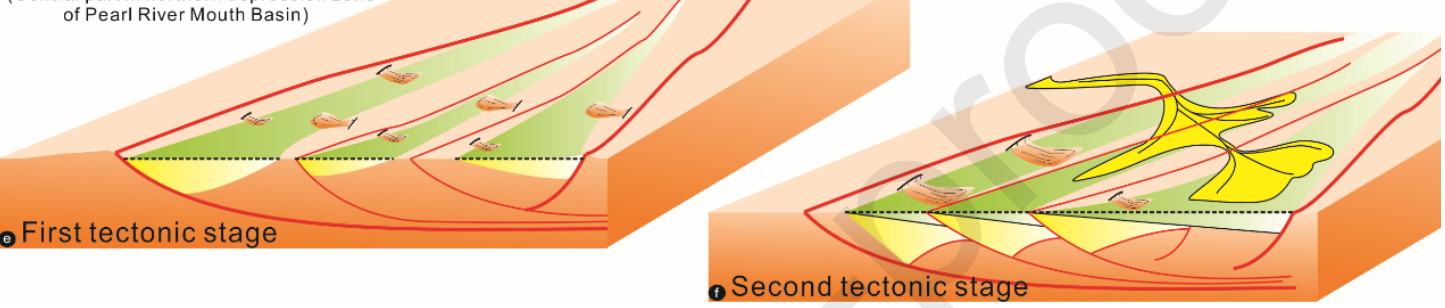




\section{Highlight}

6 1. Episodically rifting processes in PRMB include uniform rifting, decelerated rifting,

7 and accelerated rifting according to their rifting rates.

8 2. There was a change of provenance in the North PRMB from a proximal to a distal

9 area during the Eocene -Oligocene.

103 . Sediment supply was the dominant factor in the decelerated rifting basin, whereas

11 the relative height was the dominant factor in the accelerated rifting basin.

12

13

14

15

16

17

18 